University of Tennessee Health Science Center

UTHSC Digital Commons

\title{
Feasibility and Acceptability of Using Mobile Health Apps in Underserved Patients with Diabetes
}

Jieyu Luo

University of Tennessee Health Science Center

Follow this and additional works at: https://dc.uthsc.edu/dissertations

Part of the Analytical, Diagnostic and Therapeutic Techniques and Equipment Commons, Community Health and Preventive Medicine Commons, Endocrine System Diseases Commons, Health and Medical Administration Commons, Health Information Technology Commons, Health Services Administration Commons, Health Services Research Commons, Nutritional and Metabolic Diseases Commons, and the Public Health Education and Promotion Commons

\section{Recommended Citation}

Luo, Jieyu (https://orcid.org/0000-0002-4802-6168), "Feasibility and Acceptability of Using Mobile Health Apps in Underserved Patients with Diabetes" (2021). Theses and Dissertations (ETD). Paper 556. http://dx.doi.org/10.21007/etd.cghs.2021.0538.

This Dissertation is brought to you for free and open access by the College of Graduate Health Sciences at UTHSC Digital Commons. It has been accepted for inclusion in Theses and Dissertations (ETD) by an authorized administrator of UTHSC Digital Commons. For more information, please contact jwelch30@uthsc.edu. 


\title{
Feasibility and Acceptability of Using Mobile Health Apps in Underserved Patients with Diabetes
}

\begin{abstract}
Introduction. Diabetes mellitus is a condition with a growing morbidity and mortality burden. An estimated 30 million adults currently live with diabetes, with each individual spending over $\$ 9500$ annually on medical care. The successful management of diabetes is a lifelong endeavor. This involves balancing a variety of factors including diet, medications, and glucose monitoring. It has been well established that successful control of diabetes depends largely upon patients' daily lifestyle habits and activities. Not all patients, however, have the resources necessary for effective diabetes management. Health disparities lead to a higher rate of diabetes development in minority and poor populations. Since underserved patients have limited access to traditional healthcare avenues, providers should explore other means, like mobile health (mHealth), to help such patients. The rapid adoption of smartphones within the last decade has allowed an opportunity for patients to use mHealth and smartphone applications (apps) as a lowcost way to get health information and services. mHealth has the potential to address such disparities in access to health care. Little is known about the effectiveness of using apps to help underserved patients with their diabetes management. Assessing these patients' current self-management practices and their interest in using smartphone apps for their diabetes management is the first step in determining how $\mathrm{mHealth}$ may benefit this patient population.
\end{abstract}

Purpose. The purpose of this study was to assess how underserved patients with limited access to primary care physicians handled their diabetes on their own at home, to determine what challenges they faced with their self-management, and to examine their willingness to use diabetes mHealth apps on their smartphones to assist with their diabetes management.

Methods. This study employed purposive sampling to select patients for individual interviews. Participant selection occurred at a Memphis hospital located in an area of town with predominately low-income and minority residents, as well as a high prevalence of diabetes. Semi-structured interviews were conducted on-site at the hospital based on McNamara's interview staging. In all, 15 interviews were recorded, transcribed, and coded according to the interpretative phenomenological analysis framework.

Results. The data produced 5 topic clusters related to at-home diabetes management, which supported 2 overarching themes, and 7 clusters related to mHealth smartphone app use, which supported 3 overarching themes. The themes related to self-management are as follows: 1 . Patients are aware that successful diabetes control requires active engagement on their part but voiced struggles related to balancing limited income and a healthy diet, how to manage fluctuating glucose readings throughout the day, and affording medications; and 2. Lacking a traditional relationship with a primary care doctor, these underserved patients turn to friends and family, written materials, and the internet as health care resources. The themes related to smartphone mHealth are as follows: 1 . Despite limited knowledge about health apps and varying phone use patterns, patients were all willing to try at least one diabetes-related app; 2. App functions should be individualized to meet each patient's needs for maximum benefit; and 3 . Barriers to app use were varied but commonly included knowledge and technological challenges and security issues.

Conclusion. Interviews from this vulnerable population demonstrated that individuals understood the importance of their own active involvement in controlling their diabetes. Yet, because of limited economic and health care resources, these patients struggle with the implementation of effective lifestyle choices in their daily routine. Furthermore, interviewees expressed interest in trying mobile health apps for diabetes management, despite minimal knowledge about the technology. Responses showed that selecting apps tailored to each individual's needs, instead of offering one blanket multifunctional app, would provide 
patients with the greatest benefit. Smartphone apps may be a low-cost health resource that patients without regular access to physicians can use for their at-home diabetes management.

\section{Document Type}

Dissertation

Degree Name

Doctor of Philosophy $(\mathrm{PhD})$

\section{Program}

Health Outcomes and Policy Research

Research Advisor

Shelley White-Means,PhD

\section{Keywords}

diabetes, health disparities, mhealth, smartphone app

\section{Subject Categories}

Analytical, Diagnostic and Therapeutic Techniques and Equipment | Community Health and Preventive Medicine | Diseases | Endocrine System Diseases | Health and Medical Administration | Health Information Technology | Health Services Administration | Health Services Research | Medicine and Health Sciences | Nutritional and Metabolic Diseases | Public Health | Public Health Education and Promotion 


\title{
UNIVERSITY OF TENNESSEE HEALTH SCIENCE CENTER
}

\author{
DOCTORAL DISSERTATION
}

\section{Feasibility and Acceptability of Using Mobile Health Apps in Underserved Patients with Diabetes}

Author:

Jieyu Luo
Advisor:

Shelley White-Means, Ph.D.

A Dissertation Presented for The Graduate Studies Council of

The University of Tennessee Health Science Center

in Partial Fulfillment of the Requirements for the Doctor of Philosophy degree from

The University of Tennessee

in

Health Outcomes and Policy Research/Health Policy

College of Graduate Health Sciences 
Copyright (C) 2021 by Jieyu Luo.

All rights reserved. 


\section{ACKNOWLEDGEMENTS}

Infinite gratitude to my committee members, Drs. White-Means, George, Graff, Franklin, and Spivey for your continued support and guidance throughout this entire process. Also, thank you to the pharmacy team at Methodist South, Drs. Stafford, Smith, and Patterson, for your invaluable help during the patient selection and interview process. 


\begin{abstract}
Introduction. Diabetes mellitus is a condition with a growing morbidity and mortality burden. An estimated 30 million adults currently live with diabetes, with each individual spending over $\$ 9500$ annually on medical care. The successful management of diabetes is a lifelong endeavor. This involves balancing a variety of factors including diet, medications, and glucose monitoring. It has been well established that successful control of diabetes depends largely upon patients' daily lifestyle habits and activities. Not all patients, however, have the resources necessary for effective diabetes management. Health disparities lead to a higher rate of diabetes development in minority and poor populations. Since underserved patients have limited access to traditional healthcare avenues, providers should explore other means, like mobile health (mHealth), to help such patients. The rapid adoption of smartphones within the last decade has allowed an opportunity for patients to use mHealth and smartphone applications (apps) as a low-cost way to get health information and services. mHealth has the potential to address such disparities in access to health care. Little is known about the effectiveness of using apps to help underserved patients with their diabetes management. Assessing these patients' current self-management practices and their interest in using smartphone apps for their diabetes management is the first step in determining how mHealth may benefit this patient population.
\end{abstract}

Purpose. The purpose of this study was to assess how underserved patients with limited access to primary care physicians handled their diabetes on their own at home, to determine what challenges they faced with their self-management, and to examine their willingness to use diabetes mHealth apps on their smartphones to assist with their diabetes management.

Methods. This study employed purposive sampling to select patients for individual interviews. Participant selection occurred at a Memphis hospital located in an area of town with predominately low-income and minority residents, as well as a high prevalence of diabetes. Semi-structured interviews were conducted on-site at the hospital based on McNamara's interview staging. In all, 15 interviews were recorded, transcribed, and coded according to the interpretative phenomenological analysis framework.

Results. The data produced 5 topic clusters related to at-home diabetes management, which supported 2 overarching themes, and 7 clusters related to mHealth smartphone app use, which supported 3 overarching themes. The themes related to self-management are as follows: 1. Patients are aware that successful diabetes control requires active engagement on their part but voiced struggles related to balancing limited income and a healthy diet, how to manage fluctuating glucose readings throughout the day, and affording medications; and 2. Lacking a traditional relationship with a primary care doctor, these underserved patients turn to friends and family, written materials, and the internet as health care resources. The themes related to smartphone mHealth are as follows: 1. Despite limited knowledge about health apps and varying phone use patterns, patients were all willing to try at least one diabetes-related app; 2. App functions should 
be individualized to meet each patient's needs for maximum benefit; and 3. Barriers to app use were varied but commonly included knowledge and technological challenges and security issues.

Conclusion. Interviews from this vulnerable population demonstrated that individuals understood the importance of their own active involvement in controlling their diabetes. Yet, because of limited economic and health care resources, these patients struggle with the implementation of effective lifestyle choices in their daily routine. Furthermore, interviewees expressed interest in trying mobile health apps for diabetes management, despite minimal knowledge about the technology. Responses showed that selecting apps tailored to each individual's needs, instead of offering one blanket multifunctional app, would provide patients with the greatest benefit. Smartphone apps may be a low-cost health resource that patients without regular access to physicians can use for their athome diabetes management. 


\section{TABLE OF CONTENTS}

CHAPTER 1. INTRODUCTION ..............................................................................

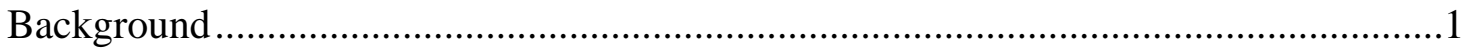

Statement of the Problem...................................................................................

Importance of Diabetes Self-Management ...............................................................

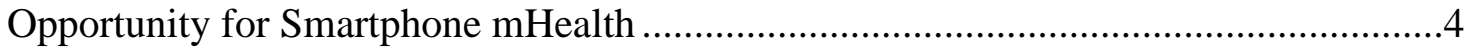

Overall Purpose of the Study ................................................................................

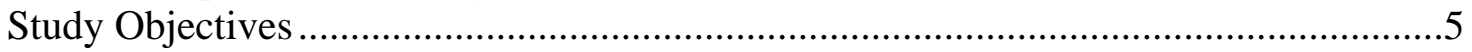

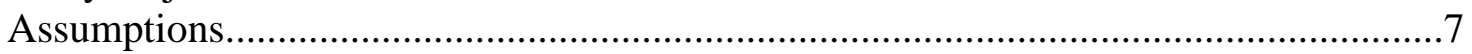

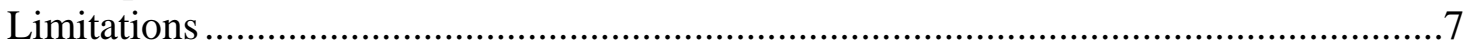

Relevance to Health Outcomes Research ..............................................................

CHAPTER 2. LITERATURE REVIEW ..................................................................9

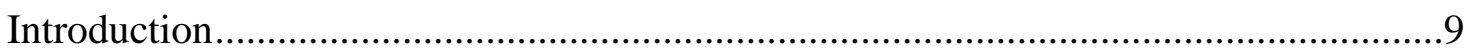

Prevalence and Cost of Diabetes ....................................................................... 9

Guidelines for Diabetes Management............................................................

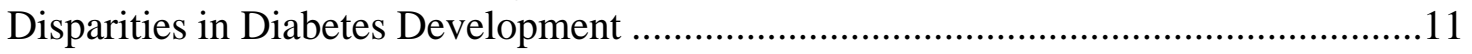

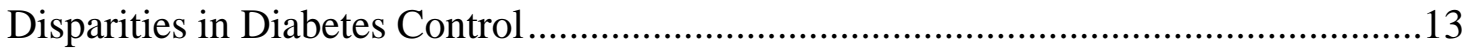

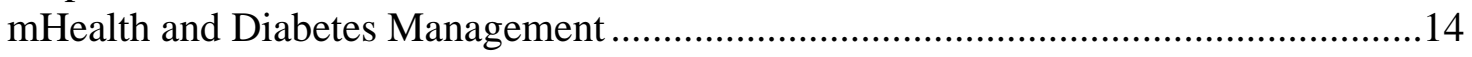

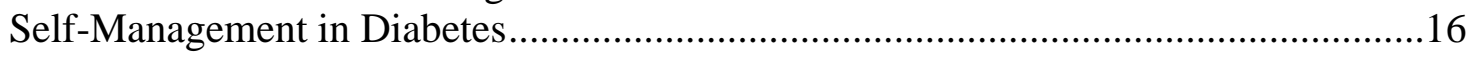

CHAPTER 3. METHODS ............................................................................................23

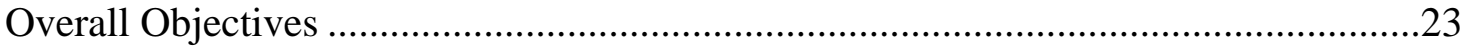

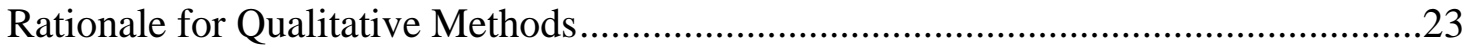

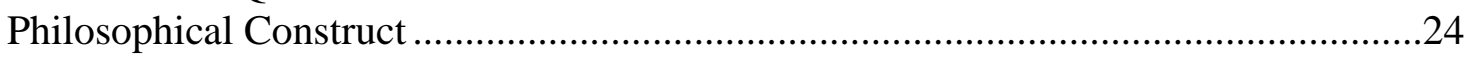

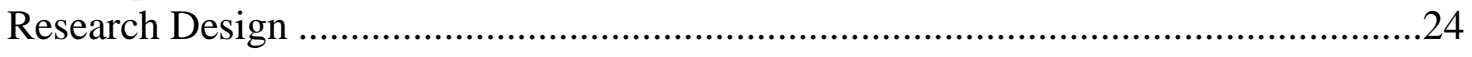

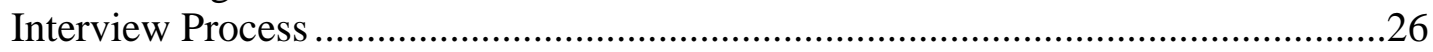

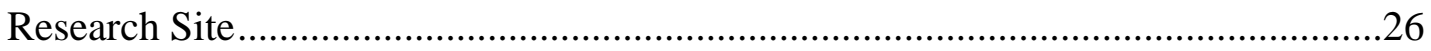

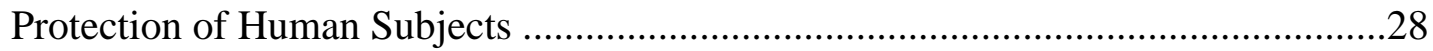

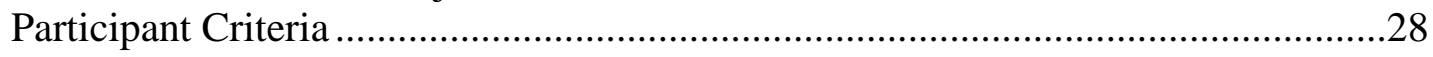

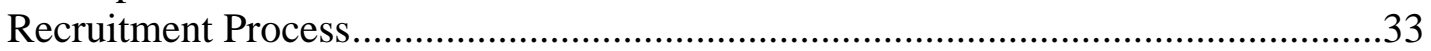

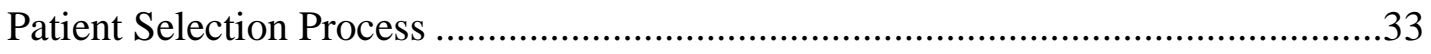

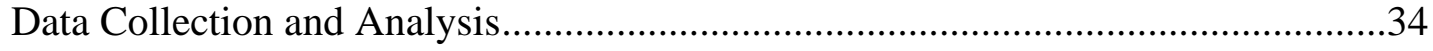

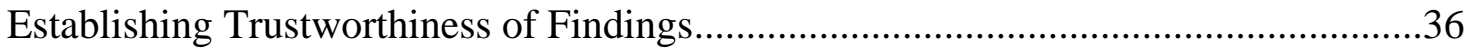

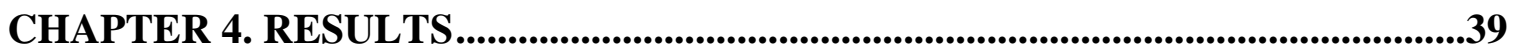

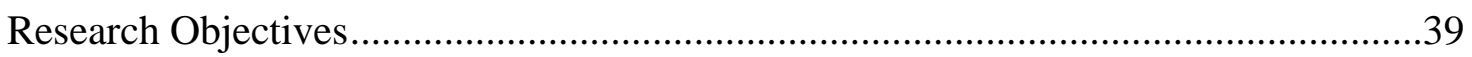

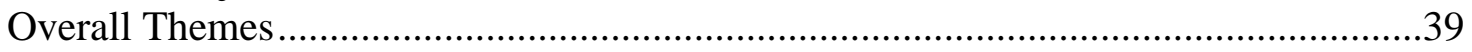

Theme 1: Diabetes as a Chronic Condition Requires Active Engagement on the

Part of the Patient for Successful Management .................................................41

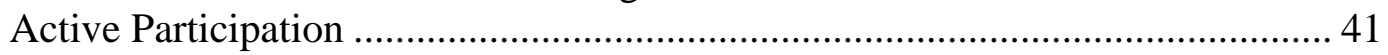

Goal Setting and Monitoring ................................................................... 42

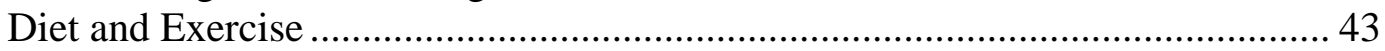


Theme 2: Patients Often Cited Social Support, Written Material, and the Internet as Meaningful Resources They Used for Their Diabetes

Theme 3: Despite Limited Knowledge about Health Apps and Varying Phone

Usage Patterns, Patients All Indicated a Willingness to Try at Least One

Diabetes-related App

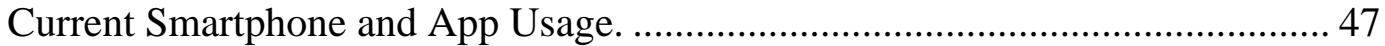

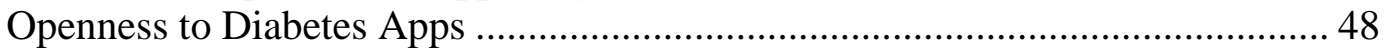

Theme 4: App Functions Should Be Individualized to Meet Each Patient's

Needs for Maximum Benefit . .48

Theme 5: Barriers to App Use Were Varied but Commonly Included Knowledge and Technological Challenges and Security Issues

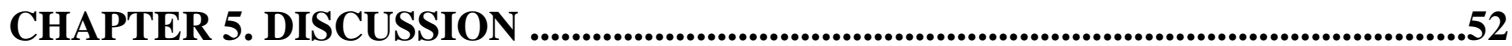

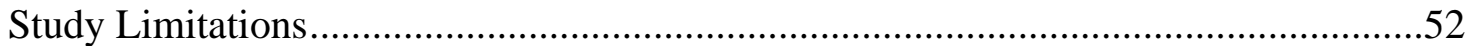

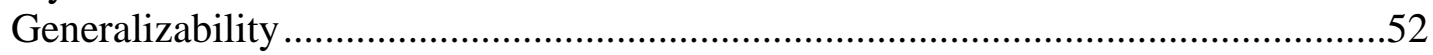

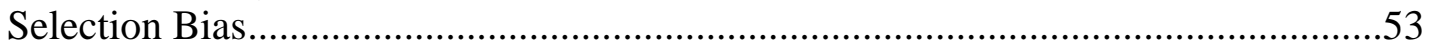

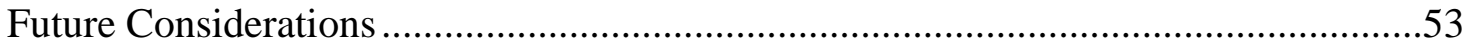

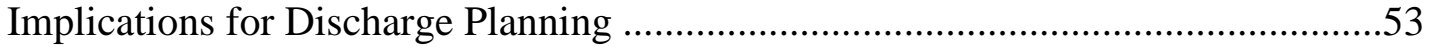

Training for Healthcare Providers ......................................................................54

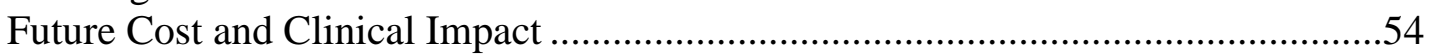

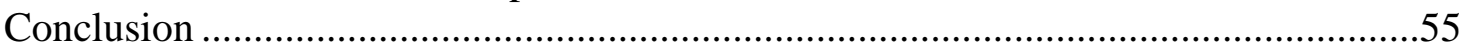

LIST OF REFERENCES ..............................................................................................................57

APPENDIX A. INTERVIEW GUIDE .................................................................65

APPENDIX B. UTHSC IRB STUDY APPROVAL LETTER .....................................68

APPENDIX C. STUDY CONSENT FORM ..............................................................70

APPENDIX D. ICD-9 AND ICD-10 CODES FOR STUDY PARTICIPATION.......72

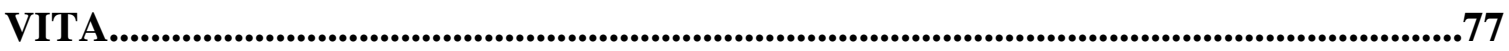




\section{LIST OF TABLES}

Table 1-1. Percent of adults by demographic who own smartphones...........................2

Table 1-2. Percent of adults by demographic who are smartphone dependent ...............6

Table 2-1. Summary of lifestyle modifications for diabetes self-management ............12

Table 2-2. App functionality in relation to diabetes............................................ 17

Table 2-3. Summary of randomized controlled trials on diabetes app use ...................18

Table 4-1. Themes and supporting clusters derived from interviews ..........................40

Table D-1. Qualifying ICD-9 codes for participant selection ...................................72

Table D-2. Qualifying ICD-10 codes for participant selection .................................74 


\section{LIST OF FIGURES}

Figure 2-1. Percentage of disease-specific apps by disease type................................15

Figure 3-1. Stepwise process for conducting personal interviews ..............................27

Figure 3-2. Locations of primary care offices around the Whitehaven, TN, area ..........29

Figure 3-3. Locations of primary care offices in the greater Memphis, TN, area ...........30

Figure 3-4. Age-adjusted diabetes mortality rates for the Whitehaven, TN, area ..........31

Figure 3-5. Age-adjusted diabetes mortality rates for the greater Memphis, TN, area ...32

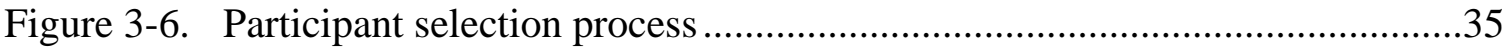




\section{LIST OF ABBREVIATIONS}

AACE

ADA

app

CDC

ED

ESRD

FDA

FPL

HbA1c

ICD

IPA

IRB

IQVIA

KFF

mHealth

$\mathrm{OMH}$

PCP

PRC

QALYs

QOL

SES

SMBG

T1DM

T2DM

UTHSC

WHO
American Association of Clinical Endocrinologists

American Diabetes Association

smartphone application

Centers for Disease Control and Prevention

emergency department

end stage renal disease

Food and Drug Administration

federal poverty level

hemoglobin A1c

International Classification of Diseases

interpretative phenomenological analysis

institutional review board

IQVIA Institute for Human Data Science

Kaiser Family Foundation

mobile health

Office of Minority Health

primary care physician

Pew Research Center

quality-adjusted life years

quality of life

socioeconomic status

self-monitoring of blood glucose

type 1 diabetes mellitus

type 2 diabetes mellitus

University of Tennessee Health Science Center

World Health Organization 


\section{CHAPTER 1. INTRODUCTION}

\section{Background}

Diabetes mellitus is a metabolic disease characterized by elevated glucose levels in the blood. This is due to the body's inability to produce enough or any insulin, the hormone necessary to break down glucose, or an inability to properly respond when insulin is produced. The American Diabetes Association (ADA) defines a diabetes diagnosis as having a hemoglobin A1c (HbA1c) $\geq 6.5 \%$, a fasting blood glucose $\geq 126$ $\mathrm{mg} / \mathrm{dL}$, or a two hour postprandial blood glucose $\geq 200 \mathrm{mg} / \mathrm{dL}$ (ADA, 2019). Having persistently high blood glucose levels can lead to a constellation of serious complications including end stage renal disease (ESRD), stroke, neuropathy, and blindness. Once developed, diabetes itself is a chronic condition. Consequently, its management is often a lifelong endeavor. Successful diabetes control extends beyond glycemic control; it involves a whole host of factors ranging from a consistent patient-provider relationship to regular physical activity.

Not all individuals with diabetes, however, have access to an adequate arsenal of resources needed for effective disease control. Health disparities either related to race, income, or other social environmental constraints contribute to a higher frequency of diabetes development in poor and racial and ethnic minority populations. Moreover, health care disparities limit the care these patient populations receive. This then leads to lack of knowledge about diabetes itself and an inability to form a consistent relationship with an ambulatory care team. Ultimately, a lack in care and attention toward the disease leads to both costly emergency and hospitalization services and major organ damage. Because underserved populations have little to no access to traditional means of healthcare, providers must explore other avenues to reach this patient group.

Mobile health (mHealth), or the practice and delivery of health care via mobile devices like cell phones, tablets, or wearable electronics, has grown significantly in the last decade. With the fast-paced adoption of cell phones, mobile health presents the opportunity to offer patients with diabetes a low-cost way to receive health information, to communicate with providers, and to self-manage different chronic conditions. It has been well established that low-income, racial and ethnic minority populations experience several barriers to receiving basic health care including uninsurance, limited transportation, and high out-of-pocket costs. The provision of health care via mobile devices may have the potential to address such health disparities. Over $90 \%$ of American adults now own a cell phone; $81 \%$ say that their cell phone is a smartphone (Pew Research Center (PRC), 2019). As noted in Table 1-1, there is no significant difference in smartphone ownership by race. While those with lower income and education and those of older age are less likely to own a phone compared to their counterparts, the vast majority still demonstrated ownership. This ownership offers an opportunity for mHealth to overcome access barriers in diabetes care delivery. 
Table 1-1. Percent of adults by demographic who own smartphones

\begin{tabular}{lc}
\hline Demographic & Smartphone ownership \\
\hline Gender & \\
Female & $79 \%$ \\
Male & $84 \%$ \\
Age & \\
$18-29$ & $96 \%$ \\
$30-49$ & $92 \%$ \\
$50-64$ & $79 \%$ \\
$\geq 65$ & $53 \%$ \\
Race & \\
White & $82 \%$ \\
Black & $80 \%$ \\
Hispanic & $79 \%$ \\
Highest Education Level & \\
Less than high school graduate & $66 \%$ \\
High school graduate & $72 \%$ \\
Some college & $85 \%$ \\
College graduate & $91 \%$ \\
Income & \\
\$30,000 & $71 \%$ \\
$\$ 30,000-\$ 49,999$ & $78 \%$ \\
$\$ 50,000-\$ 74,999$ & $90 \%$ \\
$\geq \$ 75,000$ & $95 \%$ \\
\hline
\end{tabular}

Modified with permission. Pew Research Center. Mobile fact sheet (12 Jun 2019). https://www.pewresearch.org/internet/fact-sheet/mobile/ (accessed 30 Jun 2019). 


\section{Statement of the Problem}

Diabetes is a chronic condition experiencing rapid growth in the United States. According to the latest statistic report from the Centers for Disease Control and Prevention (CDC) (2017), over 9\% of the US population, about 30.3 million Americans, are currently living with diabetes. An estimated 1.5 million adults are newly diagnosed diabetes each year. Additionally, about $24 \%$ of all diabetes cases remain undiagnosed, meaning that an additional 7.2 million Americans are unaware of their condition. Left unmanaged, the condition often leads to increased morbidity from common complications like renal failure or amputation. Diabetes remains the seventh leading cause of death in the US (CDC, 2017).

In addition, economic and social disadvantages contribute to health disparities in the diabetes. This means that individuals with certain socioeconomic characteristics are at higher risk of developing diabetes. Groups who experience health disparities have an increased burden of illness, disability, injury, or mortality compared to others. In the case of diabetes, poverty, minority race, and low education level all serve as independent risk factors for developing the disease (Geiss et al., 2014; Beckles \& Chou, 2016; CDC, 2017, Gaskin et al., 2014).

Along with disparities in diabetes development, there also exist disparities in accessing health care for the disease. Minority and low-income populations often lack the proper resources and treatment necessary for successful blood glucose control. When compared to whites (13\% uninsured), blacks (21\%), Hispanics (32\%), and American Indians (27\%) demonstrate higher rates of uninsurance (Kaiser Family Foundation (KFF), 2012). Low-income populations (32\% of those with income under the federal poverty level (FPL)), as well, have a higher rate of uninsurance compared to those with higher incomes (15\% for income between 200 and 399\% FPL, 5\% for income $\geq 400 \%$ FPL) (KFF, 2012). As a result, these low-income and racial and ethnic minority populations experience more barriers to accessing care and poorer quality care. More African Americans, Hispanics, and Asians cite the emergency room as their usual source of care compared to whites, and conversely, were less likely than whites to indicate a doctor's office or private clinic as their primary care source (Mead et al., 2008). The percentage of people with a source of ongoing care to help their health management is significantly lower for those with low income (77.5\% vs. $92.1 \%$ for high-income groups) and also lower for those with less education $(74.2 \%$ for those with less than a high school education vs. $82.2 \%$ for those with some college education) (Agency for Healthcare Research and Quality, 2010).

\section{Importance of Diabetes Self-Management}

The successful management of diabetes extends beyond a few doctor's visits and check-ups. It involves the development of a well-informed patient who is able and willing to make daily lifestyle adjustments. The use of smartphones and mobile health may help in creating an informed and actively engaged patient, a marker of successful chronic disease management. Successful management of chronic illnesses extends beyond usual 
care office visits with a physician (Wagner, 1998). A large contributor to the deficiencies in chronic disease care is a healthcare system that prioritizes the urgency of quelling acute symptoms over the long-term commitment to optimize control of chronic conditions. In a system ill equipped to address the chronic nature of diabetes, patients became passive and uninformed with only brief, sporadic visits with ill-prepared health care providers (Bodenheimer, Wagner, \& Grumbach, 2002).

Successful chronic care means demanding quality not just from health care providers and the overarching health system but also from the community-at-large (Bodenheimer, Wagner, \& Grumbach, 2002). In addition to improving patient care via traditional elements like using evidenced-based guidelines to make daily practice decisions or promoting team-based care in a health care organization, elements that empower the patient himself like offering self-management support and community resources outside the health care environment are equally as important (Coleman et al., 2009). The end goal is to produce an informed, engaged patient (Wagner, 1998). In this way, providing patients with the resources and knowledge to take care of their diabetes throughout their daily lives is just as meaningful as traditional patient-provider interactions.

As this study focused on the management of a chronic condition, diabetes, via mobile resources, it addressed two elements of patient empowerment: the provision of health resources outside a health care setting and self-management support. The population included in the study has limited access to traditional ambulatory and primary care physician (PCP) offices. Thus, for these underserved patients, it is prudent to capitalize on what resources they do have to manage their health. These resources would be their smartphones, which unlike health care systems, are something they engage with every day. This study sought to explore whether this vulnerable population might be receptive to obtaining health care information and resources via smartphones to help increase their self-management skills. The effectiveness of a patient's ability to control his disease progression is often the largest determinant of his health outcomes. Selfmanagement is the ability of the patient to make autonomous choices regarding his health (Bodenheimer et al., 2002). It addresses the patient question of "What can I do to manage my diabetes?" The concept of patient empowerment dovetails with self-management. Empowerment involves giving patients the tools, problem-solving skills, and confidence necessary to take responsibility for their diabetes (Bodenheimer et al., 2002). By providing patients with mHealth resources, this study aimed to foster a transition from passive, provider-driven decisions ("My doctor wants me to take my medications.") to active, patient-driven ones ("It is important to me to take my medications.").

\section{Opportunity for Smartphone mHealth}

The smartphone has been one of the fasting growing and adopted technologies in the past decade. Compared to 35\% ownership in 2011, 81\% of American adults in 2019 now own a smartphone (PRC, 2019). What makes the smartphone such a desirable resource is its ability to offer multiple functions in a portable device. In fact, most 
smartphone owners use their devices for more than just calls. Over $80 \%$ of owners use their phones to text, check e-mail, and access internet; over 55\% also use them for social networking, watching videos, and news. Almost all smartphone owners, 99\%, used their devices at home. The majority of smartphone owners also view their devices as a valuable resource. Positive attitudes included 93\% deeming their phones as helpful, $80 \%$ as worth the cost, and $72 \%$ as connecting (Smith, 2015).

Unlike traditional healthcare services, the smartphone is a resource that is readily available and used by minority and low-income populations. Of note, $62 \%$ of smartphone owners have already used their phones to find information about a health condition (Smith et al., 2015). As shown in Table 1-1, almost the same percentage of minorities ( $80 \%$ of blacks, $79 \%$ of Hispanics) own a smartphone compared to whites (82\%). While smartphone ownership rises with increased income, a good majority, over $70 \%$, of those in the lowest income bracket, earning $<\$ 30,000$ per year, indicated smartphone possession (PRC, 2019). With increased smartphone ownership also comes an increase in smartphone dependency. Currently, $37 \%$ of American adults mostly use their smartphones to access the internet. Additionally, $17 \%$ are completely smartphonedependent; their phones are the only means to go online at home (Anderson, 2019). Those who are minority or with the lowest income display more dependency (Table 1-2). Accordingly, this data shows that there exists an opportunity to engage lower income and racial and ethnic minority populations via a mobile health platform.

\section{Overall Purpose of the Study}

The purpose here was twofold. First, this study aimed to determine how underserved patients with limited access to PCPs currently self-managed their diabetes at home and any challenges they face with their self-management. Second, the study aimed to assess the interest in and feasibility of using smartphone applications (apps) to help low-income, disadvantaged patients in the Memphis area manage their own healthcare.

\section{Study Objectives}

Study objectives and respective research question were:

1. Determine what patients are currently doing at home to manage their diabetes.

a. What habits or routines have they developed regarding their diabetes?

b. What do patients identify as challenges or struggles with managing their diabetes at home?

2. Explore the attitudes toward and interest in the use of mobile health technology in an underserved population.

a. What do patients know about apps for diabetes?

b. How confident or comfortable are patients with using smartphones and mHealth?

c. How do patients feel about using their smartphones on a routine basis to monitor 
Table 1-2. Percent of adults by demographic who are smartphone dependent

\begin{tabular}{lc}
\hline Demographic & Smartphone dependency \\
\hline Gender & \\
Female & $16 \%$ \\
Male & $17 \%$ \\
Age & \\
$18-29$ & $22 \%$ \\
$30-49$ & $18 \%$ \\
$50-64$ & $14 \%$ \\
$\geq 65$ & $12 \%$ \\
Race & \\
White & $12 \%$ \\
Black & $23 \%$ \\
Hispanic & $25 \%$ \\
Highest Education Level & \\
Less than high school graduate & $32 \%$ \\
High school graduate & $24 \%$ \\
Some college & $18 \%$ \\
College graduate & $4 \%$ \\
Income & \\
$\quad \$ 30,000$ & $26 \%$ \\
$\$ 30,000-\$ 49,999$ & $20 \%$ \\
$\$ 50,000-\$ 74,999$ & $10 \%$ \\
$\geq \$ 75,000$ & $6 \%$ \\
\hline
\end{tabular}

Modified with permission. Pew Research Center. Mobile fact sheet (12 Jun 2019). https://www.pewresearch.org/internet/fact-sheet/mobile/ (accessed 30 Jun 2019). 
their diet, exercise, medications, and blood glucose?

3. Assess patients' willingness to download and continue using a health app on their smartphones.

a. What app functions do patients have the most interest in using?

b. Would patients be willing to pay for an app download?

c. How frequently would patients continue to use mobile health apps?

d. What would stop patients from downloading or continuing to use an app?

\section{Assumptions}

The study included the following assumptions:

1. Each participant completely answered all study questions honestly and to the best of his ability.

2. The study population represented the target population.

\section{Limitations}

For this study, the following limitations existed:

1. Findings may only be limited to the Memphis sample population and not generalizable to the greater US population.

2. Because this was a pilot study, findings were exploratory and longer, more rigorous studies may be needed to determine any clinical benefits of smartphone health apps.

3. Findings may be limited only to diabetes apps discussed in the study and not generalizable to other healthcare apps with similar functions.

\section{Relevance to Health Outcomes Research}

An intensive search of the literature shows that very little has been published about leveraging mHealth to address health disparities. There has been much suggestion about the potential of using smartphone apps to improve health outcomes among the disadvantaged population (Kratzke \& Cox, 2012; Luxton et al., 2011; Moore, 2012), but research in this area is still nascent. Nonetheless, smartphones have the potential to act as a new vehicle for health information and care where patients have had longstanding access barriers to the more traditional brick-and-mortar physician office.

The smartphone has the potential to bridge the divide between the low-income, racial and ethnic minority populations and health care services. Some $46 \%$ of all smartphone owners prefer to use their phones over any other devices for going online. Of 
the $27 \%$ of Americans who do not have broadband internet at home, $45 \%$ state the reason for not having home internet is that their smartphone "lets them do everything they need to do online" (Anderson, 2019). The demographics of these smartphone-only internet users (Table 1-2) align with those of the healthcare disadvantaged: low-income, lesseducated, and minority. Therefore, the provision of health services through this already existing mobile platform may help provide care to a patient group that has struggled to obtain care through traditional means.

As of yet, there is no literature on the use of smartphone apps in underserved populations to address diabetes management. This study hopes to provide the following the original contributions: 1 . Determine the ability of a traditionally resource-limited population to access and use diabetes smartphone applications, and 2. Gauge patients' willingness to accept apps to manage their diabetes. Ideally, the results from this study will act as a springboard for the development of further research on utilizing smartphone health applications in a resource-limited patient population. 


\section{CHAPTER 2. LITERATURE REVIEW}

\section{Introduction}

Diabetes mellitus carries an ever-growing onus of morbidity and mortality in the United States. The cost is substantial: billions of dollars each year go toward the treatment of diabetic emergencies and complications. Optimal management and control of the disease are key to reducing this burden. Successful diabetes control, however, extends beyond drug therapy. In order to understand the totality of diabetes management, a review of the 2019 guidelines from the American Diabetes Association is below. Because the study population contains mainly minority patients, an examination of the disparity in diabetes control between blacks/Hispanics and white follows. Then a review of mHealth use for diabetes management and mHealth use in disadvantaged populations presents what is known so far about cell phone use to provide health care. Finally, a brief discussion of the relationship between self-management and diabetes outcomes highlights why an active, informed patient is necessary for clinical control.

\section{Prevalence and Cost of Diabetes}

In the 20 years from 1990 to 2010, the number of American adults living with diabetes more than tripled from 6.2 to 20.9 million (CDC, 2019). Of these individuals, about $90-95 \%$ have type 2 diabetes mellitus (T2DM), while the remaining $5 \%$ have type 1 diabetes mellitus (T1DM) (CDC, 2017). An estimated 1.5 million adults are newly diagnosed each year (CDC, 2017). In total, about $10 \%$ of the American population has diabetes; if the present trend continues, up to 1 in 3 Americans will have diabetes by 2050 (Boyle et al., 2010). Once affected, patients with diabetes carry a significant, lifelong health burden. If diagnosed early at age 10, boys will lose, on average, 18.7 total life-years and 31 quality-adjusted life years (QALYs); girls will lose, on average, 19 total life-years and 32.8 QALYs (Narayan et al., 2003). Even when diabetes is diagnosed later in life, the disease still has a marked morbidity and mortality impact. If diagnosed at age 60, men would lose 7.3 life-years and 11.1 QALYs; women would lose 9.5 life-years and 13.8 QALYs (Narayan et al., 2003). Diabetes is responsible for over 14 million emergency department (ED) visits annually and is the seventh leading cause of death in the United States (CDC, 2017).

Along with the health costs, the economic costs for diabetes are just as great. In the 5 years from 2012 to 2017, the cost of diabetes rose 26\% (ADA, 2018). For 2017, diagnosed diabetes carried a cumulative cost of $\$ 327$ billion, with $\$ 237$ billion in medical costs and $\$ 90$ billion in diminished productivity costs (ADA, 2018). This amount represents an 88\% increase in the decade from 2007 to 2017 (ADA, 2013; ADA, 2018). People with diabetes spend an average of $\$ 16,750$ per year on health care costs, of which over half, $\$ 9,600$, goes toward diabetes-related care; in fact, they spend 2.3 times more money on health care than they would have in the absence of diabetes (ADA, 2018). Individuals diagnosed with diabetes at age 40 spent $\$ 124,600$ more on medical 
expenditures throughout the rest of their lifetime than those without diabetes; those diagnosed later at age 60 still spent $\$ 53,800$ more (Zhou et al., 2014). There also exist disparities in the cost of diabetes. Compared to those with insurance, people with diabetes who are uninsured experience $79 \%$ fewer physician visits but have $55 \%$ more ED encounters; African Americans have 75\% more ED visits than the diabetes population as a whole (ADA, 2013). Inpatient hospital costs are also $41.3 \%$ higher for black patients with diabetes than whites (ADA, 2013). Overall, the economic burden is substantial with 1 in every 4 health care dollar spent on caring for someone with diagnosed diabetes (ADA, 2018).

\section{Guidelines for Diabetes Management}

The American Diabetes Association published the most current diabetes management guidelines, Standards of Medical Care in Diabetes, in 2019. The ADA standards are further augmented by the most recent clinical practice guidelines from the American Association of Clinical Endocrinologists (AACE). The ADA recognizes four distinct categories of diabetes: Type 1 (absolute insulin deficiency), type 2 (insufficient insulin production that leads to resistance), diabetes of other origins (i.e. drug- or diseaseinduced), and gestational diabetes (diagnosed only during pregnancy). Diagnosis of diabetes depends on having at least one of these three criteria: hemoglobin A1c $\geq 6.5 \%$, fasting blood glucose $\geq 126 \mathrm{mg} / \mathrm{dL}$, or a two hour glucose $\geq 200 \mathrm{mg} / \mathrm{dL}$ during an oral glucose tolerance test (ADA, 2019; AACE, 2015).

In addition to screening and diagnosis recommendations, the guidelines focus on therapeutic actions that both patients and providers must take to achieve optimal diabetes control. Once diagnosed, a patient should form a "collaborative therapeutic alliance" (ADA, 2014) with his family, physician, and health care team to produce the most comprehensive care. The guidelines strongly urge that all treatment goals and plans follow patient preferences and needs. This patient-centered approach extends to the selection of drug therapy as well. Because T1DM occurs when the pancreas is unable to produce insulin, medication treatment options are generally limited to long acting basal insulins and shorter acting, prandial insulins (ADA, 2019). T2DM, however, has a variety of drug therapy choices available. Whereas previous versions of the ADA guidelines provided a stepwise, more prescriptive approach to selection of medications for T2DM (Nathan et al., 2009), the guidelines from 2014 onward are less rigid (ADA, 2014; ADA, 2019). Based on extensive evidence of its safety and efficacy, metformin remains the first preferred medication. If after three months on maximum dose single agent therapy the patient does not have adequate blood glucose control, then a second medication, and if needed, a third, may be added to the patient's medication regimen (ADA, 2019). Other oral medications used to treat T2DM may include sulfonylureas (e.g. glyburide), thiazolidinediones (e.g. pioglitazone), DDP-4 inhibitors (e.g. sitagliptin), GLP-1 receptor agonists (e.g. liraglutide), meglitinides (e.g. nateglinide), and SGLT2 inhibitors (e.g. canagliflozin) (Tran et al., 2015). More complex therapy may involve both basal (e.g. glargine) and shorter acting (e.g. aspart) insulin when noninsulin therapy is not enough to achieve glucose goals (AACE, 2015). Selection of any medication should not be based on efficacy alone. Pharmacological therapy decisions should take into consideration patient- 
specific factors like side effects tolerability, weight and comorbidities, out of pocket costs, and daily pill burden (ADA, 2019).

For most non-pregnant adults, the ADA recommends targeting $\mathrm{HgA1c}<7 \%$. Fasting blood glucose should be between $80-130 \mathrm{mg} / \mathrm{dL}$, and postprandial glucose should be $\leq 180 \mathrm{mg} / \mathrm{dL}$ (ADA, 2019). To target achievement of these goals, patients should engage in regular self-monitoring of blood glucose (SMBG). Controlling blood glucose to within these goals is crucial to delay the onset of micro- and macrovascular complications associated with diabetes. SMBG is an important component of patient selfmanagement. When done routinely, SMBG can facilitate better diabetes control by improving patients' awareness of hypo- and hyperglycemia, allowing patients and providers to create an individualized medication regimen based on how that patient's glucose fluctuates throughout the day, and empowering patients to make appropriate diet and exercise decisions based on their daily glucose values (Benjamin, 2002). The guidelines recognize that SMBG plays an integral role in helping patients achieve their glycemic goals but also states that each patient's specific routines and needs should determine SMBG timing and frequency (ADA, 2019; AACE, 2015).

The current guidelines recognize that medication therapy alone is not sufficient for chronic diabetes management. Lifestyle modifications are a recommended therapy for all patients, regardless of disease severity, and "all people with diabetes should participate in diabetes self-management education to facilitate the knowledge, skills, and ability necessary for diabetes self-care" (ADA, 2019). Therapeutic lifestyle modifications range from diet and nutrition planning to tobacco cessation. In order for these modifications to have any efficacy, patients must receive the proper education, resources, and motivation to make and sustain changes to their daily routine. Lifestyle changes should also be individualized to each patient's needs and experiences (ADA, 2019; AACE; 2015). A summary of the recommended lifestyle improvements for diabetes management is listed in Table 2-1.

\section{Disparities in Diabetes Development}

It is well established in the literature that individuals of low socioeconomic status (SES) possess an increased risk of developing diabetes. As discussed previously, diabetes prevalence continues to rise every year. Yet this growth disproportionately affects those of lower SES. Lower education levels are associated with a higher diabetes prevalence. While only $7.2 \%$ of adults with more than a high school education have diagnosed diabetes, $9.5 \%$ of adults with a high school education and $12.6 \%$ of adults with less than a high school education have diagnosed diabetes (CDC, 2018). Similar to education, diabetes prevalence is inversely related to household income level. Adults living in the poorest households at FPL $<200 \%$ have the highest rate of diabetes at over 12\%; adults at $\mathrm{FPL} \geq 200 \%$ and $<300 \%$ have an $11 \%$ rate, adults at FPL $\geq 300 \%$ and $<400 \%$, a $9 \%$ rate, and adults at FPL $\geq 400 \%$, a 5\% rate (Gaskin et al., 2014). Furthermore, in a study that analyzed the relationship between poverty, education, and occupational status and T2DM prevalence among black and non-Hispanic white adults age 40-74, low income 
Table 2-1. Summary of lifestyle modifications for diabetes self-management

\begin{tabular}{ll}
\hline Modification & \multicolumn{1}{c}{ Recommendations } \\
\hline Diet & Understand and use information presented in Nutrition Facts Label \\
& for foods. \\
& Monitor carbohydrate intake by either counting or by experience- \\
& based estimation. \\
& Choose fruits, vegetables, legumes, whole grains, and dairy as a \\
& carbohydrate source over other high in fats, sugars, or sodium. \\
& Consume foods with long-chain n-3 fatty acids (i.e. fatty fish or nuts) \\
& over those with lots of trans or saturated fat. \\
& Limit or avoid intake of sugar-sweetened (i.e. high fructose corn \\
& syrup or sucrose) beverages.
\end{tabular}

Alcohol Limit consumption to a maximum of 1 drink for women and 2 drinks for men per day.

Salt intake Restrict daily sodium intake to $<2,300 \mathrm{mg} /$ day. Further sodium restriction may be taken for adults with both diabetes and hypertension.

Weight loss For overweight or obese adults with diabetes, moderate weight loss of about $5 \%$ of body weight may have clinical benefit.

Avoid fasting as a technique to encourage weight loss; caloric reduction with regular meals and snacks is preferred.

Exercise $\quad$ Perform $\geq 150$ minutes/week of moderate intensity exercise spread over at least 3 days/week and resistance training at least 2 days/week. Reduce daily sedentary behavior; interrupt prolonged sitting every 30 minutes with light physical activity.

Mental health Practice stress reduction techniques.

Use family and social support to help with diabetes self-management. Maintain regular sleep habits to ensure optimal sleep quality and quantity.

Tobacco Avoid use of all tobacco products, including cigars, cigarettes, chewing tobacco, as well as e-cigarettes.

For tobacco users ready and willing to quite, engage in active smoking cessation counseling and pharmacotherapy as needed.

Data Sources: American Association of Clinical Endocrinologists. Clinical practice guidelines for developing a diabetes mellitus comprehensive care plan. Endocrine Practice. 2015; 21(1):1-87; American Diabetes Association. Standards of medical care in diabetes-2019. Diabetes Care. 2019; 42(Suppl. 1):S1-S186. 
was the socioeconomic factor most strongly associated with diabetes development; this association presented itself with both whites and blacks and occurred largely independent of other risk factors (Robbins et al., 2001).

Minority race also serves as a risk factor for diabetes development. For instance, while $7.4 \%$ of all non-Hispanic whites age 18 and over have diabetes, $12.7 \%$ of blacks, $12.1 \%$ of Hispanics, and 8\% of Asians adults have diabetes (CDC, 2018). African Americans with the lowest socioeconomic status are four times more likely to develop diabetes when compared to whites (Brancati et al., 1996). Data provided by the Office of Minority Health $(\mathrm{OMH})$, a division of the Department of Health and Human Services, show Asian Americans as $40 \%$ more likely to be diagnosed with diabetes than whites (2019a). Hispanic adults too are 1.7 times more likely to be diagnosed compared to whites (OMH, 2019b). Even after controlling for racial differences in age, SES, and weight, blacks still hold twice the risk of having diabetes compared to whites (Brancati et al., 1996). This indicates that minority race appears as an independent risk factor for diabetes.

\section{Disparities in Diabetes Control}

Akin to the differences seen in the prevalence of diabetes, there also exist disparities in the maintenance of the condition and related comorbidities. For minority patients, differences in quality of care often lead to poorer diabetes control. Black and Hispanic individuals with diabetes are less likely to self-monitor their blood glucose and consequently, more likely to have a HbAlc $\geq$ the ADA goal of 7\% (Harris et al., 1999). When compared to whites, Hispanics are less likely to receive non-oral diabetes medications and to check for foot sores or ulcers (Thackeray et al., 2004). African American patients are more likely to experience what is termed "clinical inertia" (Cook et al., 1999); this is when providers fail to step up medication therapy despite compelling clinical indications. Patients who encounter clinical inertia have worse diabetes control (Cook et al., 1999). Other studies have confirmed that compared to whites, Hispanics and African Americans with diabetes receive less testing and treatment for comorbid conditions like hypertension and dyslipidemia (Arday et al., 2002; Hertz et al., 2006; Massing et al., 2003).

Moreover, racial and ethnic minority groups experience higher rates of developing diabetes-related complications and even death. In contrast to Caucasian adults with diabetes, African Americans showcase more obesity and central adiposity (Brancati et al., 1996). African Americans have about 2-4 times more kidney disease, blindness, and amputations than Caucasians (Carter et al., 1996; Lanting et al., 2005). Specifically, African Americans are 50\% more likely to develop diabetes-related retinopathy (Chow et al., 2012) and have a 2.6 times higher rate of end stage renal disease (ESRD) than Caucasians (Perneger et al., 1994). Blacks with diabetes are 1.5 times more likely to become hospitalized than whites (Chow et al., 2012). Hispanics, as well, demonstrate higher rates of renal disease and retinopathy (Carter et al., 1996; Lanting et al., 2005; Emanuele et al., 2005). Similarly, Asian Americans are 80\% more likely to have 
diagnosed ESRD than Caucasians (OMH, 2019a). Socioeconomic disparities carry over to diabetes-related mortality, as well. Compared to adults with the highest income ( $4 \mathrm{x}$ the federal poverty level), those with family incomes under the poverty level have over a two-fold higher mortality rate (Saydah \& Lochner, 2010).

\section{mHealth and Diabetes Management}

The rising adoption of mobile technology has created the opportunity for patients to leverage their own cell phones as a health care resource. Recent research indicates that more and more people are using their mobile devices for more than just calling. In addition to placing and receiving calls, a majority of cell phone owners report using their devices to send/receive text messages, browse the internet, send/receive e-mails, and download mobile applications (Smith, 2015). Almost 20\% of smartphone owners are completely dependent on their phones as their only source of internet (Anderson, 2019). Similar to the disparities discussed above with diabetes care and development, smartphone internet dependency presents more in lower income and racial and ethnic minority populations. While only $6 \%$ of adults with an annual income of at least $\$ 75,000$ reported smartphone-only internet access, $26 \%$ of adults making less than $\$ 30,000$ annually reported smartphone internet dependency (Anderson, 2019). Minorities, as well, rely more on their smartphones as their only source of internet. Compared to just $12 \%$ of white, $23 \%$ of blacks and $25 \%$ of Hispanics are smartphone-only internet users (Anderson, 2019).

An emerging resource in the healthcare arena, smartphone applications (apps) are a potential low cost tool to benefit individuals in the self-management of their diabetes. The overwhelming majority of health apps, $84 \%$, are available for consumer download at no cost; when there is a charge, the average per download is around \$2 (IQVIA Institute for Human Data Science (IQVIA), 2015). Mobile health technology has grown tremendously in the past decade. Seventy-five percent of American adults state that technology is important for their health management (Accenture, 2018). In the four years from 2013 to 2017, the number of commercially available health apps for download has nearly quintupled from about 66,000 to 318,000 (IQVIA, 2017). Comparatively, in the four years from 2014 to 2018, the percentage of adults reporting the use of a mobile health app has tripled from 16\% to 48\% (Accenture, 2018). The continued expansion of mHealth has led the Food and Drug Administration (FDA) to create guidelines for the approval and regulation of healthcare apps, especially those that act as a mobile platform for a medical device (FDA, 2019). With over 1,000 apps available for Android or iOs download (Research2guidance, 2014), diabetes represent $16 \%$ of all disease-specific apps (IQVIA, 2017). This makes it the second most common disease state represented among all apps (Figure 2-1). Despite the large volume of apps available, several barriers exist to patients' use including lack of knowledge and limited to no provider input. For those that choose to download an app, they may make that decision based on whether the app seems most popular in the online store and not based on the functions they most need to help manage their diabetes. While the literature shows continued growth and development of diabetes smartphone apps, there is little research focused on how patients with diabetes 


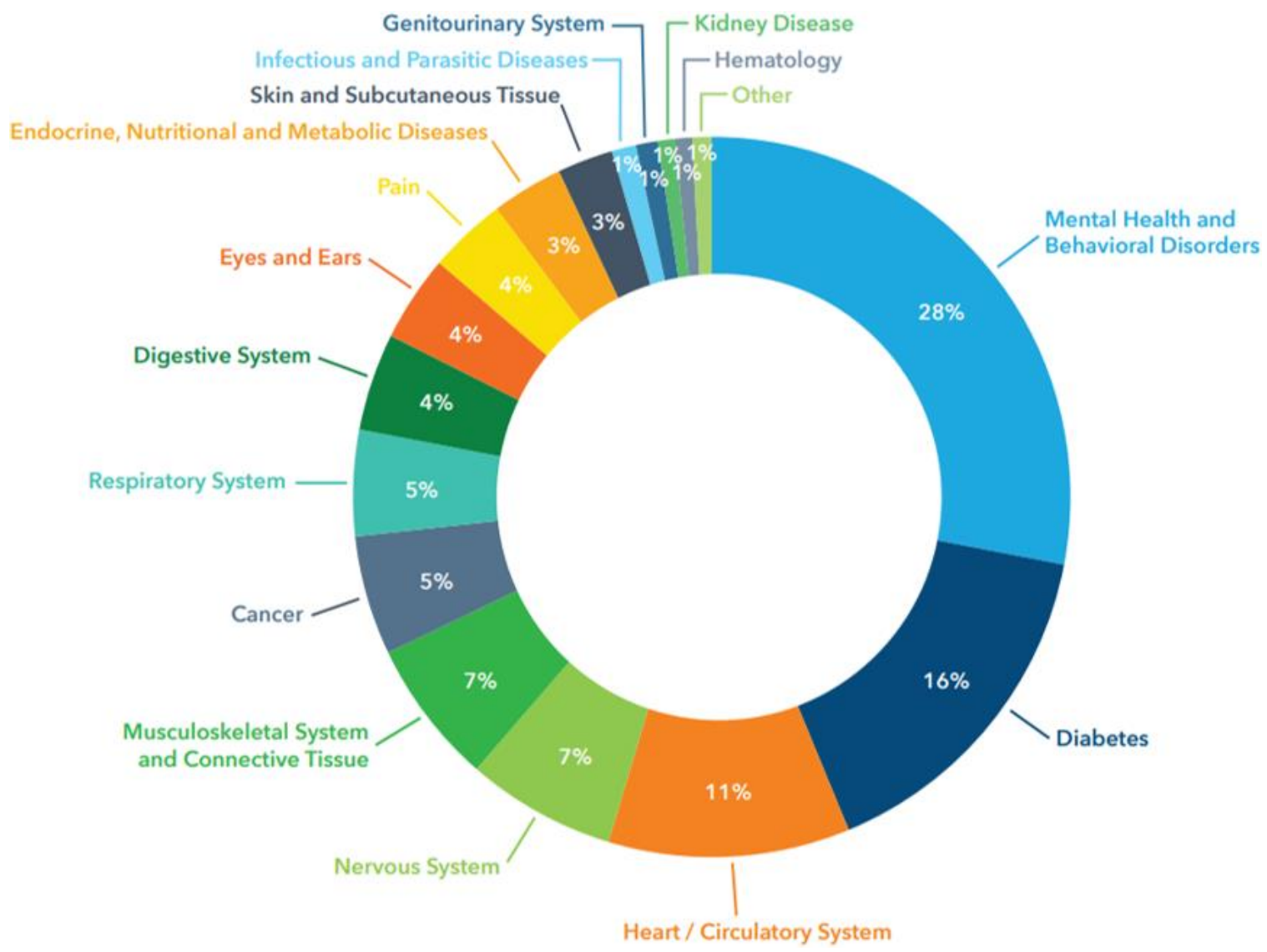

Figure 2-1. Percentage of disease-specific apps by disease type

Modified with permission. IQVIA Institute for Human Data Science. The growing value of digital health: Evidence and impact on human health and the healthcare system (Nov 2017). https://www.iqvia.com/-/media/iqvia/pdfs/institute-reports/the-growing-value-ofdigital-health.pdf? =1599234197223 (accessed 2 Apr 2018). 
select what health apps to download. This is an area this study addresses.

Recent literature has indicated the potential boon mobile apps may be on patients' diabetes self-management. A recent review of available diabetes apps on the market shows that most common features include insulin/medication recording, automatic data entry \& communication, diet recording, and weight management (Conway et al., 2016; Tran et al., 2012). Table 2-2 lists the different app functions available for diabetes management. There are a limited number of American studies available that have examined the effect of mobile app use to augment diabetes self-management. Nonetheless, they have demonstrated positive results. One, which looked at the use of WellDoc, an FDA-approved app that provides real-time feedback to physicians on patients' blood glucose, keeps tracks of medication regimens, and provides hypo- and hyperglycemia treatment algorithms, in a randomized controlled trial that compared app use to usual care. After three months, participants in the intervention group saw a significant reduction in their A1c levels $(2.03 \%$ vs. $0.68 \%)$ and also had more medication titrations/changes (84\% vs. 23\%) from their healthcare providers (Quinn et al., 2008). Another randomized trial examined the use of a popular and commercially available application, Glucose Buddy, in helping patients with diabetes manage their chronic condition. At the conclusion of the nine month study, the patients who utilized the app had a significant improvement $(7.8 \%)$ in their A1c levels from baseline $(9.08 \%)$ compared to the patients in the control group (8.58\% at follow-up, $8.47 \%$ at baseline) (Kirwan et al., 2013). For studies conducted outside the United States on the effects of using smartphone diabetes apps, Table 2-3 provides a summary. Results from these studies demonstrate an overall benefit from app use not only on clinical measures like HbA1c but also on quality of life (QOL) measures like confidence and self-efficacy.

\section{Self-Management in Diabetes}

Broadly, the concept of self-management involves a patient developing adequate knowledge and skills to keep their blood glucose at goal. In practice, self-management encompasses a wide variety of aspects like developing competence to interpret blood glucose numbers, properly using a blood glucose machine, monitoring for symptoms of hypo- and hyperglycemia, and maintaining a healthy diet/exercise regime. The American Diabetes Association considers success self-management so crucial to chronic diabetes control that it publishes and updates yearly national guidelines for diabetes selfmanagement (ADA, 2019).

These guidelines outline different standards related to physical fitness, nutrition, and general wellness that patients and providers should strive to meet. Mobile health apps may help patients in an at-home setting with their self-management. Because the majority of patients with diabetes do not receive much structured diabetes education, it is crucial first to acknowledge and then to help patients overcome any barriers to receiving support. This may often "entail identifying resources outside the provider's practice that can assist in the ongoing support of the participant" (Haas et al., 2012). mHealth apps provide an avenue through which patients with no or limited access to traditional primary care 
Table 2-2. App functionality in relation to diabetes

\begin{tabular}{ll}
\hline App function & \multicolumn{1}{c}{ Application to diabetes } \\
\hline Educate & $\begin{array}{l}\text { Provide general information related to the overall disease state, } \\
\text { including pathophysiology, risk factors, and differences between } \\
\text { the major types. } \\
\text { Can be presented in text, video, animation, or picture format. }\end{array}$ \\
Direct & $\begin{array}{l}\text { Give instructions to users on how to perform diabetes-related tasks } \\
\text { like administering insulin or finger sticks for glucose monitoring. } \\
\text { Can be presented as a stepwise list or as how-to videos. }\end{array}$ \\
Record & $\begin{array}{l}\text { Store user-entered data regarding caloric intake, physical activity, } \\
\text { or glucose readings. }\end{array}$ \\
Display & $\begin{array}{l}\text { Generate visual representation as graphs or charts of user generated } \\
\text { data. }\end{array}$ \\
Alert & $\begin{array}{l}\text { Notify users with reminders to do tasks at certain times like taking } \\
\text { medications or checking blood glucose. } \\
\text { Provide signals or alarms for values that are out of normal range } \\
\text { like blood glucose. }\end{array}$ \\
Communicate & $\begin{array}{l}\text { Send messages or data between health care providers and patients. } \\
\text { Can be for asking questions to providers, requesting refills from } \\
\text { pharmacies, or making new health appointments. }\end{array}$ \\
\hline
\end{tabular}

Modified with permission. IQVIA Institute for Human Data Science. Patient adoption of mHealth: Use, evidence and remaining barriers to mainstream acceptance (Sept 2015). https://www.iqvia.com/-/media/iqvia/pdfs/institute-reports/patient-adoption-ofmhealth.pdf (accessed 1 Feb 2017). 
Table 2-3. Summary of randomized controlled trials on diabetes app use

\begin{tabular}{|c|c|c|c|c|c|c|c|}
\hline $\begin{array}{l}\text { Authors and } \\
\text { year }\end{array}$ & Country & $\begin{array}{l}\text { Study } \\
\text { length }\end{array}$ & $\begin{array}{c}\text { Diabetes } \\
\text { type }\end{array}$ & $\begin{array}{c}\text { Primary } \\
\text { outcome(s) }\end{array}$ & Intervention & Control & Results \\
\hline $\begin{array}{l}\text { Berndt R, } \\
\text { Takenga C, } \\
\text { Preik P, et al., } \\
2014\end{array}$ & Germany & 1 month & Type 1 & $\begin{array}{l}\text { HbA1c levels, } \\
\text { weight, and QOL } \\
\text { satisfaction } \\
\text { measured by the } \\
\text { DQOLY }\end{array}$ & $\begin{array}{l}\text { Use of the Mobil } \\
\text { Diab app to track } \\
\text { SMBG values and } \\
\text { interfaces entered } \\
\text { information in real } \\
\text { time to medical } \\
\text { staff }\end{array}$ & $\begin{array}{l}\text { Standard } \\
\text { care }\end{array}$ & $\begin{array}{l}\text { Both groups had a } \\
\text { significant decrease } \\
\text { in HbA1c. The } \\
\text { control group had a } \\
\text { significant increase } \\
\text { in weight and BMI } \\
\text { vs. no change in the } \\
\text { Mobil Diab group. } \\
\text { No QOL changes in } \\
\text { the control group. } \\
\text { The Mobile Diab } \\
\text { group reported } \\
\text { significantly greater } \\
\text { self-efficacy scores. }\end{array}$ \\
\hline $\begin{array}{l}\text { Charpentier G, } \\
\text { Benhamou PY, } \\
\text { Dardari D, et } \\
\text { al., } 2011\end{array}$ & France & 6 months & Type 1 & $\begin{array}{l}\text { HbAlc levels in } \\
\text { patients with } \\
\text { baseline HbA1c } \\
\geq 8 \%\end{array}$ & $\begin{array}{l}\text { Use of the Diabeo } \\
\text { smartphone } \\
\text { software and } \\
\text { quarterly follow } \\
\text { up OR use of the } \\
\text { Diabeo software } \\
\text { with teleconsults } \\
\text { and no in-office } \\
\text { follow ups }\end{array}$ & $\begin{array}{l}\text { Usual in- } \\
\text { office } \\
\text { quarterly } \\
\text { follow up }\end{array}$ & $\begin{array}{l}\text { Mean HbA1c was } \\
\text { significantly lower } \\
\text { in the Diabeo } \\
\text { software + } \\
\text { teleconsults group } \\
\text { vs. control (8.41 vs. } \\
\text { 9.1). The Diabeo } \\
\text { software alone } \\
\text { produced a } 0.67 \% \\
\text { HbA1c reduction. }\end{array}$ \\
\hline
\end{tabular}


Table 2-3. (Continued)

\begin{tabular}{|c|c|c|c|c|c|c|c|}
\hline $\begin{array}{l}\text { Authors and } \\
\text { year }\end{array}$ & Country & $\begin{array}{l}\text { Study } \\
\text { length }\end{array}$ & $\begin{array}{c}\text { Diabetes } \\
\text { type }\end{array}$ & $\begin{array}{c}\text { Primary } \\
\text { outcome(s) }\end{array}$ & Intervention & Control & Results \\
\hline $\begin{array}{l}\text { Drion I, } \\
\text { Pameijer LR, } \\
\text { van Dijk PR, et } \\
\text { al., } 2015\end{array}$ & Netherlands & 3 months & Type 1 & $\begin{array}{l}\text { Change in QOL } \\
\text { measured by the } \\
\text { RAND-36 } \\
\text { questionnaire }\end{array}$ & $\begin{array}{l}\text { Use of the } \\
\text { Diabetes Under } \\
\text { Control digital } \\
\text { diary app }\end{array}$ & $\begin{array}{l}\text { Use of a } \\
\text { standard } \\
\text { paper diary }\end{array}$ & $\begin{array}{l}\text { No difference in } \\
\text { QOL between the } \\
\text { groups. }\end{array}$ \\
\hline $\begin{array}{l}\text { Goyal S, Nunn } \\
\text { CA, Rotondi M, } \\
\text { et al., } 2017\end{array}$ & Canada & 1 year & Type 1 & HbA1c levels & $\begin{array}{l}\text { Standard care }+ \\
\text { use of bant, a } \\
\text { blood glucose } \\
\text { tracker app with } \\
\text { out-of-range } \\
\text { glucose alerts and } \\
\text { coaching for out- } \\
\text { of-range causes } \\
\text { and fixes }\end{array}$ & $\begin{array}{l}\text { Standard } \\
\text { care }\end{array}$ & $\begin{array}{l}\text { No difference in } \\
\text { HbA1c between the } \\
\text { groups. For patients } \\
\text { doing SMBG } \geq 5 \\
\text { times daily, there } \\
\text { was a significant } \\
\text { HbA1c decrease in } \\
\text { the bant user group } \\
\text { vs. control }(0.58 \% \\
\text { vs. } 0.06 \%) .\end{array}$ \\
\hline $\begin{array}{l}\text { Holmen H, } \\
\text { Torbjørnsen A, } \\
\text { Wahl AK, et al., } \\
2014\end{array}$ & Norway & 1 year & Type 2 & HbA1c levels & $\begin{array}{l}\text { Use of the Few } \\
\text { Touch Application } \\
\text { digital diary app } \\
\text { OR use of app and } \\
4 \text { months of phone } \\
\text { health counseling }\end{array}$ & $\begin{array}{l}\text { No app use } \\
\text { or phone } \\
\text { counseling }\end{array}$ & $\begin{array}{l}\text { All groups } \\
\text { experienced a } \\
\text { decrease in } \mathrm{HbA} 1 \mathrm{c} \\
\text { from baseline. } \\
\text { Differences } \\
\text { between groups } \\
\text { were not significant. }\end{array}$ \\
\hline
\end{tabular}


Table 2-3. (Continued)

\begin{tabular}{|c|c|c|c|c|c|c|c|}
\hline $\begin{array}{l}\text { Authors and } \\
\text { year }\end{array}$ & Country & $\begin{array}{l}\text { Study } \\
\text { length }\end{array}$ & $\begin{array}{c}\text { Diabetes } \\
\text { type }\end{array}$ & $\begin{array}{c}\text { Primary } \\
\text { outcome(s) }\end{array}$ & Intervention & Control & Results \\
\hline $\begin{array}{l}\text { Huang Z, Tan } \\
\text { E, Lum E, et al., } \\
2019\end{array}$ & Singapore & 3 months & Type 2 & $\begin{array}{l}\text { Medication } \\
\text { adherence } \\
\text { measured by the } \\
\text { ASK-12 }\end{array}$ & $\begin{array}{l}\text { Standard care }+ \\
\text { use of the } \\
\text { Medisafe } \\
\text { medication } \\
\text { reminder app }\end{array}$ & $\begin{array}{l}\text { Standard } \\
\text { care }\end{array}$ & $\begin{array}{l}\text { The intervention } \\
\text { group reported more } \\
\text { adherence with the } \\
\text { app and significantly } \\
\text { lower adherence } \\
\text { barrier scores. }\end{array}$ \\
\hline $\begin{array}{l}\text { Nagrebetsky A, } \\
\text { Larsen M, } \\
\text { Craven A, et al., } \\
2013\end{array}$ & $\begin{array}{l}\text { United } \\
\text { Kingdom }\end{array}$ & 6 months & Type 2 & $\begin{array}{l}\text { Self-titration of } \\
\text { oral diabetes } \\
\text { medications }\end{array}$ & $\begin{array}{l}\text { Use of } t+\text { diabetes/ } \\
t+\text { medical digital } \\
\text { diary app with real } \\
\text { time feedback on } \\
\text { graphed SMBG } \\
\text { levels }\end{array}$ & $\begin{array}{l}\text { Medication } \\
\text { titration via } \\
\text { standard } \\
\text { care }\end{array}$ & $\begin{array}{l}86 \% \text { of intervention } \\
\text { patients vs. } 57 \% \text { of } \\
\text { control patients } \\
\text { made changes to } \\
\text { their medication } \\
\text { regimen based on } \\
\text { glucose readings. }\end{array}$ \\
\hline $\begin{array}{l}\text { Orsama AL, } \\
\text { Lähteenmäki J, } \\
\text { Harno K, et al., } \\
2013\end{array}$ & Finland & 10 months & Type 2 & $\begin{array}{l}\text { HbA1c levels, } \\
\text { weight, and } \\
\text { blood pressure }\end{array}$ & $\begin{array}{l}\text { Use of the Monica } \\
\text { app, which } \\
\text { provides graphs } \\
\text { and feedback } \\
\text { communication } \\
\text { from nurses based } \\
\text { on entered blood } \\
\text { pressure, weight, } \\
\text { exercise, and } \\
\text { glucose values }\end{array}$ & $\begin{array}{l}\text { Standard } \\
\text { care with } \\
\text { diabetes } \\
\text { education } \\
\text { and } \\
\text { counseling }\end{array}$ & $\begin{array}{l}\text { The intervention } \\
\text { group saw a } \\
\text { significantly greater } \\
\text { HbA1c decrease } \\
(-0.4 \% \text { vs. }+0.036 \% \\
\text { for the control } \\
\text { group) and weight } \\
\text { reduction }(-2.1 \mathrm{~kg} \\
\text { vs. }+0.4 \mathrm{~kg}) \text {. There } \\
\text { was no difference in } \\
\text { blood pressure. }\end{array}$ \\
\hline
\end{tabular}


Table 2-3. (Continued)

\begin{tabular}{|c|c|c|c|c|c|c|c|}
\hline $\begin{array}{l}\text { Authors and } \\
\text { year }\end{array}$ & Country & $\begin{array}{l}\text { Study } \\
\text { length }\end{array}$ & $\begin{array}{c}\text { Diabetes } \\
\text { type }\end{array}$ & $\begin{array}{c}\text { Primary } \\
\text { outcome(s) }\end{array}$ & Intervention & Control & Results \\
\hline $\begin{array}{l}\text { Rossi MC, } \\
\text { Nicolucci A, Di } \\
\text { Bartolo P, et al., } \\
2010\end{array}$ & Italy & 6 months & Type 1 & $\begin{array}{l}\text { Time required } \\
\text { for education and } \\
\text { treatment \& } \\
\text { QOL satisfaction } \\
\text { measured by the } \\
\text { WHO-DTSQ \& } \\
\text { SF-36, } \\
\text { respectively }\end{array}$ & $\begin{array}{l}\text { Use of a } \\
\text { smartphone } \\
\text { Diabetes } \\
\text { Interactive Diary }\end{array}$ & $\begin{array}{l}\text { Standard } \\
\text { carbohydrate } \\
\text { counting }\end{array}$ & $\begin{array}{l}\text { Education time was } \\
6 \text { hours for the } \\
\text { intervention and } 12 \\
\text { hours for the control } \\
\text { group. Intervention } \\
\text { group had } \\
\text { significantly higher } \\
\text { score increases for } \\
\text { treatment } \\
\text { satisfaction and } \\
\text { QOL measures. }\end{array}$ \\
\hline $\begin{array}{l}\text { Waki K, Fujita } \\
\text { H, Uchimura Y, } \\
\text { et al., } 2014\end{array}$ & Japan & 3 months & Type 2 & $\begin{array}{l}\text { HbA1c and } \\
\text { fasting blood } \\
\text { glucose levels }\end{array}$ & $\begin{array}{l}\text { Use of the } \\
\text { DialBetics } \\
\text { smartphone } \\
\text { software }\end{array}$ & $\begin{array}{l}\text { No } \\
\text { smartphone } \\
\text { software use }\end{array}$ & $\begin{array}{l}\text { HbA1c fell } 0.4 \% \text { in } \\
\text { the Dialbetics group } \\
\text { vs. an increase of } \\
0.1 \% \text { in the control. } \\
\text { Fasting glucose } \\
\text { changes were also } \\
\text { significant in the } \\
\text { Dialbetics group } \\
\text { ( }-5.5 \mathrm{mg} / \mathrm{dl} \text { vs. } \\
+16.9 \mathrm{mg} / \mathrm{dl} \text { in the } \\
\text { control). }\end{array}$ \\
\hline
\end{tabular}

Notes: QOL = quality of life; DQOLY = Diabetes Quality of Life for Youth scale; BMI = body mass index; ASK-12 = Adherence Starts with Knowledge 12 questionnaire; WHO-DTSQ = World Health Organization-Diabetes Treatment Satisfaction Questionnaire; SF-36 = 36-Item Short Form Health Survey 
services can access self-management resources. Additionally, mHealth carries the advantage of offering a variety of support functions ranging from medication adherence to diet/carbohydrate monitoring. Such a diverse offering dovetails with the concept of management individualization. Patients with diabetes comprise a heterogeneous population, differing in cultural, educational, and psychosocial backgrounds. Therefore, self-management support must be tailored to each patient's needs in order to be effective (Haas et al., 2012). With smartphone applications, patients are able to pick and choose from hundreds of apps those that are relevant to their lifestyle and health goals.

Numerous clinical trials have demonstrated the benefits of developing selfmanagement skills on diabetes outcomes. Several studies have demonstrated increased frequency of physical activity, diet monitoring, and SMBG (Bielamowicz et al., 1995; Glasgow et al., 2012; Lorig \& Gonzalez, 2000). Others have shown significant decreases in HgA1c levels, including among low-income and racial and ethnic minority populations (Gregg et al., 2007; Liebman, Heffernan, \& Sarvela, 2007; Rosal et al., 2005; SamuelHodge et al., 2009). Accordingly, patients with diabetes who report higher confidence in and ability to provide self-care have better clinical and QOL of life measures. In one study, patients who rated themselves in the $95^{\text {th }}$ percentile for self-management had an average HbA1c of 7.3 compared to 8.3 for patients rating themselves in the lowest $5^{\text {th }}$ percentile (Heisler et al., 2003). For low-income, racial and ethnic minority populations, self-management ability has been found to have a statistically significant association with diet, exercise, medication adherence, glucose testing and control, and mental health QOL (Walker et al., 2014). Comparatively, people who use health apps were significantly more likely to express intentions to improve exercise, weight loss, and fruit/vegetable consumption than non-app users (Carroll et al., 2017). Diabetes apps may have the potential to help underserved patients with their self-management behaviors, which in turn, may lead to better clinical and QOL outcomes. 


\section{CHAPTER 3. METHODS}

This chapter provides a description of the qualitative research methods used in this study. The statement of purpose given below guides the data collection process subsequently detailed. Finally, the chapter closes with an overview of the sample population and site.

\section{Overall Objectives}

The underlying reason for this study is to the examine patients' perception of and willingness to use mobile health applications in the self-management of their diabetes. This includes determining their current understanding of mHealth apps and their interest in using their phones as a healthcare resource. Because health management is such a personal affair, a qualitative approach best suits the research process.

\section{Rationale for Qualitative Methods}

Qualitative research at its core examines how people create and value a social experience (Denzin \& Lincoln, 2008). More, specifically, this refers to any research about "persons' lives, lived experiences, behaviors, emotions, and feelings as well as about organizational functioning, social movements, and cultural phenomena" (Strauss \& Corbin, 1998). Unlike quantitative inquiry, which reduces worldly observations down to structured numeric values, qualitative research involves a more linguistic approach, which allows for more flexibility and openness with the data (Corbin \& Strauss, 2008). This type of research focuses on the exploration of multiple perspectives of an experience. Exploring different patients' perceptions of mobile health allows a fuller understanding of the factors and influences that make people open to using their smartphones for health management. As mobile technology is a newer platform for healthcare, it is also a newer social experience. Therefore, exploration of mHealth use lends itself well to qualitative research, in which investigators ask questions with a beginner's mindset that is open to viewing everything as if for the first time (Maxwell, 2013).

Qualitative research permits the researcher to study and interpret behavior in context or natural setting (Denzin \& Lincoln, 2008; Merriam \& Tisdell, 2016); this means that people's families, work, and backgrounds are equally important as the outcome-of-interest itself. This notion is especially relevant to this study, which sought to understand patients' reception of mobile health technology in the setting of limited access to traditional healthcare providers. The research is about producing thick description (Geertz, 1973), or a detailed portrayal of the social and cultural relationships that affect how a person perceives an experience. By fully detailing the context, emotions, and process of the research, investigators can offer readers a story of what they might expect if in a similar situation. Thick description "merges the participants' lived experiences 
with the interpretation of these experiences" (Ponterotto, 2006), allowing the researcher to share his own theories and ideas about the phenomenon.

\section{Philosophical Construct}

For this dissertation, the theoretical framework for the qualitative research is constructivism. This paradigm asserts that people build meaning in different ways, even as they experience the same event. Realities are "socially and experientially based" and "local and specific in nature" but can also have shared elements across groups and individuals (Guba \& Lincoln, 1994). There are several assumptions of constructivism pertinent to this study: 1. People are constantly engaging with the world and make sense of it through a lens of culture and previous personal experience; 2 . The basic creation of meaning is always social, arising from interactions with the community at large; 3 . Openended, qualitative questions are the best tool to capture how people engage with and then interpret the world around them (Crotty, 1998). The selection of smartphone apps is not a one-size-fits-all approach. Each person sees, treats, and lives with diabetes differently. What one deems as a useful, necessary app function may not hold true for another. Nonetheless, these individuals have a shared quality of limited primary care access and therefore might have commonalities across their experiences.

Because all interpretations and results in qualitative research are context-specific, the investigator holds a central role in the research process. In constructivism, the interviewer and subject interact in a way so that "findings are literally created as the investigation proceeds" (Guba \& Lincoln, 1994). The researcher thus holds a dual role of gatherer and interpreter (Stake, 1995). For this study, the gathering consists of culling information about receptiveness to smartphone apps for diabetes management, and the interpreting consists of determining these apps usefulness in the context of limited healthcare access.

\section{Research Design}

Phenomenology serves as the primary methodology for this study. This particular method of inquiry investigates the way people experience and think about the world around them. It is concerned about uncovering and describing lived experiences and answers the question "What is this like to experience x?" (Ploeg, 1999; Nieswiadomy, 2007; Laverty, 2008). Phenomenology recognizes that each person perceives and interacts with the world-at-large differently, and that the world or reality does not exist as a separate entity from the person (Laverty, 2008). Because this type of inquiry focuses on how people assign meaning to events lived in their daily existence, phenomenology is best suited for research that attempts to understand how people perceive, experience, and react to a certain situation or event. Researchers ask respondents to describe their experiences through written or oral interviews (Nieswiadomy, 2007). In addition to offering new insights into how individuals find meaning in a given phenomenon, these descriptions may include thoughts that are often taken for granted or considered common sense or uncover any forgotten meanings (Laverty, 2008). Phenomenology is a popular 
research tool in the social and health sciences and can be used to examine a whole host of unquantifiable health-related situations like insomnia, caregiver frustrations, or management of chronic pain (Creswell, 2013).

Because phenomenology is a person-centered research approach, it is fitting for this study. The main research question involves a phenomenon, the use of smartphone apps for diabetes management, and how people perceive their use. Phenomenology is also useful to study topics in which there exists little knowledge in the literature. The application of mobile health to this study's population of interest, low-income or minority individuals without access to primary care providers, has not been examined before. To determine if smartphone apps can be an appropriate resource for these individuals, a qualitative study is necessary to gauge what value this population would assign to such apps and how they would use them. A well-executed phenomenological approach eliminates any taken-for-granted assumptions or preformed opinions about how mobile health would benefit this resource-limited group and would instead offer valuable insight into what motivates these individuals to use an app and how they would incorporate the app into their daily health management. Results from this study also have real-world applicability since information collected highlights the types of mobile apps individuals would seek on their own, instead of information about an app which researchers preselected for the individuals to use.

Specifically, this study utilized interpretative phenomenological analysis (IPA) to investigate how people make sense of using smartphone apps for diabetes selfmanagement. IPA assumes that every person is self-interpreting the world around him (Smith, Flowers, \& Larkin, 2009). This means that each person sees life through a lenses made of familial history, previous experience, current knowledge, religious and cultural customs and beliefs, and geographical context. Therefore, two people who experience the same event may not see or remember the same things. IPA, therefore, tries to make sense of what an experience is like from each individual's perspective. IPA recognizes that both person and context have equal importance in living a phenomenon (Smith, Flowers, \& Larkin, 2009; Pietkiewicz \& Smith, 2014). This approach was particularly suitable to this research question, which seeks to understand how medically underserved patients with diabetes (presentation of a particular context) assign meaning (personal interpretation) to the use of smartphone health apps (shared phenomenon). Consistent with IPA, this study did not seek to test a hypothesis but rather the generation of codes from gathered data. Rich, descriptive accounts were collected from patients with diabetes about their experiences with smartphone apps and then each and every account was reviewed in their unique contexts before making any generalized assessments. Data analysis in IPA is a distinguishing feature. It is what is termed double hermeneutic, or double interpretative (Pietkiewicz \& Smith, 2014). First, the participants made meaning of the event, the use of smartphone apps. Then the researcher tried to make sense of how the participants interpret their own experiences. In coding the data, recurring patterns or themes would emerge in the text (Pietkiewicz \& Smith, 2014). These themes and superordinate themes are likely to indicate what matters to the patients and what would influence them the most to seek out and use mobile health. 


\section{Interview Process}

The personal interview served as the vehicle of choice for data collection. These interviews are designed to capture "the meanings that life experiences hold for the interviewees" (DiCiccio-Bloom \& Crabtree, 2006). Because management of a chronic condition like diabetes involves a variety of tasks that must be individualized to the patient, each person's experience with the disease state is unique. No two patients have the same home and social environment either. Therefore, the decisions one patient makes about self-care differs from other patients. One-on-one interviews are a suitable way to chronicle such personal accounts. They also offer the advantage of revealing any issues or concerns patients might have with mobile health that the researcher would not have considered (Pope, van Royen, \& Baker, 2002).

This study used semi-structured interviews. These types of interviews are the preferred way of gathering data for IPA analysis (Smith \& Osborn, 2008). Each encounter starts with a predetermined question set but allow for digression from that question list to explore topics that emerge during the interviewer/interviewee exchange (DiCiccio-Bloom \& Crabtree, 2006). This type of interview format is appropriate when trying to cover specific topics in a certain order and when only having one chance to interview a participant (Bernard, 2011). Moreover, the semi-structured interview allows for probing questions, which are open-ended general questions seeking information on a topic, as well as follow-up questions, which allow for further response or clarification on a topic (Kvale, 1996). Veering away from a regimented list of questions allows the researcher to elicit a more fruitful response from the participant by following his knowledge and interests. This allows the interviewer to "facilitate and guide, rather than dictate exactly what will happen during the encounter" (Smith \& Osborn, 2008). Even silence on the part of the interviewer can act as a tool to encourage spontaneous statements from the subject (Kvale, 1996). The interview questions for this study appear in Appendix A. The interview process, adapted from McNamara's steps to staging the interview follows the outline in Figure 3-1 (McNamara, 2006).

\section{Research Site}

Methodist South is a 156 bed hospital with a 24 hour emergency department (ED) located in South Memphis, TN (Methodist Le Bonheur Healthcare, 2015). While the Methodist Le Bonheur healthcare system has several other hospitals in the greater Memphis area, this particular location was most appropriate. This study sought research subjects with both limited access to primary care providers and ready access to a hospital ED. The patient populations serviced by Methodist South were most likely to represent these characteristics. Located in Whitehaven, a neighborhood of South Memphis, this hospital covers an area that demonstrates characteristics related to an underserved health population. This community has a predominant minority residency of African Americans (92\%) and Hispanics (3\%) (U.S. Census Bureau, 2016). The average Whitehaven household income is $\$ 46,964$, which is approximately $\$ 8,000$ less than the city average $(\$ 55,297$ for Memphis) and approximately $\$ 21,000$ less than the county average $(\$ 68,182$ 


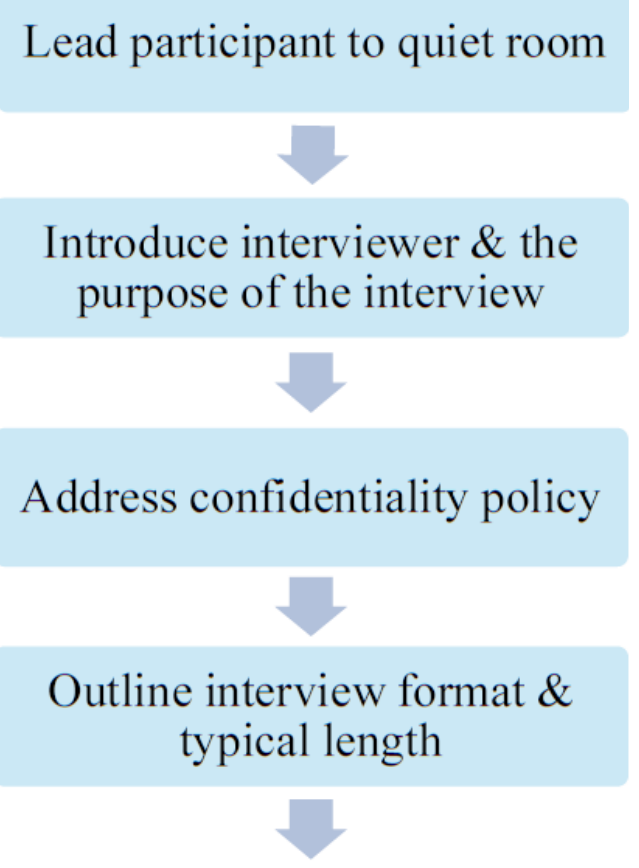

Ask for questions prior to starting interview

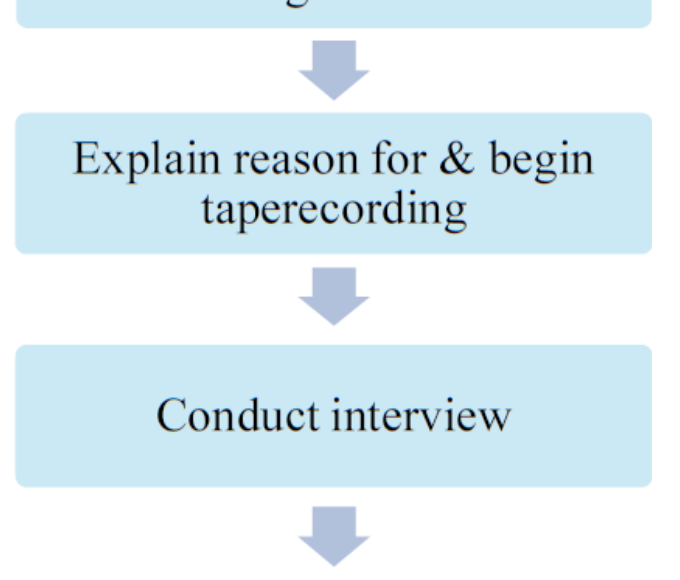

Stop taperecording \& ask for questions at end of interview

\section{Offer contact information for any post-interview concerns}

Figure 3-1. Stepwise process for conducting personal interviews

Data Source: McNamara C. General guidelines for conducting research interviews (2006). https://managementhelp.org/businessresearch/interviews.htm (accessed 12 Jun 2015). 
for Shelby County) (U.S. Census Bureau, 2016). Moreover, Whitehaven has few primary care offices (Figure 3-2), a large portion of which are affiliated with the Methodist South campus (Research Center of Health Disparities, Equity, \& the Exposome, 2017). This is in great contrast to the density of primary care locations in the city at large (Figure 3-3). Most importantly, this South Memphis area demonstrates a higher prevalence of diabetes than the city-at-large. Whitehaven has an average age-adjusted mortality rate of 41.92 deaths per 100,000 people (Figure 3-4) vs. 28.9 for all of Shelby County (Figure 3-5) (Research Center of Health Disparities, Equity, \& the Exposome, 2017).

\section{Protection of Human Subjects}

The University of Tennessee Health Science Center (UTHSC) Institutional Review Board (IRB) provided approval for this study (Appendix B) and related selection procedures to recruit adults with diabetes for personal interviews. Through Cooperative Agreements/IRB Authorization Agreements, the Methodist Healthcare-Memphis Hospitals also provided institutional approval for participant recruitment from Methodist South Hospital. The UTHSC IRB standard operation procedures (2016) notes the necessity of obtaining informed consent from all study participants prior to the start of all interviews. Before each interview, the researcher provided a consent form (Appendix C) and obtained verbal approval from every participant. Interviewees could refuse to answer any question they did not wish to address. They were also able to withdraw consent at any point during the study without consequences.

\section{Participant Criteria}

While the literature does not offer an exact number of personal interviews to conduct, data saturation is key. This means that if after developing themes from previously collected interviews, the researcher feels that the data from the next few interviews fall within these existing themes, then the study has reached data adequacy, or saturation (Morse, 1995). For phenomenological studies, several authors (Morse, 1994; Creswell, 2013) recommend a sample size of between 5 and 15 interviews; although, there are no official guidelines for the a priori estimation of interview numbers needed for saturation (Morse, 1995). IPA echoes this call for small sample sizes with previously published IPA literature featuring sample sizes ranging from 1 to 15 or more subjects (Smith \& Osborn, 2008). More emphasis should fall on obtaining thick, rich description than on the total amount of interviews obtained. For IPA especially, if the sample size were too large, the researchers might become "overwhelmed by the vast amount of data generated by a qualitative study and are not able to produce a sufficiently penetrating analysis" (Smith \& Osborn, 2008).

This study employed purposeful sampling (Patton, 2002) in the selection of patients for personal interviews. Purposeful sampling involves selecting for intensity: picking individuals based on certain characteristics that would provide greater depth to the data collected (Patton, 2002). Purposeful sampling also produces a cohesive study 


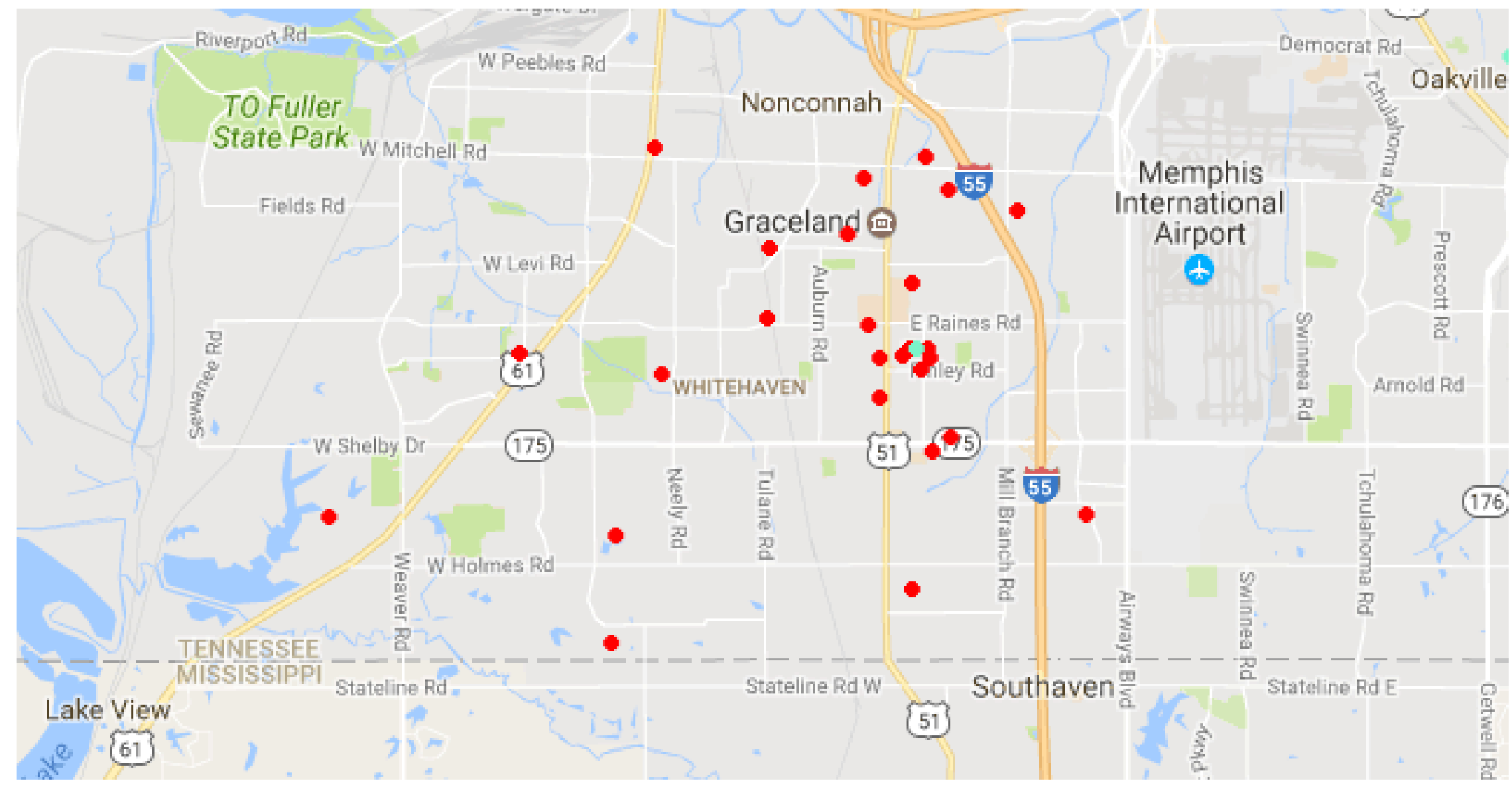

Figure 3-2. Locations of primary care offices around the Whitehaven, $T N$, area

Notes: The red dots indicate locations of primary care offices. The light blue dot is the location of Methodist South hospital, around which are clustered several offices.

Reprinted with permission. Research Center on Health Disparities, Equity, \& the Exposome. Interactive map of health equity in Memphis, Tennessee: Health data (2017). http://www.immemphis.com/health-data (accessed 11 Mar 2017). 


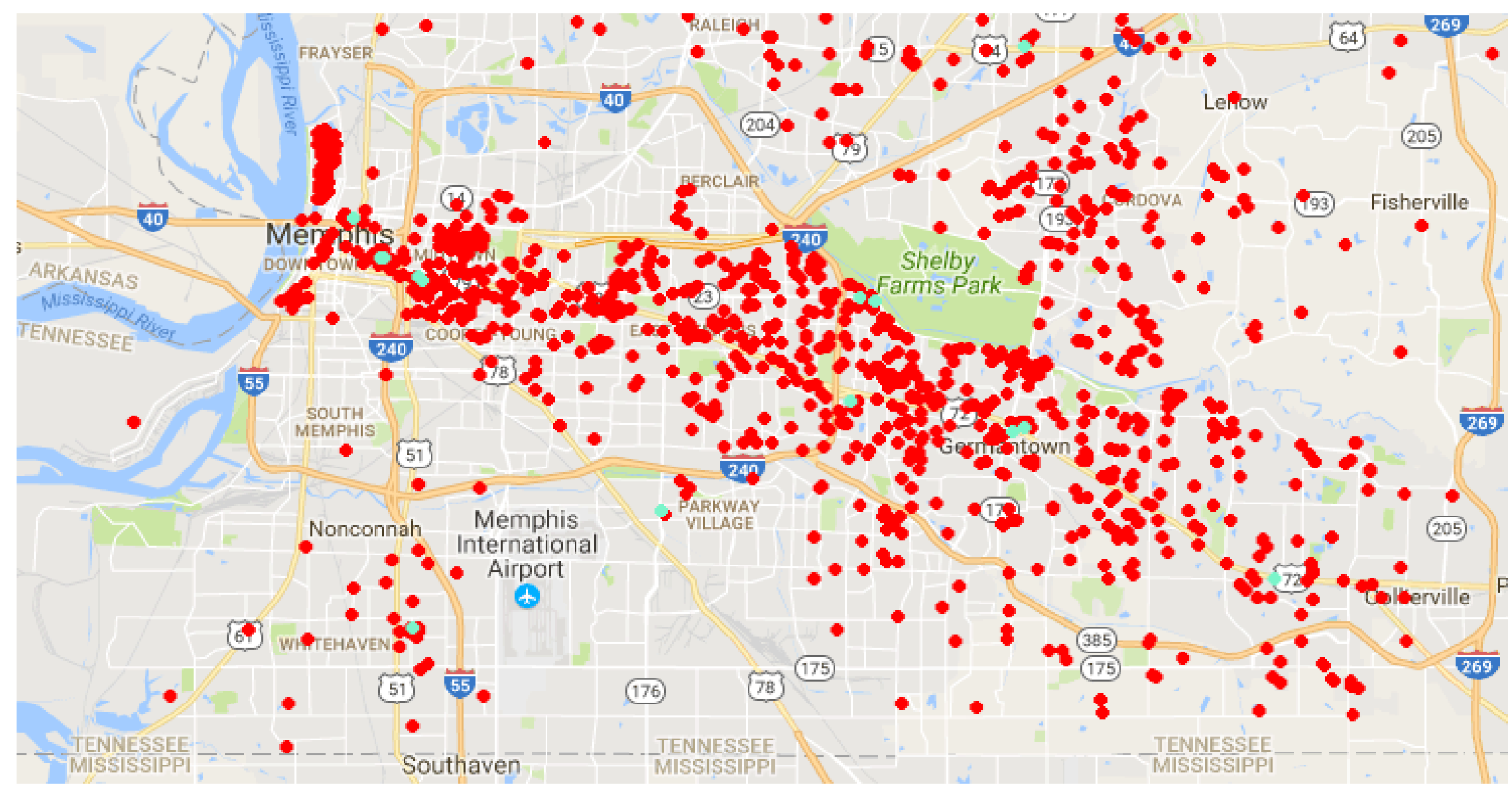

Figure 3-3. Locations of primary care offices in the greater Memphis, TN, area

Notes: The red dots indicate locations of primary care offices. The light blue dots indicate locations of hospitals.

Reprinted with permission. Research Center on Health Disparities, Equity, \& the Exposome. Interactive map of health equity in Memphis, Tennessee: Health data (2017). http://www.immemphis.com/health-data (accessed 11 Mar 2017) 


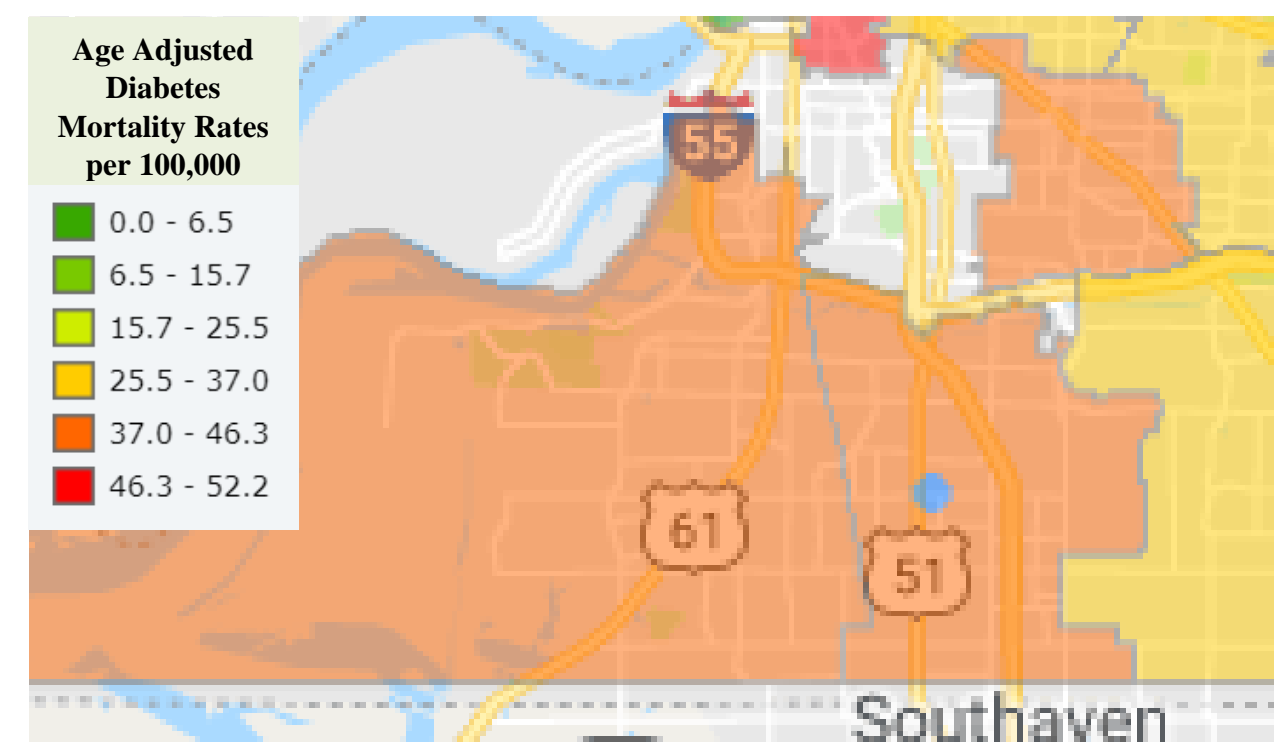

Figure 3-4. Age-adjusted diabetes mortality rates for the Whitehaven, TN, area Note: The light blue dot represents Methodist South hospital.

Reprinted with permission. Research Center on Health Disparities, Equity, \& the Exposome. Interactive map of health equity in Memphis, Tennessee: Health data (2017). http://www.immemphis.com/health-data (accessed 11 Mar 2017). 


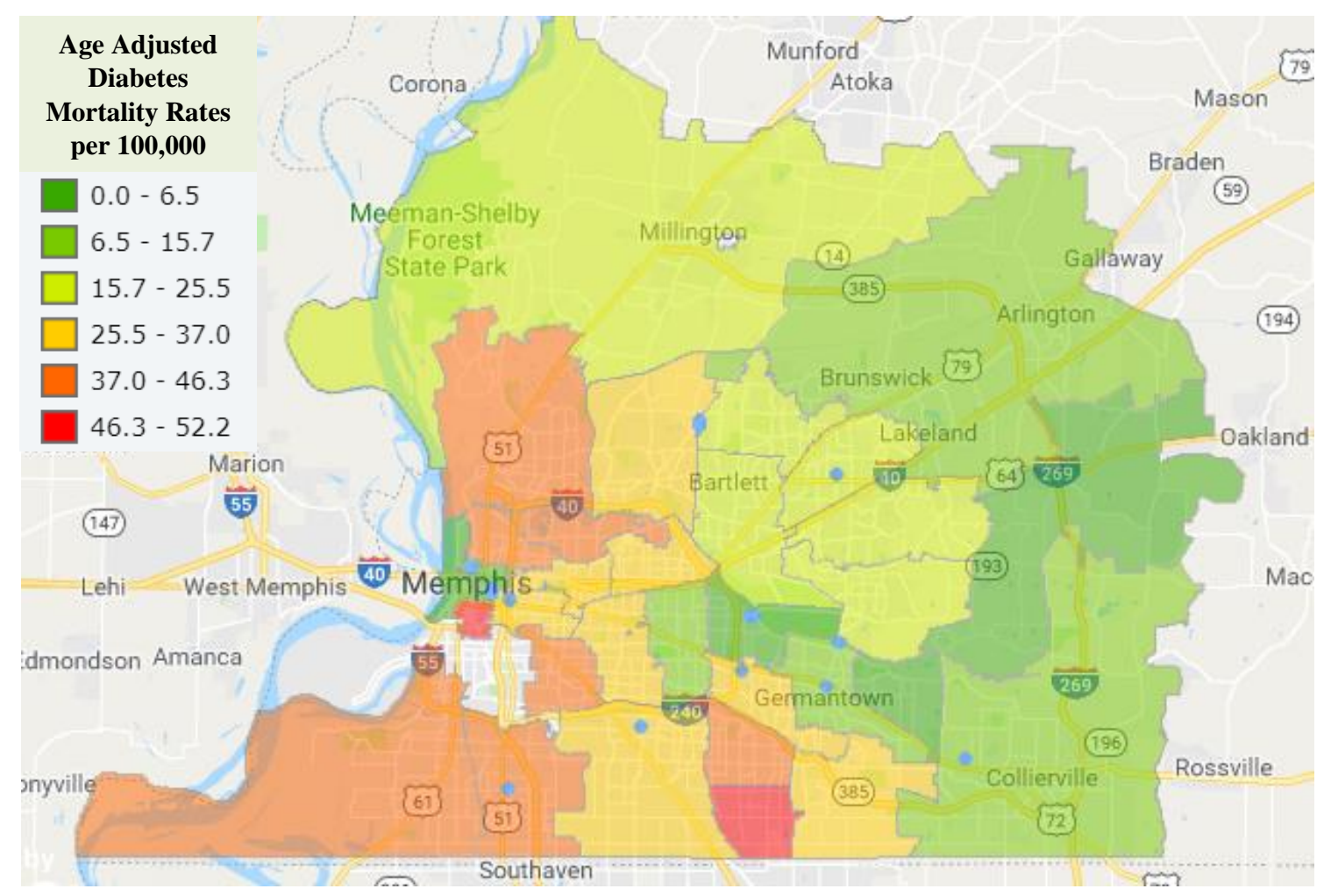

Figure 3-5. Age-adjusted diabetes mortality rates for the greater Memphis, TN, area

Note: The light blue dots represents Memphis-area hospitals.

Reprinted with permission. Research Center on Health Disparities, Equity, \& the Exposome. Interactive map of health equity in Memphis, Tennessee: Health data (2017). http://www.immemphis.com/health-data (accessed 11 Mar 2017). 
population. The more cohesive a sample, the faster data saturation occurs (Morse, 1995). Selected participants then provide information-rich details about the phenomenon of interest.

Inclusion criteria were as follows: 1 . age $\geq 18$ years with diagnosed type 1 or 2 diabetes; 2 . ownership of or ability to have access to a smartphone that is able to download and open apps (self-reported); 3. limited or no access to a regular primary care provider (self-reported); 4. recent ED visit for a diabetes-related incident. Exclusion criteria included: 1. patients with diabetes hospitalized without an ED admission; 2. diagnosis of drug- or chemical-induced or gestational diabetes; 3. patients participating in other studies related to diabetes treatment and coaching. Appendix D (Tables D-1 through D-4) lists the International Classification of Diseases (ICD) codes used to identify qualifying diabetes-related encounters from patient charts.

\section{Recruitment Process}

Both an emergency department pharmacist and a transitions of care clinical pharmacist at Methodist South worked to identify potential participants. The ED pharmacist began the screening process by reviewing the patient chart for the reason for admission. Then she confirmed the patient's age and that the patient has a qualifying diabetes diagnosis through the History and Physical Examination notes and/or an appropriate ICD-9 or ICD-10 code in the patient's historical conditions summary. After confirming both a diabetes-related reason for admission to the emergency room and a documented diabetes diagnosis, the emergency room pharmacist passed the patient's information on to the transitions of care pharmacist. This second pharmacist then went to speak with the patient. She confirmed with the patient their reason for coming to the hospital and their diabetes diagnosis. She then provided an overview of the study and asked if the patient had a regular primary care physician. If the patient expressed interest in participating in the study, the pharmacist would verify the contact phone number for the patient to pass on to the study investigator.

Patients who expressed interested in the study then received a phone call about participation detailing the researcher's identity, study purpose, and methods. The investigator would reaffirm the patient's interest in participating in a face-to-face interview. During the call, the researcher and patient would arrange a time to meet. The availability of times for both participant and researcher to meet drove the decision for interview selection. Each participant provided one interview. All interviews were held on-site in a private conference room at Methodist South.

\section{Patient Selection Process}

The recruitment process took place between May 2017 and February 2018. The ED pharmacist and transitions of care pharmacist together determined that a total of 34 patients met the eligibility criteria for the study. From these patients, the investigator was 
able to schedule an interview with 23 of them. Of this group, the investigator successfully met and interviewed 15 patients. Figure 3-6 summarizes the selection process.

\section{Data Collection and Analysis}

Data collection in phenomenological research involves gathering deep, rich information from subjects. Important to this process is bracketing. This is when the researcher first identifies what he expects to discover or what he believes or feels about the phenomenon; then he deliberately sets aside, or brackets, these preconceived opinions and ideas in order to produced unbiased data (Strauss \& Corbin, 1998; Corbin \& Strauss, 2008).

When the researcher sets aside his own thoughts, it is possible to view the experience from the perspective of the person who lived it, and the researcher himself remains open to the meaning each individual assigns to the phenomenon. The data collection process itself involves allowing the participants to provide a full description of their experience without any leading or coloring from the researcher (Denzin \& Lincoln, 2008). A full description may involve any opinions, feelings, images, memories, or sensations.

Analysis in qualitative research is the process of creating meaning. Because this involves a continuous exchange between data collection and analysis, data analysis began as soon as the first interview concluded (Strauss \& Corbin, 1998). The identification of patterns and themes with the first few interviews helps facilitate further data collection (Strauss \& Corbin, 1998). While the literature agrees that there exists no singular approach for qualitative data analysis, there are common overarching steps to the process. The first involves familiarization, or becoming intimately acquainted with the data (Pope, van Royen, \& Baker, 2002; Esterberg, 2002; Creswell, 2009). To do this, the researcher must first organize the data to prepare it for analysis; this involved repeated listening to interview tapes and immediate transcription of the audio data. Then the researcher read through the transcribed interviews several times to become fully immersed in and familiar with the data (Smith \& Osborn, 2008). From these close readings and familiarization, the researcher could then begin identifying themes and patterns. For this study, the researcher broke the transcribed data into segments and then organized the sentence/phrase segments into categories. The researcher then titled each category based on what the text data said. The next step in this coding process was to build emerging themes from the categories and data clusters identified. For this step, the researcher grouped similar or related categories together to identify an emerging theme or descriptor; the researcher rearranged the clusters of text to produce narrative passages that supported the themes into which they fell (Pope, van Royen, \& Baker 2000; Creswell, 2009).

The final step to the data analysis process involves interpreting the meaning of the data (Creswell, 2009). Interpretative phenomenological analysis studies like this one involve drawing themes and understandings from close analysis of lengthy individual transcripts (Smith \& Osborn, 2008). For this study, this meant discovering how each 


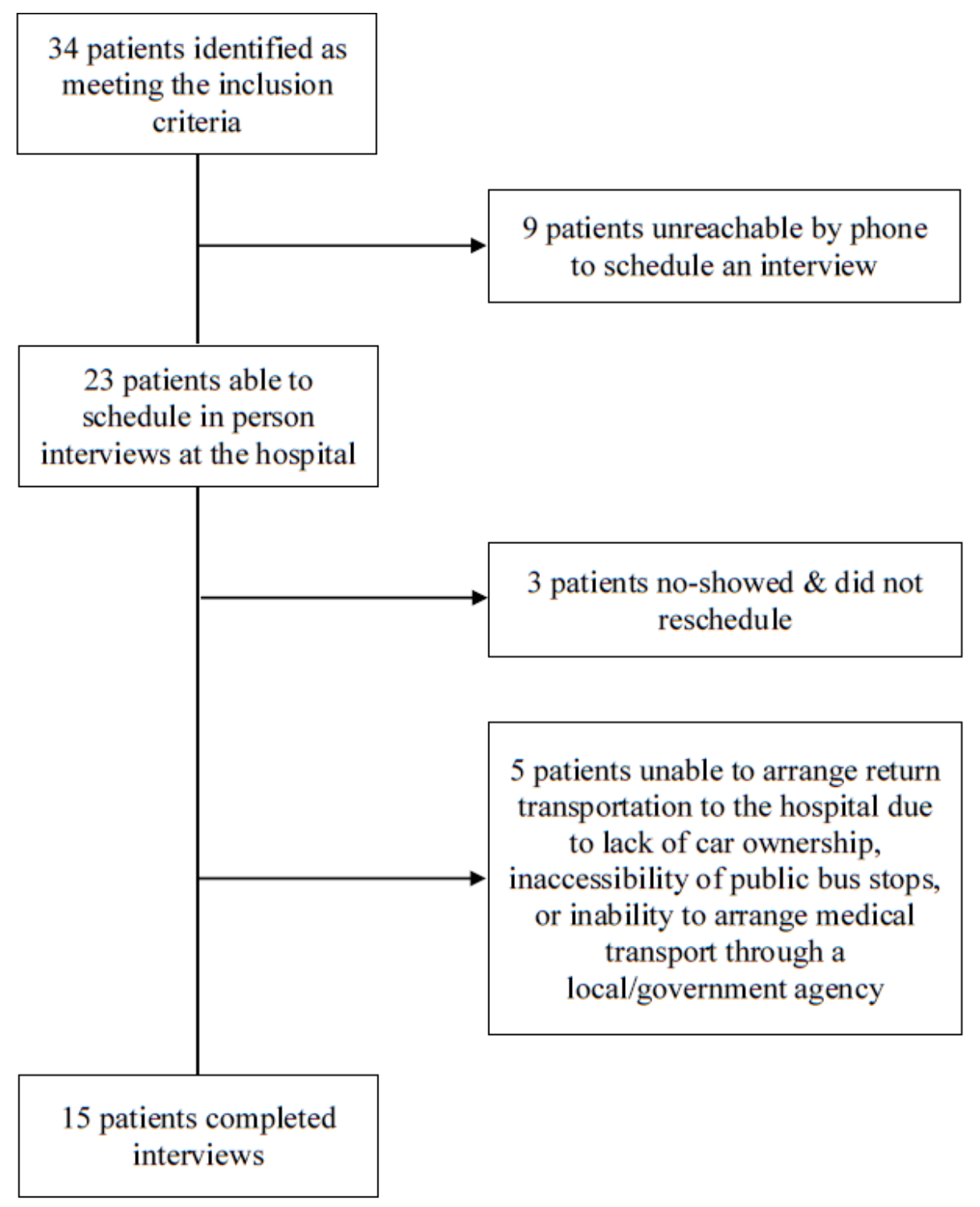

Figure 3-6. Participant selection process 
participant's story contributes to understanding how patients assign worth and significance to smartphone apps for diabetes management. Important to this final step is accurately conveying participants' perceptions of their experiences. The analysis process for phenomenological data is unique in that it is not hypothesis driven. Instead, the data itself drives the analysis. Readings and review of collected data lead to the emergence of patterns, which can then be used to code further collected data. Usually, the process first begins with searching for significant statements that then build into clusters of meaning and broader themes to describe the experience. From this, the researcher is able to determine the essence of the phenomenon (Smith, Flowers, \& Larkin, 2009). Put another way, the data allows the researcher to build underlying structure common to the experience.

\section{Establishing Trustworthiness of Findings}

As with quantitative research, where internal and external validity are crucial to establishing if the research findings accurately reflect what the study observed and if those findings can be generalized outside the study, qualitative research uses measures of trustworthiness. Lincoln and Guba noted four criteria for establishing trustworthiness and goodness of results obtained from a qualitative study: credibility, transferability, dependability, and confirmability (1985). This study employed several techniques to establish each of the four aforementioned criteria and overall trustworthiness of the gathered results.

The first of the criteria, credibility, refers to the confidence in the results reflecting what the phenomenon the researchers intended to study (Lincoln \& Guba, 1985). There were several ways in which this study sought to confirm credibility. Using a research method that is well-established in the literature ensured that the correct procedures were used to gather and analyze data (Graneheim \& Lundman, 2004). As previously mentioned, the use of semi-structured interviews to gather data on patients' willingness to use mobile apps is appropriate for phenomenology research. Additionally, the data analysis outlined aligns with methods widely employed by qualitative researchers to develop codes and themes. Establishing trust with participants plays a large role in the collection of accurate data (Cresswell, 2015). To build trust in this study, the researcher only recruited participants who showed interested in taking part, notified subjects at both the start and end of the interview process that they were free to withdraw at any time without penalty, and de-identified any personal information associated with the interviews. Before the start of each interview, the researcher emphasized that there were no right answers to the questions asked and no time limit for each answer, encouraging participants to contribute talk and ideas about their knowledge of and attitudes toward mobile health technology. Verifying accurate transcription through member checks and peer review is also essential to establishing credibility (Lincoln \& Guba, 1985). For member checks, the researcher would summarize at the end of each interview the stories or information the participant provided and ask the participant if that was a correct representation of what he or she meant to say (Creswell, 2015). In addition, a faculty member uninvolved in the interview process reviewed the transcribed dialogue to verify correct transcription from audio to text. A faculty cohort, either familiar with the 
IPA research process or with the topic of diabetes self-management, also reviewed the codes and categories created in NVivo to verify that any documented emerging theories or ideas had support from the gathered dialogue.

The next criterion, transferability, refers to how a study's findings may apply to other settings (Lincoln \& Guba, 1985). In order for others to see if they can relate this study's results to a similar situation, the researcher included relevant contextual information about the study group, including the research site, the population the hospital serves, and the criteria for study inclusion. The data itself also contains thick description (Geertz, 1973) of the subjects' current knowledge of and attitudes towards diabetesrelated mobile health. Thus, future readers can review the contextual information to determine if their situation has any parallels to this study. The inclusion of details from gathered interviews in the results section below also provides "an element of realism" (Creswell, 2015). The thick descriptions provided allow readers to understand fully the phenomenon of interest for this study and draw any comparisons with what they see emerging in their situation.

Dependability demonstrates consistent results (Lincoln \& Guba, 1985). This means that if another investigator were to repeat the research with the same methods, participants, and context, he would obtain similar results (Elo et al., 2014). To some extent, duplication of results is impractical because context is ever-changing. The participants interviewed for this study may have gained additional knowledge about smartphone apps for diabetes or have changes in their condition or socioeconomic status that may alter their answers if interviewed again. Lincoln and Guba assert that credibility and dependability are closely linked in that steps taken to demonstrate credibility may also ensure dependability (1985). Further measures this study took to address dependability included a faculty review of the research design used and its applicability to the research question, a step by step summary below of the data collection and analysis process, and a description of the participant selection criteria and operational details of how the researcher set up and structured the interviews. This transparency in the entire work process enables a future investigator to understand the effectiveness of the methods used and to replicate the study.

Lastly, confirmability addresses the researcher's ability to produce objective findings, results that are not biased by the researcher's own preferences, biases, or motivations (Lincoln \& Guba, 1985). To bolster credibility, the researcher acknowledged her own conceptual lens. Termed reflexivity, this is a process by which the researcher performs a self-assessment of his or her own preconceptions regarding the study and how this might shape the research process (Malterud, 2001). For this study, the researcher accomplished this by keeping personal journal notes of how her thoughts and beliefs impacted methodological decisions, descriptions of the interview setting, and her subjective thoughts on her relationship with the interviewees (Korstjens \& Moser, 2018). An example of methodological decision-making noted with reflexive journaling was the researcher recognizing a preconception that this underserved population might be sensitive about their lower income, especially when interacting with an interviewer who was pursuing higher education. Therefore, the researcher decided not to structure any 
interview questions with exact income figures or ranges in the hopes that interviewees would feel more comfortable and would then open up more about their home experiences with diabetes. Another example would be the researcher's decision-making process regarding the interview location. In journaling, the researcher noted more feelings of comfort and familiarity with the UTHSC campus and the conference rooms available there. The study participants, however, might not have ever visited the campus or knew how to get there from their homes. Despite this personal preference for the academic campus over the hospital site, the researcher chose to conduct the interviews at Methodist South, reasoning that the participants' comfort should take precedence to encourage honest, more fruitful interview responses. In addition to reflexive journaling, acknowledging the shortcomings of the study's design and any potential effects can help establish confirmability (Shenton, 2004). A discussion of this study's various limitations and their potential impact on the results appears in the final chapter. 


\section{CHAPTER 4. RESULTS}

This chapter details the findings from the qualitative interviews in terms of the study objectives outlined in the previous chapters. The results present several overarching themes drawn from the personal interviews that address the research questions posed previously.

\section{Research Objectives}

The purpose of this study was to gauge patients' perception of and willingness to use mobile health applications in management of their diabetes at home. This involved first gathering an understanding of patients' knowledge about the disease and current self-management strategies. Then the interviews also gathered information about patients' current knowledge about smartphones and health-related apps to address the following objectives and sub-questions:

1. Determine what patients are currently doing at home to manage their diabetes.

a. What habits or routines have they developed regarding their diabetes?

b. What do patients identify as challenges or struggles with managing their diabetes at home?

2. Explore the attitudes toward and interest in the use of mobile health technology in an underserved population.

a. What do patients know about apps for diabetes?

b. How confident or comfortable are patients with using smartphones and mHealth?

c. How do patients feel about using their smartphones on a routine basis to monitor their diet, exercise, medications, and blood glucose?

3. Assess patients' willingness to download and continue using a health app on their smartphones.

a. What app functions do patients have the most interest in using?

b. Would patients be willing to pay for an app download?

c. How frequently would patients continue to use mobile health apps?

d. What would stop patients from downloading or continuing to use an app?

\section{Overall Themes}

The data from all the interviews yielded 11 clusters, each highlighting a component of the patient experience, which supported 5 overall themes (Table 4-1). Additionally, 4 of the 11 clusters were further divided into subclusters, which characterized smaller but distinct components within each cluster. Of these themes, 2 related back to diabetes self-management, and the other 3 themes pertained to smartphone app use and mHealth. Table 4-1 shows a summary of the data groupings. 
Table 4-1. Themes and supporting clusters derived from interviews

\begin{tabular}{|c|c|c|c|}
\hline $\begin{array}{l}\text { Overall } \\
\text { domain }\end{array}$ & Theme & $\begin{array}{c}\text { Supporting } \\
\text { clusters }\end{array}$ & Subclusters \\
\hline \multirow[t]{5}{*}{$\begin{array}{l}\text { Diabetes } \\
\text { self- } \\
\text { management }\end{array}$} & \multirow[t]{3}{*}{$\begin{array}{l}\text { Diabetes as a chronic } \\
\text { condition requires } \\
\text { active self-management } \\
\text { for successful control. }\end{array}$} & $\begin{array}{l}\text {-diabetes } \\
\text { management }\end{array}$ & $\begin{array}{l}\text {-glucose levels } \\
\text {-complications/co- } \\
\text { morbidities } \\
\text {-lifestyle management } \\
\text {-medications } \\
\text {-blood sugar monitoring }\end{array}$ \\
\hline & & $\begin{array}{l}\text {-challenges to } \\
\text { management }\end{array}$ & \\
\hline & & $\begin{array}{l}\text {-confidence about } \\
\text { diabetes }\end{array}$ & $\begin{array}{l}\text {-high } \\
\text {-low }\end{array}$ \\
\hline & \multirow{2}{*}{$\begin{array}{l}\text { Patients often cited } \\
\text { social support, written } \\
\text { materials, and the } \\
\text { internet as meaningful } \\
\text { resources. }\end{array}$} & $\begin{array}{l}\text {-previous or } \\
\text { current phone use }\end{array}$ & \\
\hline & & $\begin{array}{l}\text {-resources and } \\
\text { social support }\end{array}$ & $\begin{array}{l}\text {-friends and family } \\
\text {-paper materials } \\
\text {-classes }\end{array}$ \\
\hline \multirow[t]{8}{*}{$\begin{array}{l}\text { Smartphone } \\
\text { app use }\end{array}$} & \multirow{4}{*}{$\begin{array}{l}\text { Despite limited } \\
\text { knowledge about } \\
\text { health apps and varying } \\
\text { phone use patterns, } \\
\text { patients were all } \\
\text { willing to try at least } \\
\text { one diabetes-related } \\
\text { app. }\end{array}$} & $\begin{array}{l}\text {-comfort using } \\
\text { smartphones }\end{array}$ & \\
\hline & & $\begin{array}{l}\text {-willingness to } \\
\text { use health apps }\end{array}$ & $\begin{array}{l}\text {-number } \\
\text {-payment }\end{array}$ \\
\hline & & $\begin{array}{l}\text {-previous or } \\
\text { current phone use }\end{array}$ & \\
\hline & & $\begin{array}{l}\text {-knowledge about } \\
\text { apps }\end{array}$ & \\
\hline & \multirow{2}{*}{$\begin{array}{l}\text { Apps functions should } \\
\text { be individualized to } \\
\text { meet each patient's } \\
\text { needs for maximum } \\
\text { benefit. }\end{array}$} & $\begin{array}{l}\text {-app functions } \\
\text { interest }\end{array}$ & \\
\hline & & $\begin{array}{l}\text {-challenges to } \\
\text { management }\end{array}$ & \\
\hline & $\begin{array}{l}\text { Barriers to app use } \\
\text { were varied but } \\
\text { commonly included }\end{array}$ & $\begin{array}{l}\text {-barriers to app } \\
\text { use }\end{array}$ & \\
\hline & $\begin{array}{l}\text { knowledge and } \\
\text { technological } \\
\text { challenges and security } \\
\text { issues. }\end{array}$ & $\begin{array}{l}\text {-comfort using } \\
\text { smartphones }\end{array}$ & \\
\hline
\end{tabular}


Listed in detail below are each of the 5 themes gathered from all 15 personal interviews. For each theme, information from relevant supporting clusters is presented. Direct interview quotes, edited only for grammatical clarity and to maintain patient anonymity, are also used to highlight key points and illustrate personal viewpoints. Although each theme is listed with a corresponding number, this is simply for convenience when referencing back a certain theme and does not indicate any form of hierarchy.

\section{Theme 1: Diabetes as a Chronic Condition Requires Active Engagement on the Part of the Patient for Successful Management}

Active Participation. All patients interviewed recognized the importance of active participation on their part in managing their diabetes. This meant that the patients knew that their eating and exercise habits, their vigilance in taking their daily medications, and their overall attitudes towards their health played a significant role in controlling their blood glucose. Patients also knew that they could not solely rely on doctors to change their diabetes outcomes. For instance, Participant A shared about his current plans to include more walking in his daily routine and his recent struggles with his constant junk food cravings. He states that "I know if I'd've keep up, kept going the way I was, I probably wouldn't've made 50." Interviewees acknowledged that successful diabetes control is a proactive process, not merely just reacting to when blood sugars approach high or low outliers. Participant $\mathrm{O}$ spoke about how in his earlier years, he believed that he had successfully cured himself with healthier lifestyle choices. As soon as he reverted back to his normal routine, he noticed a corresponding deterioration in his health:

"Uh, when I first found out I was, I was more shocked than anything because I was runnin' a mile a day. I was in college. I was physically fit. Doin' what I was supposed to do. So what I did was I started, I started eatin' like they told me to eat. Cut back on some of the stuff, but it was really, really hard. And then I went to the doctor, and they told me that I didn't have it anymore. They said I had the honeymoon effect. And I let myself go. And when I let myself go, that's when I started havin' all the other complications and problems."

Additionally, Participant E expressed how difficult glucose management could be sometimes, noting that successful control requires time and effort on the individual:

"Yeah, it's not good shape because you get sugar in your blood. It's hard to take it out from you. Yeah, it's not easy. Yeah, and it's hard to control it all the time because people be running around everywhere. It's hard to just stay, sit, and controlling this, uh, uh, this sick. It's hard to uh, it's hard little bit to fight it. Yeah, it'd be somebody like say you have time, you have a lot of resources, you have, uh, experience, you can deal with it, but however it's still not easy with diabetes."

Another key viewpoint that emerged from the interviews is how these patients 
equated healthy as being not sick, instead of being well. As defined by the World Health Organization (WHO), the traditional meaning of health is "a state of complete physical, mental, and social well-being and not merely the absence of disease or infirmity" (1948). The WHO goes on to further to explain that "health is a positive concept emphasizing social and personal resources, as well as physical capacities" (1986). Yet, for many interviewees, they viewed health not as a positive state of being. Instead, they saw good health as the lack of problems in their daily lives. They essentially defined good health as not having bad health. In the words of one interviewee: "So, in my eyes, as long as you weren't sick, you were ok. When I say sick, I mean down and couldn't get up" [personal communication by Participant B]. For many of the patients interviewed, this meant they defined good health as the absence of comorbidities, acute illness, or hospital admissions versus the presence of wellbeing in their daily home lives. Participant B continued: "To me there's no perfect when you're dealin' with diabetes. You know, you just gotta take it one day at a time."

Of interest to note with a few of the individuals with older, longstanding diabetes diagnoses is the sense of regret they feel about their lifestyle habits when they were younger and newly diagnosed. These patients talked about how, initially, they lacked an understanding of diabetes as a lifelong condition. Consequently, they spent much of their earlier years with the mindset that the health of their youth could trump their poor eating habits and missed medications. By not adequately managing their diabetes in those early stages, these patients now have to live with the complications that come with more severe disease progression. For instance, Participant L lamented:

"Well, it started workin' on my organs, my eyesight, my kidneys, and, uh, I get neuropathy now. So that's it. Well, I wasn't taking care of myself at the beginning. And now tryin' to do everything right and stuff. And it's just, I guess it's just too late to just workin' on it now. And I'll tell anybody with diabetes: Be serious with it, you know. You can control it and not let it control you. [...]I was, guess I was young then and didn't wanna do right by it. But I see now if you right by it, you can, you can be happy with it."

Participant B expressed a similar sentiment: "Now I'm older, and I'm receiving the repercussions from me not taking care of it when I was younger. So, kinda karma I guess."

Goal Setting and Monitoring. In addition to speaking about the importance of self-engagement, several participants also noted that they had goals for their blood sugar. These patients indicated that they checked their glucose on a daily basis and are aware of what constitutes a "good" or "bad" reading.

Patients also touched upon how besides using a meter to measure a numerical reading, they could tell when their glucose might be outside the normal range. Several patients described symptoms of feeling unwell. For one participant, elevated blood sugars cause changes in mood, leading to short temperedness and peevishness: "Because if, if it go too high, it'll have me real irritable, you know. The least little thing you say, it'll make 
me go off. You know, and I don't have no reason to be going off, and it'd be doin' certain things in my system. It, uh, just ain't good. Diabetes ain't good for me. [...]Mhmm, and it has me real nauseated at times. It'll have me to throw up at times." Another interviewee, a newly diagnosed patient, described a constellation of physical symptoms that let her know to seek medical attention. These symptoms ranged from a loss of taste to profuse night sweats. Finally, she stated, 'I been havin' symptoms, but I didn't pay 'em any attention. I knew something was wrong, but I just never could put my finger on it. Then, uh, when my sight started going blurry, [...] and I, uh, that's when I came to the emergency room, and I found out I was diabetic [personal communication by Participant F]." Other interviewees also spoke of similar mental and physicals signs they would watch for to indicate fluctuating sugar levels. For example. Participant $\mathrm{O}$ detailed both physical and mental changes that come with high and low glucose extremes:

"Uh, you can tell when your sugar's low because it feel like you either about to faint or you feel like something's, like a whole, whole bunch of pressure on you. Like somebody's just sittin' on you or weighing you down. Uh, another thing is you start to sweat. Uh, you'll either, you can have cold chills. Now when you're high, uh, you know that for a fact because you, you'll be runnin' back and forth to the bathroom all the time. Have to urinate just constantly [snaps fingers for emphasize], constantly, constantly tryin' to get that sugar out your body. Uh, you, you can get dizzy. Lightheaded. Um, or your heart could start to race. Or you'll be, you'll be really fatigued. You'll be tired. You be wantin' to sit down. That works both ways when it's high, and it's low. You be really fatigued. Uh, you don't have any motivation. And I'll tell you something else too with the diabetes, it'll change your mood. Uh, you'll have mood swings really, really bad. Like when my sugar is low, I snap out. When my sugar's high, I snap out. It's just like I just change into somebody else."

Others spoke about having good and bad days based on their glucose levels:

'Like when I'm doin' good, I feel better like my day goes by differently than if it's doin' wrong. Then I'm using the bathroom frequently and kinda lightheaded, you know, just little signs. Not normal, and I don't know like, it's like too high [personal communication by Participant J]."

Patients were quick to point out the importance of medication adherence. Patients also knew that lifestyle management including diet and exercise plays a role in disease progression. Knowledge and confidence in management were linked with more knowledgeable patients often citing higher confidence level. Patients also spoke about blood sugar monitoring and possibly adjusting their diet/medications based on certain readings. Patients with diabetes-related complications spoke of wishing for better control and management in their earlier years. Some stated that successful management can be costly.

Diet and Exercise. Every patient interviewed indicated awareness that simply taking medications for their diabetes was not enough to manage blood sugar. 
Interviewees recognized that keeping up healthy daily diet and exercise habits directly impacted their diabetes. For Participant D, her previously poor diet was what precipitated her latest ED admission and diabetes diagnosis. She explained, "It just flared up just like that. So I was drankin' a whole lot of sweet drinks, and, you know helpin', I was helpin' it along to tell the truth about it." Prior to her diagnosis, Participant D confessed that she was eating "anythang, I thought I could eat anythang I wanted like I was doin', you know. You know, mostly sweets. You know, I used to like, I like sweets [...] You know, a whole lot of donuts, cakes, and stuff like that, you know." After her glucose climbed to over five hundred and led to her emergency room visit, she began "eatin' the proper food," making changes to her diet to incorporate more salads.

\section{Theme 2: Patients Often Cited Social Support, Written Material, and the Internet as Meaningful Resources They Used for Their Diabetes}

All patients interviewed touched upon the importance of having someone to talk to about their diabetes. The majority of patients spoke of another living family member who also had diabetes. Additionally, several patients listed multiple family members, both living and deceased, who were also diagnosed with the chronic condition. Patients often used family history as a marker of disease progression and an example of what could happen with poor self-management. For example, some interviewees spoke at length about their extensive family history of diabetes and the complications of disease progression in close kin:

"Well, for one, my mom, she was diabetic, and she had a lot [stretches word out] of problems: amputations, uh, renal failure. So I saw her go through a lot dealing with diabetes. So that kinda put me on the straight and narrow, seeing what she went through. And, there were, she had 8, 7 siblings, and everybody was diabetic. All of 'em. So, [small hmph noise] I kinda saw what my family went through with dealin' with it. So thank god I hadn't had any serious issues, which if I had've kept goin' like I was, I probably would. But I'm gettin' better at it. You know, I didn't take it real, even though I saw what my mom went through, I still didn't take it as serious as I should have. But now, now I do. [personal communication by Participant A]"

"They never told me to watch out for it, but they always, always, you know, they always told me how bad, and I always and I saw what diabetes, you know, did to 'em. I saw what it did to my grandmother. I saw what it did to my mom. My mom just passed little over a year ago. So I know, I just know about what diabetes would do. [...] For my family, you know lookin' at them and seein' what, you know. Some of 'em got some of they, uh, fingers cut off, some of they toes cut off, you know, because of diabetes. Yeah, I, I, I know about diabetes. [personal communication by Participant F]"

Participant J also noted an extensive family history of diabetes: "My dad has it. My grandmamma had it. Well, it's like the majority of my family." Participant L also spoke 
at length on her family history: "Two of my sisters have diabetes. I have a nephew and brother. It's, it's run deep in my family. Heavy. My mother had it and, uh, aunt, aunts and uncles had it." She also noted that they had all passed away. Her one surviving relative, a brother, who also has diabetes, has a sore on his leg that will not heal and "hurts so bad when he try to walk on it."

Other interviewees also mentioned several family members with diabetes who could provide guidance and advice. Examples include:

"My mom, she died three years ago. So she was a big help to me because, like I said, she was in the medical field, AND she was diabetic. [...] So any problems I had, she had the answer, you know. [...] So, when I lost her, I lost a lot. So I have to rely on my aunt now. But as far as like callin' doctors or something, I don't you know, I have none. She pretty much helps me out. [personal communication by Participant A]"

"Yes, my sister and my brother [have diabetes]. [...] I just got to talk to my sister about it. She said you need to try to, try to get it to come down 'cuz you would end up with amputation or death. [personal communication by Participant H]'

"Um, my brother. My sister. Um, they is, they is the ones who educated me and told me some proper procedures. And my dad, he had it. [personal communication by Participant I]"

"Um, I talk, I actually talk to my grandmother. She's more, me and her more, um, close. We'll talk about it 'cuz she'll ask me sometimes, "[patient's name redacted] what do you do when your sugar drop low?" And I tell her I try to, um, [...] to get a small box of juice or some crackers whatnot. Don't get it too, don't get too low 'cuz I had to come to the hospital. [personal communication by Participant K]"

Knowledge and empathy play an important role in defining the relationship between the patient and friends/family concerning diabetes. Many participants talked about being able to turn to various friends and family members who also had diabetes to talk about experiences with the disease. Participant O expressed, "I got friends that's diabetics. So we watch out for each other." For some patients, like Participant D with his sister-in-law, they speak about how meaningful it is to receive advice from a family member who also have diabetes:

"Yeah, she gave me advice about how she do. She said, you know, don't do it, gotta get your own little pace. The way, you know, the way you want it because some days you wake up feelin' good, you know; some days you wake up feelin' bad. Some days you wake up shakin' a little bit. Gotta get you a piece of candy. She just, she just took me through the whole time. She said I need my own little pattern when I wake up in the mornin' time, what time do I wanna take it, you know." 
Participant B spoke of support in a different but equally meaningful manner. He explained that when he was younger, his mother was not as involved in his life and health. He moved out of his home at 14 to do what he "wanted to do and all that" and that he was "kinda on [his] own for the most part and managing." He described the situation as "kinda haywire." Recently, however, his mother finally took an interest in his diabetes, attending an educational session with him at his local church. He said, "For the first time since I've been diabetic. This is the first, any type of diabetic education she's ever. [...] So I was glad about that. And it looked like she was payin' attention. She was taking notes, and I could tell that a lot of the things that she thought were right, she figured out that they were wrong. So, it helped."

Other interviewees expressed how important the support of their spouses is in their daily lives. Although the spouses themselves do not have diabetes, they are integral in helping with these patients with their day-to-day at-home management. Examples include:

Participant G said, "He [referring to her husband] helps me out; he helps me out, uh, with the food. Sometimes I just can't, you know, do it."

Participant L lists, "Lately my husband's been exercising me around the house. [...]Matter of fact my husband does it all; he cooks for me. [...] Um, he help, he dresses me. Help me take baths. He combs my hair."

Participant N proclaimed, "My wife helps me a ton. She stays on me all the time to, to keep it right. And me and her have been talkin'. She says she's gonna tighten up on me when I come home 'cuz gotta be done. [...] she just watches after me, try to make sure I try to eat right and stuff."

Patients acknowledged receiving information at discharge but often felt overwhelmed or detached. When specifically asked about receiving any instruction or handouts at the end of her hospital stay, Participant G expressed indifference: "They probably did. I don't, I ain't read 'em, baby. I've been throwin' up and stuff. I dunno, can't remember." Participant E also mentioned receiving a stack of paper at discharge: "Yeah, they give us papers. They in the car. Yeah, just to eat something, a lot of time eating vegetables, no eating something like, uh, have so many sugar. Uh, that kind of education, uh, they give us. A little bit, little bit. [...] we look a little bit and put down."

More proactive patients also attended classes and turned to books/magazines, as well as looking up information with their phone's internet. Participant $\mathrm{O}$ explained about going to classes when he was first trying to learn about diabetes:

"I used to go down, and also you can go downtown to, uh, on Eastmoreland. They have, they, uh, a class down there where it's like a nurse prac, prac-somethin'. And I used to go to the classes where they teach you how to carb count and your meals. And they have those like at Christ Community and different organizations. Just pick up a sheet and found out where they is, where they at. And I used to attend those." 


\section{Theme 3: Despite Limited Knowledge about Health Apps and Varying Phone Usage Patterns, Patients All Indicated a Willingness to Try at Least One Diabetes-related App}

Current Smartphone and App Usage. Smartphone usage varied widely among the participants from no or past ownership to current ownership. While some like Participant C owned a smartphone "pretty much since they first came out," others like Participant G "never used one before" but her "kids probably got one." Those currently without a smartphone indicated that someone within their immediate household owned one that they could use. Almost all current smartphone owners expressed comfort with operating their phones. Many expressed positive feelings about their smartphones. They used their phones multiple times a day as a part of their daily routines and habits, one interviewee noting that it was "second to nature, havin' a phone" [personal communication by Participant B]. Moreover, several patients also expressed ease with their phones as a multi-functional tool. Beyond making calls, they used their phones routinely for other functions like texting, listening to and creating music, accessing social media, watching videos, and searching the internet. These patients considered their smartphones as an integral resource in supporting their daily lives.

While the majority of patients interviewed either knew nothing about smartphone mHealth apps or had never used one previously, a few did indicate previous use of a health app. These apps were mostly related to filling or pricing medications. About $20 \%$ of interviewees stated that they had previously downloaded and used a drug pricing app to help them "look around for the cheapest" way to fill a prescription, especially when they "didn't have insurance" [personal communication by Participant J]. These patients noted a positive experience with prior health app use. One participant, who had a higher comfort level with smartphone use, described a previous experience with a blood glucose app as such: "I used to have this app where you write down your blood sugar, but I, some kinda way I deleted it. I don't know why. Um, I'm comfortable in usin' 'em. It's, it's actually helpful because it usually remind me: did you take your sugar? Or I usually put in my text remind me to check my sugar. And I use the bing bing gotta take your sugar." [personal communication by Participant K]

Other interviewees spoke of the importance of using their smartphone to go online to research information about diabetes. Participant $\mathrm{C}$ stated, "Uh, I google it and read pretty much about it." Some voiced that they turned to the phones whenever they had questions about their chronic condition. One patient described a need to "googled a lot [...] whenever I had questions about anything. You know at night, I just googled all the time" [personal communication by Participant J]. Another turns to Google to "answer questions and ask [...] what are some foods to eat for diabetes concerns" [personal communication by Participant I]. Moreover, another patient described using mobile sites like Google and Youtube to see "what's gonna happen to somebody, uh, when you not take care of diabetes" and to see "picture of like I don't wanna end up like that, you know" [personal communication by Participant K]. 
Openness to Diabetes Apps. All patients, despite their varying comfort levels with using a smartphone, expressed a willingness to try a diabetes health app. Several interviewees mentioned that they would try apps based on recommendations from friends or family. For instance, Participant $\mathrm{H}$ conveyed interest in installing an app if "family members tell me about it." Participant O also stated, "Uh, if I had a friend or someone that say, 'Hey I'm doin' this such and such, and look it's workin' for me.' Then yeah I would look at it."

Patients less familiar with smartphones indicated the need for someone at the hospital or in their immediate family to educate them. Participant $\mathrm{H}$ stated that she would "get my son to come over and set it up for me." Even Participant G, who had no previous exposure to smartphones, expressed openness to using an app and that she "would have somebody show me." Those not as familiar with the smartphone platform also indicated their willingness to invest more time, "to put a foot forward," in becoming acclimated to their mobile devices, especially if "expectin' a good turnout" [person communication by Participant B]. Even though most of these patients knew very little about diabetes apps, there "ain't nothin' wrong with tryin' somethin' different once" so that if they do "get it workin' right," they "might like it" [personal communication by Participant D]. Almost all participants said that they would try to use at least one app daily. Additionally, all but one indicated a willingness to pay to download an app if they thought it might be beneficial to their diabetes management.

Almost all interviewees stated that they would be willing to continue using at least one mHealth app until they either gained perfect health or could not get any benefit from using an app anymore. Participant I proclaimed simply, "I'm gonna keep on 'til I can't." He then went on to explain that the only reason he would stop using an app is "because it's not, basically just not, um, any kind of positive direction far as helping me" [personal communication by Participant I]. In fact, Participant B mentioned that success with an app, as with anything related to diabetes self-management, requires active participation on the patient. He said, "I just know that you have to be able to go to it and put the information, be willing to put the information in. That's the, that's the other half of it. You have a responsibility to put the information in."

\section{Theme 4: App Functions Should Be Individualized to Meet Each Patient's Needs for Maximum Benefit}

Feedback provided from the interviews supports the idea of tailoring app downloads to patient need. It is better to suggest one or two apps that solely have one function vs. a one-size-fits-all multifunction app. Patient interests were varied with a majority expressing interest in something food or diet-related. Patient often expressed a need for real-world knowledge, instead of clinical or medical knowledge. They often spoke of frustrations with healthcare providers using clinical or medical language in their conversations and not really understanding how to translate this medical advice into their daily lives. A few patients had already tried a medication pricing app previously and found it to be useful. Of note, almost all patients expressed the importance of having app 
usage fit into their everyday routine. They stated that they did not want to have to go out of their way to use an app.

Participants expressed different challenges in their day-to-day diabetes management. Even when patients spoke about a similar topic, like proper diet, their struggles with that issue were different. For example, one patient expressed the following diet-related hardship:

"Well, uh, as far as I can see, it's like I have to balance. At first, I didn't worry about what I bought or what I ate, but now, I have to, uh, you know, buy the rights things to, uh, eat when I used to just eat whatever I wanted. But I can't do that no more. Being on fixed income, uh, I have to just really not, you know, just spend on, on something that I normally would. I have to just spend my money on something that's more healthy, or, you know, it's, it's been a challenge especially since you used to eatin', you know, whatever you want to. But now you've got to be limited, you know, to what you eat, and it's been a struggle." [personal communication by Participant F]

Another patient, although mentioning the same topic of diet and food, voiced a different concern:

"Oh man, stayin' away from sweets. You know, like the holidays, like

Thanksgivin', they make 'em peach cobblers and sweet potato pies. It's hard, and then when you sittin' there with all that food [...] You know hey I can only have a certain amount of this food. You know what I'm sayin'? And but you wanna try everythang. If you try everything, you gotta get real, real small portions, but then what happen when you get something you really like? Then you eat too much. You know what I'm sayin'? You overindulge. And then you got the sweet stuff. You like, "I'm a try a piece of this" or then, then your sugar's outta whack." [personal communication by Participant O]

Even though the patients above relayed food-related challenges, their struggles were different. While the first patient might appreciate a diabetes-friendly grocery list/budget tracking app, the second patient might obtain more benefit from a calorie/carb counting app. Therefore, it is better to suggest one or two apps with functions that meet each patient's greatest needs over a one-size-fits-all multifunctional app.

The same theme of individualization arose with interviewees who spoke of challenges with managing their medications. For Participant K, forgetfulness is constant issue. She lamented:

"You know, now my medications, it's a little, it's a struggle. It is a struggle. Um, uh, it, it's a struggle. [...] I'm a little clumsy with it. So I may forget. My mind sometimes forget where I put it, and it makes me go, 'I know I had it, but where did I put it at?' You know what I'm sayin'? And it's, it's hard for me to keep up with it. [personal communication by Participant K]" 
For Participant K, a medication reminder app would provide the best benefit to her daily diabetes management and help "keep [her] on track" [personal communication]. Whereas one patient might find great value in an app that reminds him to "do the insulin" on time [personal communication by Participant J], another proclaims that he "can keep up with my, you know, what I need to take and when I need to take it. You know, I can pretty much do that myself" [personal communication by Participant A]. For Participant A, remembering to take his medications was not a roadblock to his self-management. Instead, he talked about the hardship of not having health insurance and showed interest in app that could price medications for him.

"Uh, to be honest, here (pointing to an example picture of drug pricing app) it tells me about the medication and how much it may cost. (chuckles) Because that's one of, that was one of my issues for a while was bein', was affordin' the medicine that I need. [...] And that bottle of insulin is three hundred bucks (punctuating each word deliberately) [personal communication by Participant A].”

No one app can be used to help all patients with their at-home diabetes management. App selection must be tailored to each patient's specific challenges and needs.

\section{Theme 5: Barriers to App Use Were Varied but Commonly Included Knowledge and Technological Challenges and Security Issues}

Many patients stressed the importance of an app as being user-friendly, something "not hard" or "super complicated" [personal communication by Participant B]. This meant that they did not want something that required extensive training to use. Those less comfortable with operating a smartphone expressed hesitance at being able to use an app effectively. These patients would need for someone, either a hospital provider or a family member, to guide them through using an app. One of the less technically inclined interviewees, Participant N, also expressed concern about re-downloading an app used on a current phone to a new phone: "I can say if it's somethin' happened to my phone or somethin', where it quit workin', you know. And I've had had that trouble. And I don't know if I can transfer this app to another phone, or if I, I have to redo it. I don't know how that works."

Other concerns noted were related to privacy and security. Interviewees expressed concerns about inputting personal data in an app and theft of that information. Most felt comfortable in giving up health metrics like weight or blood glucose reading but were leery about disclosing any financial information. "Cuz I don't think those, what do they call them, cyber thieves or whatever, I don't think they can do a whole lot with my height and weight information. But bank account information, they can probably do something with that," explained Participant A. Those who currently owned a smartphone were more likely to bring up technological challenges like storage space or frequent need for updates. They expressed a desire for an app that would run smoothly "on the regular" without crashing their phones or have "somethin' happen $[\ldots]$ where it quit workin"" 
[personal communication by Participant N]. A couple of patients also brought up fears of too much spam or viruses. 


\section{CHAPTER 5. DISCUSSION}

Personal interviews from low-income, racial and ethnic minority patients with diabetes indicated an interest in using smartphone mHealth apps. These patients had widely different baseline exposure levels with smartphones, ranging from only seeing those in their immediate household use the phones to consistent, daily use. Nonetheless, all interviewees stated they were open to using a diabetes-related app. Even those with very little or no previous exposure to a smartphone voiced a willingness to try at least one app at home; their interest in seeing if mHealth could benefit their diabetes management overrode any hesitance over using unfamiliar technology.

Patients mentioned common hurdles related to medication affordability and adherence, proper diet and exercise, and fluctuating blood glucose management. Thus, they demonstrated interest in app features related to diet, exercise tracking, and medication management. This is similar to findings from previous survey questionnaire studies where patients indicated app preferences for activity tracking, medication reminders/alarms, carbohydrate counting, and blood glucose tracking (Conway et al., 2016; Lithgow, Edwards, \& Rabi, 2017). Participant struggles, however, were individualized to their diabetes progression and their current living situation. For instance, several patients noted struggles with their diets, but they might not benefit from using the same diet-related app. To provide the greatest benefit to this underserved population, app selection should be tailored to address each patient's specific at-home need.

Participants also expressed varying concerns over app use. These ranged from user-oriented fears, i.e. inadequate technological knowledge to work an app, to apporiented concerns, i.e. data security or virus attacks. In line with a previous survey study (Lithgow, Edwards, \& Rabi, 2017), the majority of interviewees said that they would be willing to pay for an app so cost to download would not be a barrier to use.

\section{Study Limitations}

\section{Generalizability}

Limitations of this study include a potential inability to generalize results beyond the underserved Memphis population, as patient struggles and experiences may different in light of other geographic and cultural settings. Future exploratory studies like this one should be initiated in areas outside the Southeast to capture patient backgrounds, management challenges, and technological proclivities unique to other underserved populations. Since the majority of patients interviewed had T2DM, findings from the study may not be generalizable to patients with T1DM or those with undiagnosed type 1 or 2 diabetes. Moreover, the study results may not apply to apps not readily available to the public for download, such as apps specifically developed for a hospital electronic 
medical record or a private practice group. Since this was a general exploratory study, no correlations could be drawn between patient characteristics like disease severity or duration and interest in certain apps or app functions.

\section{Selection Bias}

Selection bias may have also influenced the study's results. First, the hospital charts did not routinely collect PCP information. Patients therefore self-reported whether or not they regularly visited a PCP for their diabetes. The study was then only able to collect interviews from those who were truthful about this and was not able to gather information from patients who truly had no PCP but told the screening pharmacist that they did. The patients who agreed to participate and were able to come to an interview might have also been more inherently motivated to manage their diabetes and to express a willingness to try an app. The interviewer worked to established trust with the participants by clearly outlining before each interaction that there were no right or wrong answers and that all answers were to remain confidential and anonymous. Nonetheless, participants could have still felt compelled to please the interviewer by expressing interest in using an app, even if they truly had no desire to try one. The inclusion criteria of a diabetes-related ED visit could have also influenced the participants' responses. With the shock of a health event fresh in mind, interviewees may have been felt more compelled to express willingness to use smartphone apps than if they had not experienced a recent diabetes-related complication.

\section{Future Considerations}

An intensive search of the literature revealed no previous qualitative studies about leveraging smartphone apps to address diabetes-related health disparities. Results from this study show a potential for mHealth apps to be a valuable resource in an underserved patient population. Therefore, the findings from this study indicate a need for further research in engaging vulnerable patient populations with mHealth. This could include future pilot studies examining clinical effectiveness on blood glucose levels when making a personalized app selection for patients to use at discharge. Additional studies could examine the cost effectiveness of having underserved patients use smartphone apps at home to prevent diabetes-related ED readmissions.

\section{Implications for Discharge Planning}

During the interview process, several patients spoke about receiving a stack of papers related to diabetes education upon the leaving the hospital. They, however, did not talk about the interaction in a positive or meaningful way. These patients did not speak of having any significant face-to-face engagement with a health care worker regarding next steps for at-home self-management upon discharge either. This is a space where recommendations for app usage may fit. All interviewees from this study expressed 
interest in and openness to using a diabetes smartphone app. Those less technically inclined, however, voiced concerns about being able to navigate an app without assistance. Discharge may be a fitting time for a health provider to introduce diabetesrelated apps to patients for future use at home. In order to provide the most benefit to patients, the discharge provider would need to speak with each patient to discern challenges and needs for at-home disease management. The provider could then recommend one or two apps based on the patient's response. To be most effective, providers would also need to help patients install the app on their phones, launch the app, and use the features within the app.

One significant reason that patients who met the inclusion criteria could not participate in this study was a lack of transportation for a return trip back to the hospital. This is an example of how resource poor this sample population was. Limited transportation along with low income and/or lack of health insurance restricts these patients' access to traditional healthcare resources like clinics and physician offices. This is the resource niche that diabetes apps can fill. Unlike their troubles with transportation, all interviewees in this study indicated either ownership of or proximity to someone with ownership of a smartphone. Introducing an app to the patients at discharge would provide them with a low-cost, easily accessible resource that they could turn to on a daily basis at home. Also, having a healthcare provider offer recommendations and education might instill trustworthiness in an app. A provider recommendation would offer confidence in both the app itself as a health tool, as opposed to spam or malicious software, and the health information offered within the app. This could help address concerns related to privacy and security that some patients brought up during their interviews.

\section{Training for Healthcare Providers}

In order for the discharge process to provide the greatest benefit to these underserved patients, the healthcare workers involved would first need adequate education. Healthcare providers themselves would first have to be comfortable with using smartphones. Initially, providers would need to create a rubric to vet diabetes apps for accuracy of information, ease of use for their specific patient population, and digital security. To maximize patient benefit, each healthcare facility should develop its rubric based on characteristics like literacy level of the patient population they serve. Providers would then need to familiarize themselves with the apps that scored highest on their grading scale within each broader category of diabetes management like glucose/symptom monitoring or diet/carbohydrate counting. Thus, at discharge, providers would be able to make an informed decision on the best app to recommend each patient for home use going forward.

\section{Future Cost and Clinical Impact}

Once acceptability and openness to diabetes app use has been established, as with the underserved population in this study, it opens the way to many other future 
considerations for incorporating mHealth into healthcare practice. From a clinical standpoint, future studies could examine the effect of at-home app use on blood glucose or HbA1c measurements in low income and racial and ethnic minority patient groups with diabetes. These studies could compare app vs. no app use over different periods of time from as short as a month to as long as a year. This could help determine the minimum amount of time individuals would have to use a diabetes app to start seeing any health benefits, as well as the frequency with which patients would have to interact with an app on a daily or weekly basis. Additionally, this would keep people from quitting app use too early, within a few days or weeks, if there were published results on how long it could possibly take to notice changes. Study results showing a significant decline in glucose or HbA1c markers would demonstrate that apps could be a clinically effective tool for a population that would otherwise struggle to access traditional pathways to healthcare.

Determination of clinical efficacy would pave the way for further research regarding the economic impact of diabetes app use. Studies to examine re-hospitalization or revisits to the ED for diabetes-related episodes could possibly show reduced rates after the introduction of app use. With a 30-day readmission rate of about $20 \%$ for patients with diabetes (Rubin, 2015), the annual cost of diabetes re-hospitalizations is currently estimated to be almost $\$ 25$ billion (Soh et al., 2020). By contrast, the overwhelming majority of commercially available health apps are free to download; those that require a purchase to download average about $\$ 2$ in cost (IQVIA, 2015). Even the prevention of just a handful of readmissions for a hospital each year through the introduction of app use at discharge could present possible savings of thousands of dollars. This is an area where future research could delve into. Studies could look at introducing an app for home use to known patients with multiple monthly or annual visits to a hospital's ED for diabetesrelated crises. They could then compare ED visits pre- and post-app introduction to identify any potential reductions in visit rates and cost savings for the averted readmissions.

Accordingly, the effectiveness of these cost savings could possibly extend into changes in insurance reimbursement models. Insurance companies, as the potential recipients of study findings related to healthcare cost savings, could consider future payments for care activity related to diabetes app use. This could include anything from discharge counseling specifically directed towards diabetes app education to outpatient medication therapy management sessions that incorporate education about using adherence apps.

\section{Conclusion}

Successful long-term management of diabetes depends heavily upon choices and actions that happen beyond a doctor's office or hospital. For patients who have limited or no ability to establish a meaningful relationship with a healthcare provider, management can prove very challenging. The use of smartphone health apps could potentially address certain resource limitations for these patients. Results from this study showed that all the 
interviewed patients recognized the importance of their own actions and behaviors on their diabetes control. While these patients had differing home backgrounds and comfort levels with smartphone technology, they also all voiced a willingness to use at least one diabetes-related health app in their daily lives. This openness to mHealth serves as a foundation for further exploration into the clinical and economic impact that diabetes app use might have for a traditionally resource-poor patient population. 


\section{LIST OF REFERENCES}

Accenture. 2018 Consumer survey on digital health (2018). https://www.accenture.com/_acnmedia/PDF-71/Accenture-Health-Meet-TodaysHealthcare-Team-Patients-Doctors-Machines.pdf (accessed 18 Jan 2019).

Agency for Healthcare Research and Quality. 2010 National healthcare disparities report (2010). http://archive.ahrq.gov/research/findings/nhqrdr/nhqrdr10/minority.html (accessed 7 Oct 2015).

American Association of Clinical Endocrinologists. Clinical practice guidelines for developing a diabetes mellitus comprehensive care plan. Endocrine Practice. 2015; 21(1):1-87.

American Diabetes Association. Economic costs of diabetes in the US in 2017. Diabetes Care. 2018; 41(5):917-928.

American Diabetes Association. Economic costs of diabetes in the US in 2012. Diabetes Care. 2013; 36(4):1033-1046.

American Diabetes Association. Standards of medical care in diabetes-2019. Diabetes Care. 2019; 42(Suppl. 1):S1-S186.

American Diabetes Association. Standards of medical care in diabetes-2014. Diabetes Care. 2014; 37(Suppl. 1):S14-80.

Anderson M. Mobile technology and home broadband 2019 (13 Jun 2019). https://www.pewresearch.org/internet/2019/06/13/mobile-technology-and-homebroadband-2019/ (accessed 3 Jul 2019).

Arday DR, Fleming BB, Keller DK, Pendergrass PW, Vaughn RJ, Turpin JM, Nicewander DA. Variation in diabetes care among states: Do patient characteristics matter? Diabetes Care. 2002; 25(12):2230-2237.

Beckles GL, Chou C. Disparities in the prevalence of diagnosed diabetes-United States, 1999-2002 and 2011-2014. Morbidity and Mortality Weekly Report. 2016; 65:1265-1269.

Bielamowicz MK, Miller WC, Elkins E, Ladewig HW. Monitoring behavioral changes in diabetes care with the diabetes self-management record. The Diabetes Educator. 1995; 21(5):426-431.

Benjamin EM. Self-monitoring of blood glucose: The basics. Clinical diabetes. 2002; 20(1):45-47.

Bernard HR. Research methods in cultural anthropology: Qualitative and quantitative approaches. 5th ed. Lanham, MD: AltaMira Press; 2011:156-186.

Berndt RD, Takenga C, Preik P, Kuehn S, Berndt L, Mayer H, Kaps A, Schiel R. Impact of information technology on the therapy of type-1 diabetes: A case study of children and adolescents in Germany. Journal of Personalized Medicine. 2014; 4(2):200-217.

Bodenheimer T, Lorig K, Holman H, Grumbach K. Patient self-management of chronic disease in primary care. JAMA. 2002; 288(19):2469-2475.

Bodenheimer T, Wagner EH, Grumbach K. Improving primary care for patients with chronic illness. JAMA. 2002; 288(14):1775-1779.

Boyle JP, Thompson TJ, Gregg EW, Barker LE, Williamson DF. Projection of the year 2050 burden of diabetes in the US adult population: Dynamic modeling of 
incidence, mortality, and prediabetes prevalence. Population Health Metrics. 2010; 8(1):29.

Brancati FL, Whelton PK, Kuller LH, Klag MJ. Diabetes mellitus, race, and socioeconomic status a population-based study. Annals of Epidemiology. 1996; 6(1):67-73.

Carroll JK, Moorhead A, Bond R, LeBlanc WG, Petrella RJ, Fiscella K. Who uses mobile phone health apps and does use matter? A secondary data analytics approach. JMIR. 2017; 19(4):e125.

Carter JS, Pugh JA, Monterrosa A. Non-insulin-dependent diabetes mellitus in minorities in the United States. Annals of Internal Medicine. 1996; 125(3):221-232.

Centers for Disease Control and Prevention. International Classification of Diseases, 9th revision, clinical modification (6 Nov 2015). https://www.cdc.gov/nchs/icd/icd9cm.htm (accessed 11 Dec 2015).

Centers for Disease Control and Prevention. International Classification of Diseases, 10th revision, clinical modification (6 Nov 2015). https://www.cdc.gov/nchs/icd/icd10cm.htm (accessed 11 Dec 2015).

Centers for Disease Control and Prevention. National diabetes statistics report, 2017: Estimates of diabetes and its burden in the United States. Atlanta, GA: Centers for Disease Control and Prevention, U.S. Dept of Health and Human Services; 2017.

Centers for Disease Control and Prevention. Diabetes report card 2017. Atlanta, GA: Centers for Disease Control and Prevention, U.S. Dept of Health and Human Services; 2018.

Centers for Disease Control and Prevention. Diagnosed diabetes, total, adults aged 18+, number in 1,000s, national (2019). https://gis.cdc.gov/grasp/diabetes/diabetesatlas.html (accessed 11 Jan 2019).

Charpentier G, Benhamou PY, Dardari D, Clergeot A, Franc S, Schaepelynck-Belicar P, Catargi B, Melki V, Chaillous L, Farret A, Bosson JL. The Diabeo software enabling individualized insulin dose adjustments combined with telemedicine support improves $\mathrm{HbA} 1 \mathrm{c}$ in poorly controlled type 1 diabetic patients: a 6-month, randomized, open-label, parallel-group, multicenter trial (TeleDiab 1 Study). Diabetes Care. 2011; 34(3):533-539.

Chow EA, Foster H, Gonzalez V, McIver L. The disparate impact of diabetes on racial/ethnic minority populations. Clinical Diabetes. 2012; 30(3):130-133.

Coleman K, Austin BT, Brach C, Wagner EH. Evidence on the chronic care model in the new millennium. Health Affairs. 2009; 28(1):75-85.

Conway N, Campbell I, Forbes P, Cunningham S, Wake D. mHealth applications for diabetes: User preference and implications for app development. Health Informatics Journal. 2016; 22(4):1111-1120.

Cook CB, Ziemer DC, El-Kebbi IM, Gallina DL, Dunbar VG, Ernst KL, Phillips LS. Diabetes in urban African-Americans. XVI. Overcoming clinical inertia improves glycemic control in patients with type 2 diabetes. Diabetes Care. 1999; 22(9):1494-1500.

Corbin JM, Strauss A. Basics of qualitative research: Techniques and procedures for developing grounded theory. 3rd ed. Thousand Oaks, CA: SAGE; 2008:1-18.

Creswell JW. Research design: Qualitative, quantitative, and mixed methods approaches. 3rd ed. Thousand Oaks, CA: SAGE, 2009:173-202. 
Creswell JW. Qualitative inquiry and research design: Choosing among five approaches. 3rd ed. Thousand Oaks, CA: SAGE; 2013:69-177.

Creswell JW. 30 essential skills for the qualitative researcher. Thousand Oaks, CA: SAGE; 2015.

Crotty M. The foundations of social research: meaning and perspective in the research process. Thousand Oaks, CA: SAGE; 1998:42-65.

Denzin NK, Lincoln YS. Introduction: The discipline and practice of qualitative research. In: Denzin NK, Lincoln YS, eds. The landscape of qualitative research. 3rd ed. Thousand Oaks, CA: SAGE; 2008:1-44.

DiCiccio-Bloom B, Crabtree BF. The qualitative research interview. Medical Education. 2006; 40(4):314-321.

Drion I, Pameijer LR, van Dijk PR, Groenier KH, Kleefstra N, Bilo HJ. The effects of a mobile phone application on quality of life in patients with type 1 diabetes mellitus: A randomized controlled trial. Journal of Diabetes Science and Technology. 2015; 9(5):1086-1091.

Elo S, Kääriäinen M, Kanste O, Pölkki T, Utriainen K, Kyngäs H. Qualitative content analysis: A focus on trustworthiness. SAGE Open. 2014; 4(1).

Esterberg KG. Qualitative methods in social research. Boston: McGraw Hill; 2002.

Food and Drug Administration. Policy for device software functions and mobile medical applications: Guidance for industry and Food and Drug Administration staff (Sept 2019). https://www.fda.gov/regulatory-information/search-fda-guidancedocuments/policy-device-software-functions-and-mobile-medical-applications (accessed 20 Oct 2019).

Fooducate Ltd. Fooducate (2010). https://www.fooducate.com/ (accessed 3 Nov 2015).

Gaskin DJ, Thorpe Jr RJ, McGinty EE, Bower K, Rohde C, Young JH, LaVeist TA, Dubay L. Disparities in diabetes: The nexus of race, poverty, and place. American Journal of Public Health. 2014; 104(11):2147-2155.

Geiss LS, Wang J, Cheng YJ, Thompson TJ, Barker L, Li Y, Albright AL, Gregg EW. Prevalence and incidence trends for diagnosed diabetes among adults aged 20 to 79 years, United States, 1980-2012. JAMA. 2014; 312(12):1218-1226.

Geertz C. Thick description: Toward an interpretive theory of culture. In: Geertz C. The interpretation of cultures: Selected essays. New York: Basic Books; 1973:3-30.

Glasgow RE, Kurz D, King D, Dickman JM, Faber AJ, Halterman E, Woolley T, Toobert DJ, Strycker LA, Estabrooks PA, Osuna D. Twelve-month outcomes of an Internet-based diabetes self-management support program. Patient Education and Counseling. 2012; 87(1):81-92.

GoodRx Inc. GoodRx mobile apps (2011). https://www.goodrx.com/mobile (accessed 3 Nov 2015).

Goyal S, Nunn CA, Rotondi M, Couperthwaite AB, Reiser S, Simone A, Katzman DK, Cafazzo JA, Palmert MR. A mobile app for the self-management of type 1 diabetes among adolescents: A randomized controlled trial. JMIR mHealth and uHealth. 2017; 5(6):e82.

Graneheim UH, Lundman B. Qualitative content analysis in nursing research: Concepts, procedures and measures to achieve trustworthiness. Nurse Education Today. 2004; 24(2):105-112. 
Gregg JA, Callaghan GM, Hayes SC, Glenn-Lawson JL. Improving diabetes selfmanagement through acceptance, mindfulness, and values: A randomized controlled trial. Journal of Consulting and Clinical Psychology. 2007; 75(2):336.

Guba EG, Lincoln YS. Competing paradigms in qualitative research. In: Denzin NK, Lincoln YS, eds. Handbook of qualitative research. Thousand Oaks, CA: SAGE; 1994:105-117.

Haas L, Maryniuk M, Beck J, Cox CE, Duker P, Edwards L, Fisher E, Hanson L, Kent D, Kolb L, McLaughlin S. National standards for diabetes self-management education and support. The Diabetes Educator. 2012; 38(5):619-629.

Harris MI, Eastman RC, Cowie CC, Flegal KM, Eberhardt MS. Racial and ethnic differences in glycemic control of adults with type 2 diabetes. Diabetes Care. 1999; 22(3):403-408.

Heisler M, Smith DM, Hayward RA, Krein SL, Kerr EA. How well do patients' assessments of their diabetes self-management correlate with actual glycemic control and receipt of recommended diabetes services? Diabetes Care. 2003; 26(3):738-743.

Helparound. Helparound app (2015). https://helparound.co/platform.html (accessed 3 Nov 2015).

Hertz RP, Unger AN, Ferrario CM. Diabetes, hypertension, and dyslipidemia in Mexican Americans and non-Hispanic whites. American Journal of Preventive Medicine. 2006; 30(2):103-110.

Holmen H, Torbjørnsen A, Wahl AK, Jenum AK, Småstuen MC, Årsand E, Ribu L. A mobile health intervention for self-management and lifestyle change for persons with type 2 diabetes, part 2: One-year results from the Norwegian randomized controlled trial RENEWING HEALTH. JMIR mHealth and uHealth. 2014; 2(4):e57.

Huang Z, Tan E, Lum E, Sloot P, Boehm BO, Car J. A smartphone app to improve medication adherence in patients with type 2 diabetes in Asia: Feasibility randomized controlled trial. JMIR mHealth and uHealth. 2019; 7(9):e14914.

IQVIA Institute for Human Data Science. Patient adoption of mHealth: Use, evidence and remaining barriers to mainstream acceptance (Sept 2015). https://www.iqvia.com/-/media/iqvia/pdfs/institute-reports/patient-adoption-ofmhealth.pdf (accessed 1 Feb 2017).

IQVIA Institute for Human Data Science. The growing value of digital health: Evidence and impact on human health and the healthcare system (Nov 2017). https://www.iqvia.com/-/media/iqvia/pdfs/institute-reports/the-growing-value-ofdigital-health.pdf? =1599234197223 (accessed 2 Apr 2018).

Kaiser Family Foundation. Disparities in health and health care: Five key questions and answers (Nov 2012). http://kff.org/disparities-policy/issue-brief/disparities-inhealth-and-health-care-five-key-questions-and-answers/ (accessed 8 Oct 2015).

Kirwan M, Vandelanotte C, Fenning A, Duncan MJ. Diabetes self-management smartphone application for adults with type 1 diabetes: Randomized controlled trial. JMIR. 2013; 15(11):e235.

Korstjens I, Moser A. Series: Practical guidance to qualitative research. Part 4: Trustworthiness and publishing. European Journal of General Practice. 2018; 24(1):120-4. 
Kratzke C, Cox C. Smartphone technology and apps: Rapidly changing health promotion. Global Journal of Health Education and Promotion. 2012; 15(1):72-82.

Kvale S. InterViews: An introduction to qualitative research interviewing. Thousand Oaks, CA: SAGE; 1996: 126-135.

Lanting LC, Joung IM, Mackenbach JP, Lamberts SW, Bootsma AH. Ethnic differences in mortality, end-stage complications, and quality of care among diabetic patients: A review. Diabetes Care. 2005; 28(9):2280-2288.

Laverty SM. Hermeneutic phenomenology and phenomenology: A comparison of historical and methodological considerations. International Journal of Qualitative Methods. 2008; 2(3):21-35.

Liebman J, Heffernan D, Sarvela P. Establishing diabetes self-management in a community health center serving low-income Latinos. The Diabetes Educator. 2007; 33(S6):132S-138S.

Lincoln YS, Guba EG. Establishing Trustworthiness. In: Naturalistic Inquiry. Thousand Oaks, CA: SAGE; 1985:289-331.

Lithgow K, Edwards A, Rabi D. Smartphone app use for diabetes management: Evaluating patient perspectives. JMIR Diabetes 2017;2(1):e2.

Lorig K, Gonzalez VM. Community-based diabetes self-management education: Definition and case study. Diabetes Spectrum. 2000; 13(4):234-238.

Luxton DD, McCann RA, Bush NE, Mishkind MC, Reger GM. mHealth for mental health: Integrating smartphone technology in behavioral healthcare. Professional Psychology: Research and Practice. 2011; 42(6):505.

Malterud K. Qualitative research: Standards, challenges, and guidelines. The Lancet. 2001; 358(9280):483-488.

Massing MW, Henley NS, Carter-Edwards L, Schenck AP, Simpson RJ. Lipid testing among patients with diabetes who receive diabetes care from primary care physicians. Diabetes Care. 2003; 26(5):1369-1373.

Maxwell JA. Qualitative research design: An interactive approach. 3rd ed. Thousand Oaks, CA: SAGE; 2013:73-86.

McNamara C. General guidelines for conducting research interviews (2006). https://managementhelp.org/businessresearch/interviews.htm (accessed 12 Jun 2015).

Mead H, Cartwright-Smith L, Jones K, Ramos C, Woods K, Siegel B. Racial and ethnic disparities in US health care: A chartbook. New York: The Commonwealth Fund; 2008.

Medisafe Project Ltd. Medisafe app (2015). https://www.medisafeapp.com (accessed 3 Nov 2015).

Merriam SB, Tisdell EJ. Qualitative research: A guide to design and implementation. 4th ed. San Francisco: John Wiley \& Sons; 2016:3-21.

Methodist Le Bonheur Healthcare. Methodist South hospital (2015). http://www.methodisthealth.org/locations/methodist-south-hospital/ (accessed 2 Nov 2015).

Moore J. The benefits of mobile apps for patients and providers. British Journal of Healthcare Management. 2012; 18(9):465-467.

Morse JM. Designing qualitative research. In: Denzin NK, Lincoln YS, eds. Handbook of qualitative research. Thousand Oaks, CA: SAGE; 1994:220-235. 
Morse JM. The significance of saturation. Qualitative Health Research. 1995; 5(2):147149.

MyNetDiary Inc. MyNetDiary (2015). https://www.mynetdiary.com (accessed 3 Nov 2015).

mySugr. mySugr app (2015). https://www.mysugr.com/en-us/diabetes-app (accessed 3 Nov 2015).

Nagrebetsky A, Larsen M, Craven A, Turner J, McRobert N, Murray E, Gibson O, Neil A, Tarassenko L, Farmer A. Stepwise self-titration of oral glucose-lowering medication using a mobile telephone-based telehealth platform in type 2 diabetes: A feasibility trial in primary care. Journal of Diabetes Science and Technology. 2013; 7(1):123-134.

Narayan KV, Boyle JP, Thompson TJ, Sorensen SW, Williamson DF. Lifetime risk for diabetes mellitus in the United States. JAMA. 2003; 290(14):1884-1890.

Nathan DM, Buse JB, Davidson MB, Ferrannini E, Holman RR, Sherwin R, Zinman B. Medical management of hyperglycemia in type 2 diabetes: a consensus algorithm for the initiation and adjustment of therapy: A consensus statement of the American Diabetes Association and the European Association for the Study of Diabetes. Diabetes Care. 2009; 32(1):193-203.

Nieswiadomy R, ed. Foundations of nursing research. 5th ed. Upper Saddle River, NJ: Prentice Hall; 2007:171-184.

Office of Minority Health. Diabetes and Asian Americans (19 December 2019). https://minorityhealth.hhs.gov/omh/browse.aspx?lvl=4\&lvlid=48 (accessed 28 Dec 2019).

Office of Minority Health. Diabetes and Hispanic Americans (19 December 2019). https://minorityhealth.hhs.gov/omh/browse.aspx?lvl=4\&lvlid=63 (accessed 28 Dec 2019).

Orsama AL, Lähteenmäki J, Harno K, Kulju M, Wintergerst E, Schachner H, Stenger P, Leppänen J, Kaijanranta H, Salaspuro V, Fisher WA. Active assistance technology reduces glycosylated hemoglobin and weight in individuals with type 2 diabetes: Results of a theory-based randomized trial. Diabetes Technology \& Therapeutics. 2013; 15(8):662-669.

Patton MQ. Qualitative research and evaluation methods. 3rd ed. Thousand Oaks, CA: SAGE; 2002:37-46.

Perneger TV, Brancati FL, Whelton PK, Klag MJ. End-stage renal disease attributable to diabetes mellitus. Annals of Internal Medicine. 1994; 121(12):912-918.

Pew Research Center. Mobile fact sheet (12 Jun 2019). https://www.pewresearch.org/internet/fact-sheet/mobile/ (accessed 30 Jun 2019).

Pietkiewicz I, Smith JA. A practical guide to using interpretative phenomenological analysis in qualitative research psychology. Psychological Journal. 2014; 20(1):714.

Ploeg J. Identifying the best research design to fit the question part 2: Qualitative designs. Evidence Based Nursing. 1999; 2(2):36-37.

Ponterotto JG. Brief note on the origins, evolution, and meaning of the qualitative research concept thick description. The Qualitative Report. 2006; 11(3):538-549.

Pope C, van Royen P, Baker R. Qualitative methods in research on healthcare quality. Quality and Safety in Health Care. 2002; 11(2):148-152. 
Quinn CC, Clough SS, Minor JM, Lender D, Okafor MC, Gruber-Baldini A. WellDoc ${ }^{\mathrm{TM}}$ mobile diabetes management randomized controlled trial: Change in clinical and behavioral outcomes and patient and physician satisfaction. Diabetes Technology \& Therapeutics. 2008; 10(3):160-168.

Research Center on Health Disparities, Equity, \& the Exposome. Interactive map of health equity in Memphis, Tennessee: Health data (2017).

http://www.immemphis.com/health-data (accessed 11 Mar 2017).

Research2guidance. Diabetes app market report 2014.

http://www.research2guidance.com/index.php/diabetes-app-market-report-2014 (accessed 2 Jun 2016).

Robbins JM, Vaccarino V, Zhang H, Kasl SV. Socioeconomic status and type 2 diabetes in African American and non-Hispanic white women and men: Evidence from the Third National Health and Nutrition Examination Survey. American Journal of Public Health. 2001; 91(1):76.

Rosal MC, Olendzki B, Reed GW, Ockene I, Gumieniak O, Scavron J. Diabetes selfmanagement among low-income Spanish-speaking patients: A pilot study. Annals of Behavioral Medicine. 2005; 29(3):225-235.

Rossi MC, Nicolucci A, Di Bartolo P, Bruttomesso D, Girelli A, Ampudia FJ, Kerr D, Ceriello A, Mayor CD, Pellegrini F, Horwitz D. Diabetes Interactive Diary: A new telemedicine system enabling flexible diet and insulin therapy while improving quality of life: An open-label, international, multicenter, randomized study. Diabetes Care. 2010; 33(1):109-115.

Rubin DJ. Hospital readmission of patients with diabetes. Current Diabetes Reports. 2015; 15(4):17.

Samuel-Hodge CD, Keyserling TC, Park S, Johnston LF, Gizlice Z, Bangdiwala SI. A randomized trial of a church-based diabetes self-management program for African Americans with type 2 diabetes. The Diabetes Educator. 2009; 35(3):439-454.

Saydah S, Lochner K. Socioeconomic status and risk of diabetes-related mortality in the US. Public Health Reports. 2010; 125(3):377-388.

Shenton AK. Strategies for ensuring trustworthiness in qualitative research projects. Education for Information. 2004; 22(2):63-75.

Soh JG, Wong WP, Mukhopadhyay A, Quek SC, Tai BC. Predictors of 30-day unplanned hospital readmission among adult patients with diabetes mellitus: A systematic review with meta-analysis. BMJ Open Diabetes Research and Care. 2020; 8(1):e001227.

Smith A. U.S. smartphone use in 2015 (1 Apr 2015). https://www.pewresearch.org/internet/2015/04/01/us-smartphone-use-in-2015/ (accessed 2 Oct 2015).

Smith JA, Flowers P, Larkin M. Interpretative phenomenological analysis: Theory, method, and research. Thousand Oaks, CA:SAGE; 2009.

Smith JA, Osborn M. Interpretative phenomenological analysis. In: Smith JA, ed. Qualitative psychology: A practical guide to research methods. 2nd ed. Thousand Oaks, CA: SAGE; 2008:53-80.

Stake RE. The art of case study research. Thousand Oaks, CA: SAGE; 1995: 99-103.

Strauss A, Corbin JM. Basics of qualitative research: Techniques and procedures for developing grounded theory. 2nd ed. Thousand Oaks, CA: SAGE; 1998:10-11. 
Thackeray R, Merrill RM, Neiger BL. Disparities in diabetes management practice between racial and ethnic groups in the United States. The Diabetes Educator. 2004; 30(4):665-675.

Tran J, Tran R, White JR. Smartphone-based glucose monitors and applications in the management of diabetes: An overview of 10 salient "apps" and a novel smartphone-connected blood glucose monitor. Clinical Diabetes. 2012 Oct; 30(4):173-178.

Tran L, Zielinski A, Roach AH, Jende JA, Householder AM, Cole EE, Atway SA, Amornyard M, Accursi ML, Shieh SW, Thompson EE. Pharmacologic treatment of type 2 diabetes: Oral medications. Annals of Pharmacotherapy. 2015; 49(5):540-556.

United States Census Bureau. 2011-2015 American community survey 5 year estimates (2016). http://www.census.gov/acs/www/data/data-tables-and-tools/index.php (accessed 12 Dec 2016).

University of Tennessee Health Science Center Institutional Review Board. Standard operating procedures (2016).

https://www.uthsc.edu/research/compliance/irb/researchers/standard-operatingprocedures.php (accessed 3 Apr 2016).

Wagner EH. Chronic disease management: What will it take to improve care for chronic illness? Effective clinical practice. 1998; 1(1):2-4.

Waki K, Fujita H, Uchimura Y, Omae K, Aramaki E, Kato S, Lee H, Kobayashi H, Kadowaki T, Ohe K. DialBetics: A novel smartphone-based self-management support system for type 2 diabetes patients. Journal of Diabetes Science and Technology. 2014; 8(2):209-215.

Walker RJ, Smalls BL, Hernandez-Tejada MA, Campbell JA, Egede LE. Effect of diabetes self-efficacy on glycemic control, medication adherence, self-care behaviors, and quality of life in a predominantly low-income, minority population. Ethnicity \& Disease. 2014; 24(3):349.

World Health Organization. Preamble to the constitution of the World Health Organization. New York. 1948.

World Health Organization. The Ottawa charter for health promotion. Ottawa. 1986.

Zhuo X, Zhang P, Barker L, Albright A, Thompson TJ, Gregg E. The lifetime cost of diabetes and its implications for diabetes prevention. Diabetes Care. 2014; 37(9):2557-2564. 


\section{APPENDIX A. INTERVIEW GUIDE}

Questions Related to General Diabetes Self-Management

1. What do you currently do to manage your diabetes?

2. How confident do you feel about how you manage your diabetes right now?

3 . What resources do you currently use to help you manage your diabetes?

4. What is the biggest challenge you face with your diabetes management?

\section{Questions Related to Current Smartphone Use}

5. How comfortable are you with using a smartphone?

6. Other than calling, what do you currently use your phone to do? How often do you use it?

\section{Questions Related to Smartphone App Use}

7. What do you know about smartphone apps designed to help you manage your health? Have you tried one?

8. How do you feel about using a smartphone app to help manage your diabetes?

9. What would be a reason to persuade you to use a health app (i.e. recommendation from friends/family, saw a commercial, high reviews in the app store from users)?

10. What kind of app features or functions would be most helpful to you?*

11. How often would you be willing to use an app? How many apps would you be willing to use?

\section{Questions Related to Barriers}

12. What concerns do you have about using a smartphone app for your diabetes?

13. What reasons would stop you from using an app? 
*Along with question 10 , the interviewer also provided some sample images of smartphone apps as shown below.

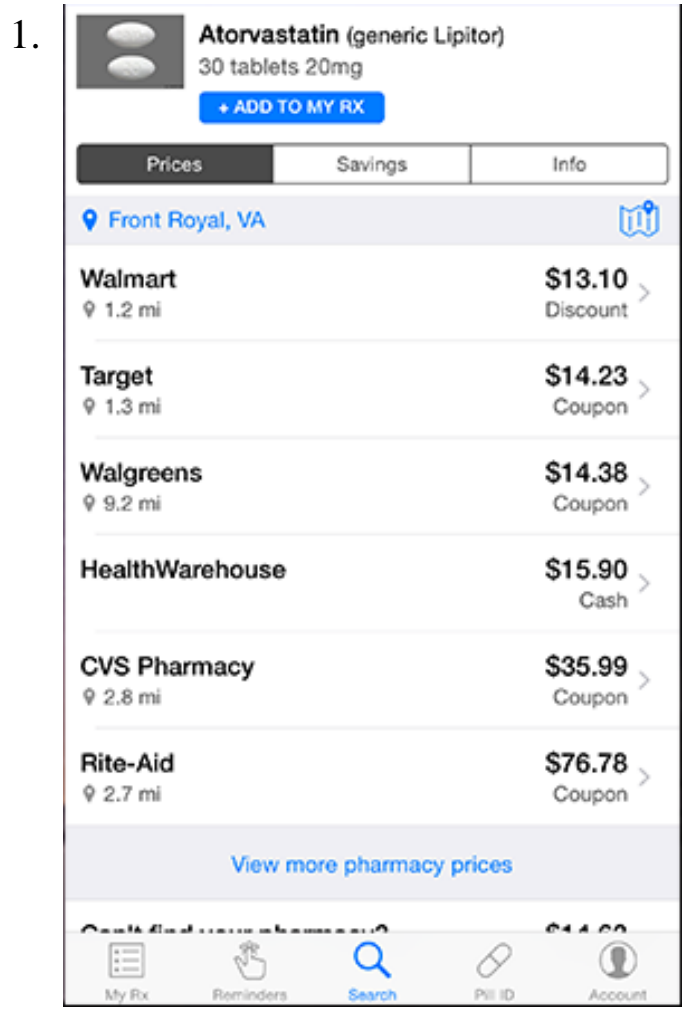

2.
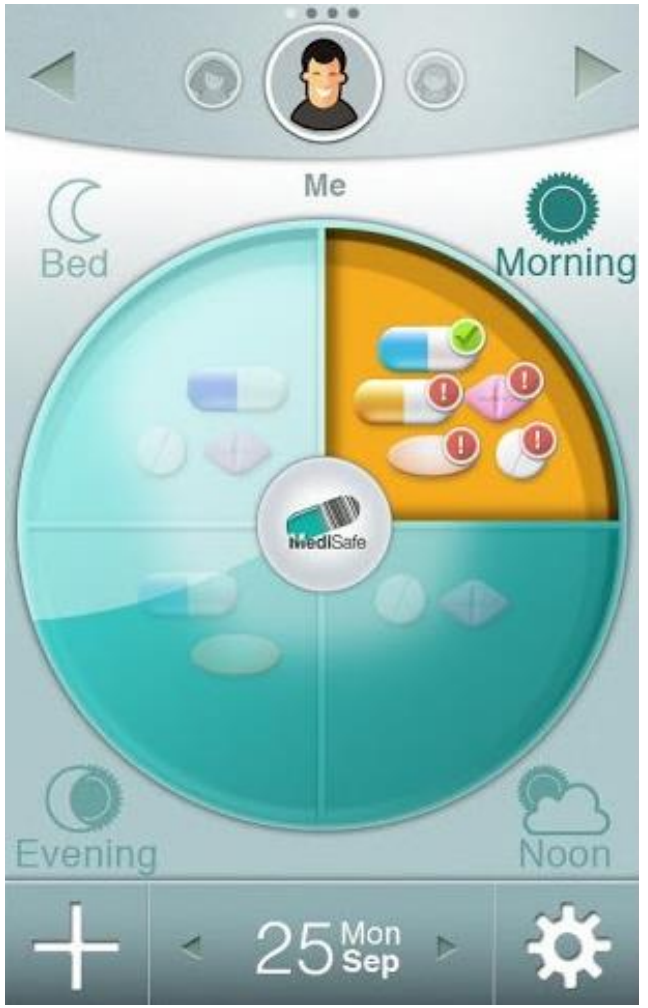

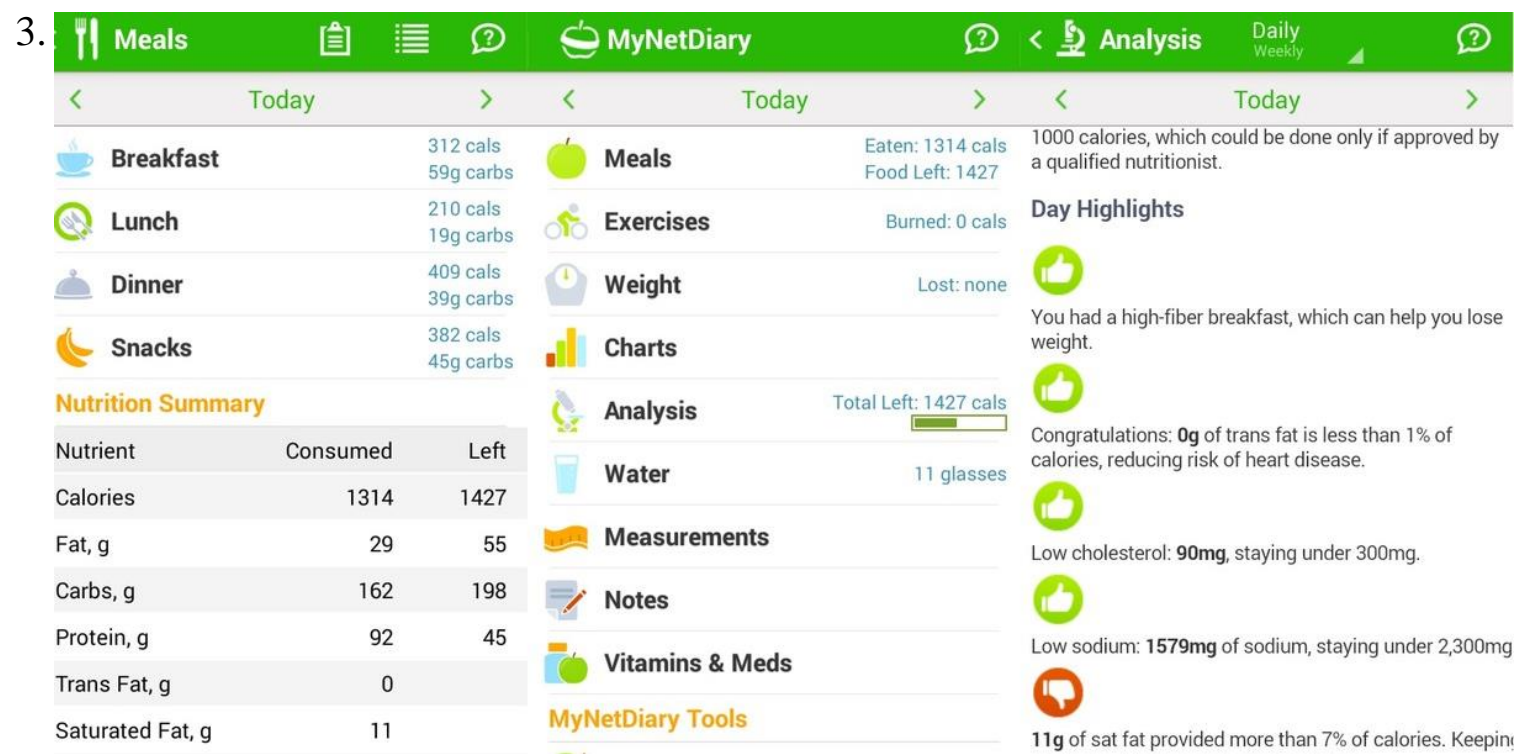

Reprinted with permission. 1. GoodRx Inc. GoodRx mobile apps (2011). https://www.goodrx.com/mobile (accessed 3 Nov 2015). 2. Medisafe Project Ltd. Medisafe app (2015). https://www.medisafeapp.com (accessed 3 Nov 2015). 3. MyNetDiary Inc. MyNetDiary (2015). https://www.mynetdiary.com (accessed 3 Nov 2015). 
4.

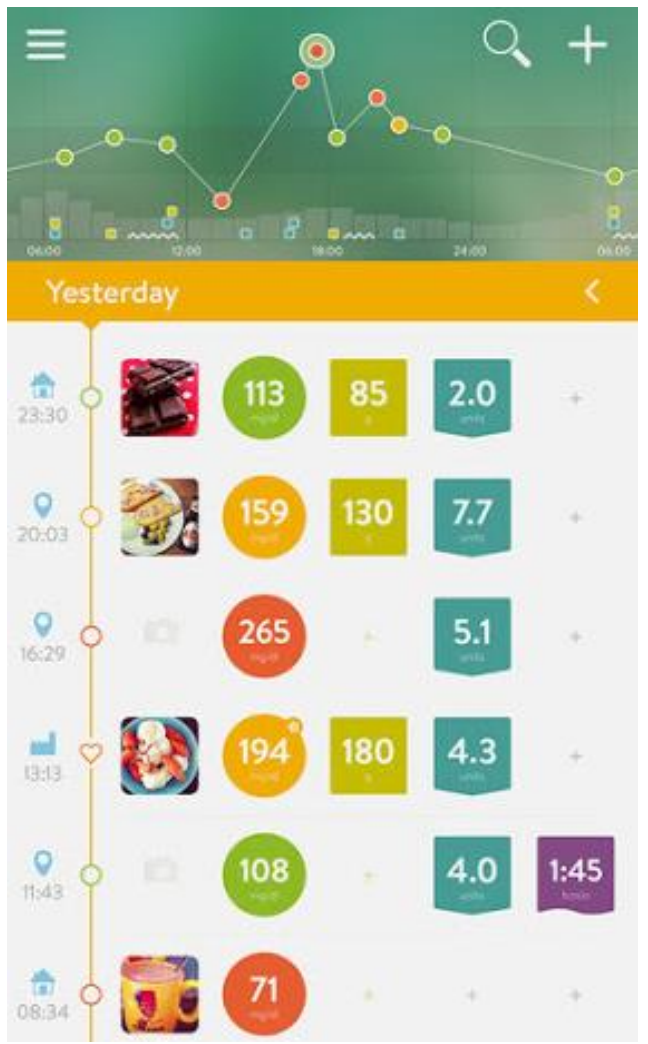

5.

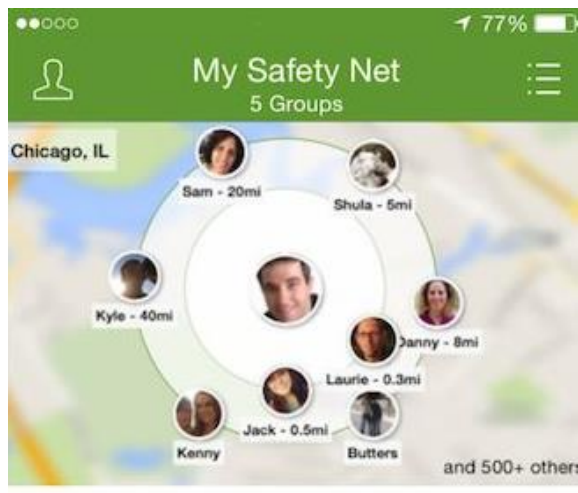

Safety Net Strength in Chicago, IL $90 \%+$ INVITE

Alex from Oak Park, IL

Does anyone have an emergency meter in their car or office? Today I went to dance class and left it at home. I felt uneasy!

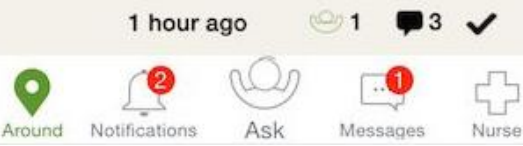

6. Personalized nutrition toolbox
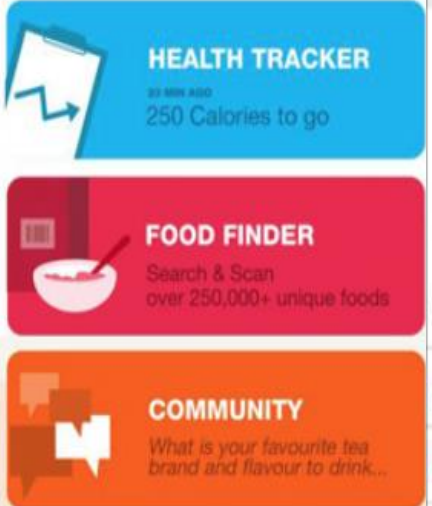

RECIPES

Sweet $\&$ Salty Yarns

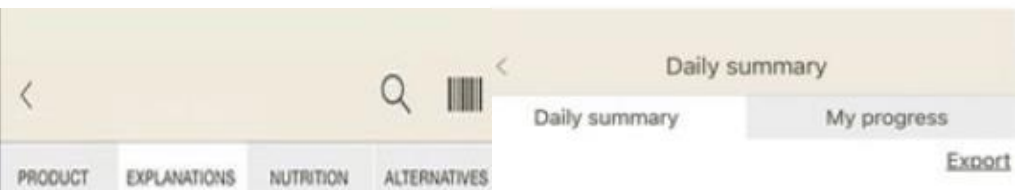

Average food grade: $\mathrm{B}+$
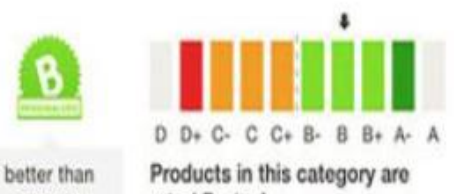

better than average rated $D+$ to $A$.

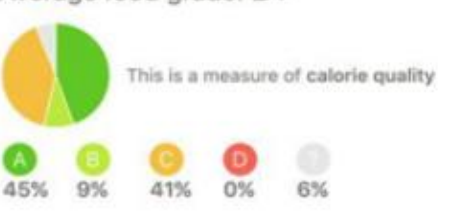

Category: Cold cereals

Calories $112058 * 362$

Nice! $100 \%$ whole grain

Budget 1870 Net 1696 Left 174

(2) 2.5 tsp of sugars per serving

> Calories: Solid vs. Liquid

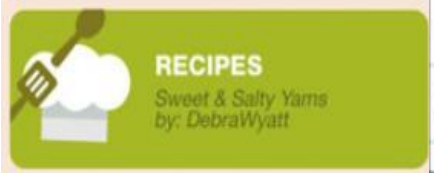

(6) For dieters: FoodPoints value is 5 >
(6) Puffed up with protein?

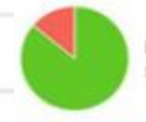

Limit your calories from liquids, they don't satiate as well as solid food

$>$ Solid Liquid

Reprinted with permission. 4. mySugr. mySugr app (2015). https://www.mysugr.com/enus/diabetes-app (accessed 3 Nov 2015). 5. Helparound. Helparound app (2015). https://helparound.co/platform.html (accessed 3 Nov 2015). 6. Fooducate Ltd. Fooducate (2010). https://www.fooducate.com/ (accessed 3 Nov 2015). 


\section{APPENDIX B. UTHSC IRB STUDY APPROVAL LETTER}

Institutional Review Board

910 Madison Avenue, Suite 600

Memphis, TN 38163

Tel: (901) 448-4824

February 15, 2017

Jieyu Luo,

UTHSC - COP - Pharmaceutical Sciences

Re: 16-04701-XP

Study Title: Feasibility and Acceptability of Using Mobile Health Applications in Diabetes SelfManagement: A Qualitative Approach

Dear Dr. Luo:

The Administrative Section of the UTHSC Institutional Review Board (IRB) has received your written acceptance of and/or response dated 11/21/2016, 12/11/2016, and $02 / 14 / 2017$ to the provisos outlined in our correspondence of 08/04/2016, 12/06/2016 and 12/16/2016 concerning the above referenced project. The IRB determined that your application is eligible for expedited review under 45 CFR 46.110(b)(1) categories (6) and (7). The IRB has reviewed these materials and determined that they do comply with proper consideration for the rights and welfare of human subjects and the regulatory requirements for the protection of human subjects. Therefore, this letter constitutes full approval by the IRB of your application (version 1.4) as submitted including:

- Survey consent elements dated $12 / 11 / 2016$;

- Email correspondence dated 08/08/2016; and

- Interview questions dated 07/18/2016.

All of the above were stamped IRB-approved 02/15/2017. You must use the date-stamped versions of study documents. Date-stamped materials are available in the Informed Consent and Other Project Documents folders of iMedRIS.

Approval of this study will be valid from February 15, 2017 to December 03, 2017.

This study may not be initiated until you receive approval from the institution(s) where the research is being conducted.

In accord with 45 CFR 46.116(d), informed consent may be altered, with the cover statement used in lieu of an informed consent interview. The requirement to secure a signed consent form is waived under 45 CFR 46.117 (c)(2). 
In addition, the request for waiver of HIPAA authorization in order to identify potential subjects is approved in accord with the criteria and review procedures specified at 45 CFR 164.512(i)(2). The waiver applies to the medical records of adult patients admitted in the emergency room for diabetes care at Methodist South Hospital.

In the event that subjects are to be recruited using solicitation materials, such as brochures, posters, web-based advertisements, etc., these materials must receive prior approval of the IRB. Any revisions in the approved application must also be submitted to and approved by the IRB prior to implementation. In addition, you are responsible for reporting any unanticipated serious adverse events or other problems involving risks to subjects or others in the manner required by the local IRB policy. Lastly, you must request to close your project when you have completed data analysis. All of the above should be submitted to the IRB via the appropriate form in iMedRIS.

Re-approval of your project is required by the IRB in accord with the conditions specified above. You may not continue the research study beyond the time or other limits specified unless you obtain prior written approval of the IRB.

Sincerely,

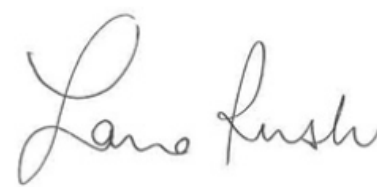

Signature applied by Laura C Rush on 02/15/2017 02:22:26 PM CST

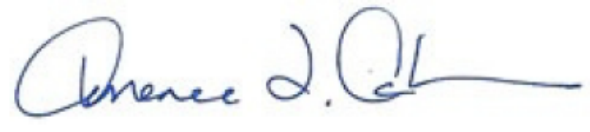

Laura Rush, MPH

Regulatory Specialist

UTHSC IRB
Terrence F. Ackerman, Ph.D.

Chairman

UTHSC IRB 


\section{APPENDIX C. STUDY CONSENT FORM}

TITLE: Feasibility and Acceptability of Using Mobile Health Applications in Diabetes SelfManagement

PRINCIPAL INVESTIGATOR:

CO-INVESTIGATOR:
J. Jenny Luo 818 Madison Ave. Suite 214 Memphis, TN 38163

901-628-4180

Shelley White-Means, $\mathrm{PhD}$

818 Madison Ave. Suite 202 Memphis, TN 38163

\section{INTRODUCTION:}

You have the opportunity to participate in this research study. The purpose of this consent form is to help you decide if you want to be in the research study. This consent form may contain words that you do not understand. Please ask the study staff to explain any words or information that you do not clearly understand. Please tell the study staff if you are taking part in another research study.

\section{PURPOSE OF THE RESEARCH:}

The purpose of this study is to investigate the potential of smartphone health applications (apps) to help people without traditional primary care doctors manage their diabetes. The study will examine people's attitudes and thoughts about using mobile phone technology and their willingness to get or keep track of information related to their health and diabetes with their phones. Additionally, this project will explore how people currently feel about their diabetes management and how they might use a smartphone app in their daily health routine.

\section{PROCEDURES TO BE FOLLOWED:}

Should you agree to the study, you will participate in a single one-on-one interview. All interviews will take place in a private room at Methodist South with only you and the interviewer present. Interviews will consist of approximately 15 questions related to your diabetes management and smartphone use. There are no right or wrong answers and no time limit to answer each question. All interviews will be audio recorded and later transcribed word-for-word into text for analysis. The interviewer may play back a portion of the audio recording to you to verify that the recorder accurately captured your answers. The entire interview should take about 30-45 minutes to complete.

\section{RISKS ASSOCIATED WITH PARTICIPATION:}

Having your voice recorded, may make you feel uncomfortable. You may take a break during any time of the study. The interview questions are not designed to make you feel uncomfortable or to gather any sensitive information. You may refuse to answer any questions, and you may stop the interview at any time. 


\section{BENEFITS ASSOCIATED WITH PARTICIPATION:}

There are no direct benefits to you for participating in this study. The results of this study may help people with diabetes in the future by determining if smartphone apps may be a useful resource, especially for people without regular access to family doctors. Information collected from these interviews may help doctors and nurses make recommendations for apps for patients to use at home.

\section{VOLUNTARY PARTICIPATION AND WITHDRAWAL:}

Your participation in this research study is voluntary. You may decide not to participate or you may leave the study at any time without penalty. If you decide to stop being part of the study, you should tell the study investigator, and any information that you have already provided will be kept in a confidential manner.

\section{CONFIDENTIALITY:}

All information collected during the study will remain confidential. There will not be any identifying information on the audiotapes, notes from, or the transcripts of the interview. All audio files and interview transcriptions will remain in the possession of the interviewer and will only be shared with her research advisor and committee members. Your name and identity will also remain confidential in any publications from this study. 


\section{APPENDIX D. ICD-9 AND ICD-10 CODES FOR STUDY PARTICIPATION}

\section{Table D-1. Qualifying ICD-9 codes for participant selection}

\begin{tabular}{|c|c|}
\hline ICD-9 code & Code description \\
\hline 250.00 & Type 2 or unspecified diabetes, not uncontrolled, without complication \\
\hline 250.01 & Type 1 diabetes, not uncontrolled, without complication \\
\hline 250.02 & Type 2 or unspecified diabetes, uncontrolled, without complication \\
\hline 250.03 & Type 1 diabetes, uncontrolled, without complication \\
\hline 250.10 & Type 2 or unspecified diabetes, not uncontrolled, with ketoacidosis \\
\hline 250.11 & Type 1 diabetes, not uncontrolled, with ketoacidosis \\
\hline 250.12 & Type 2 or unspecified diabetes, uncontrolled, with ketoacidosis \\
\hline 250.13 & Type 1 diabetes, uncontrolled, with ketoacidosis \\
\hline 250.20 & Type 2 or unspecified diabetes, not uncontrolled, with hyperosmolarity \\
\hline 250.21 & Type 1 diabetes, not uncontrolled, with hyperosmolarity \\
\hline 250.22 & Type 2 or unspecified diabetes, uncontrolled, with hyperosmolarity \\
\hline 250.23 & Type 1 diabetes, uncontrolled, with hyperosmolarity \\
\hline 250.30 & Type 2 or unspecified diabetes, not uncontrolled, with other coma \\
\hline 250.31 & Type 1 diabetes, not uncontrolled, with other coma \\
\hline 250.32 & Type 2 or unspecified diabetes, uncontrolled, with other coma \\
\hline 250.33 & Type 1 diabetes, uncontrolled, with other coma \\
\hline 250.40 & $\begin{array}{l}\text { Type } 2 \text { or unspecified diabetes, not uncontrolled, with renal } \\
\text { manifestations }\end{array}$ \\
\hline 250.41 & Type 1 diabetes, not uncontrolled, with renal manifestations \\
\hline 250.42 & Type 2 or unspecified diabetes, uncontrolled, with renal manifestations \\
\hline 250.43 & Type 1 diabetes, uncontrolled, with renal manifestations \\
\hline 250.50 & $\begin{array}{l}\text { Type } 2 \text { or unspecified diabetes, not uncontrolled, with ophthalmic } \\
\text { manifestations }\end{array}$ \\
\hline 250.51 & Type 1 diabetes, not uncontrolled, with ophthalmic manifestations \\
\hline 250.52 & $\begin{array}{l}\text { Type } 2 \text { or unspecified diabetes, uncontrolled, with ophthalmic } \\
\text { manifestations }\end{array}$ \\
\hline 250.53 & Type 1 diabetes, uncontrolled, with ophthalmic manifestations \\
\hline 250.60 & $\begin{array}{l}\text { Type } 2 \text { or unspecified diabetes, not uncontrolled, with neurological } \\
\text { manifestations }\end{array}$ \\
\hline 250.61 & Type 1 diabetes, not uncontrolled, with neurological manifestations \\
\hline 250.62 & $\begin{array}{l}\text { Type } 2 \text { or unspecified diabetes, uncontrolled, with neurological } \\
\text { manifestations }\end{array}$ \\
\hline 250.63 & Type 1 diabetes, uncontrolled, with neurological manifestations \\
\hline 250.70 & $\begin{array}{l}\text { Type } 2 \text { or unspecified diabetes, not uncontrolled, with peripheral } \\
\text { circulatory disorders }\end{array}$ \\
\hline 250.71 & Type 1 diabetes, not uncontrolled, with peripheral circulatory disorders \\
\hline
\end{tabular}


Table D-1. (Continued)

\begin{tabular}{|c|c|}
\hline ICD-9 code & Code description \\
\hline 250.72 & $\begin{array}{l}\text { Type } 2 \text { or unspecified diabetes, uncontrolled, with peripheral } \\
\text { circulatory disorders }\end{array}$ \\
\hline 250.73 & Type 1 diabetes, uncontrolled, with peripheral circulatory disorders \\
\hline 250.80 & $\begin{array}{l}\text { Type } 2 \text { or unspecified diabetes, not uncontrolled, with other specified } \\
\text { manifestations }\end{array}$ \\
\hline 250.81 & Type 1 diabetes, not uncontrolled, with other specified manifestations \\
\hline 250.82 & $\begin{array}{l}\text { Type } 2 \text { or unspecified diabetes, uncontrolled, with other specified } \\
\text { manifestations }\end{array}$ \\
\hline 250.83 & Type 1 diabetes, uncontrolled, with other specified manifestations \\
\hline 250.90 & $\begin{array}{l}\text { Type } 2 \text { or unspecified diabetes, not uncontrolled, with unspecified } \\
\text { complication }\end{array}$ \\
\hline 250.91 & Type 1 diabetes, not uncontrolled, with unspecified complication \\
\hline 250.92 & $\begin{array}{l}\text { Type } 2 \text { or unspecified diabetes, uncontrolled, with unspecified } \\
\text { complication }\end{array}$ \\
\hline 250.93 & Type 1 diabetes, uncontrolled, with unspecified complication \\
\hline 357.2 & Polyneuropathy in diabetes \\
\hline 250.72 & $\begin{array}{l}\text { Type } 2 \text { or unspecified diabetes, uncontrolled, with peripheral } \\
\text { circulatory disorders }\end{array}$ \\
\hline 250.73 & Type 1 diabetes, uncontrolled, with peripheral circulatory disorders \\
\hline 250.80 & $\begin{array}{l}\text { Type } 2 \text { or unspecified diabetes, not uncontrolled, with other specified } \\
\text { manifestations }\end{array}$ \\
\hline 250.81 & Type 1 diabetes, not uncontrolled, with other specified manifestations \\
\hline 250.82 & $\begin{array}{l}\text { Type } 2 \text { or unspecified diabetes, uncontrolled, with other specified } \\
\text { manifestations }\end{array}$ \\
\hline 250.83 & Type 1 diabetes, uncontrolled, with other specified manifestations \\
\hline 250.90 & $\begin{array}{l}\text { Type } 2 \text { or unspecified diabetes, not uncontrolled, with unspecified } \\
\text { complication }\end{array}$ \\
\hline 250.91 & Type 1 diabetes, not uncontrolled, with unspecified complication \\
\hline 250.92 & $\begin{array}{l}\text { Type } 2 \text { or unspecified diabetes, uncontrolled, with unspecified } \\
\text { complication }\end{array}$ \\
\hline 250.93 & Type 1 diabetes, uncontrolled, with unspecified complication \\
\hline 357.2 & Polyneuropathy in diabetes \\
\hline
\end{tabular}

Data Source: Centers for Disease Control and Prevention. International Classification of Diseases, 9th revision, clinical modification (6 Nov 2015). https://www.cdc.gov/nchs/icd/icd9cm.htm (accessed 11 Dec 2015). 
Table D-2. Qualifying ICD-10 codes for participant selection

\begin{tabular}{|c|c|}
\hline ICD-10 code & Code description \\
\hline E10.10 & Type 1 diabetes with ketoacidosis, no coma \\
\hline E10.11 & Type 1 diabetes with ketoacidosis with coma \\
\hline E10.21 & Type 1 diabetes with diabetic nephropathy \\
\hline E10.22 & Type 1 diabetes with diabetic chronic kidney disease \\
\hline E10.29 & Type 1 diabetes with other diabetic kidney complication \\
\hline E10.311 & $\begin{array}{l}\text { Type } 1 \text { diabetes with unspecified diabetic retinopathy with macular } \\
\text { edema }\end{array}$ \\
\hline E10.319 & $\begin{array}{l}\text { Type } 1 \text { diabetes with unspecified diabetic retinopathy, no macular } \\
\text { edema }\end{array}$ \\
\hline E10.321 & $\begin{array}{l}\text { Type } 1 \text { diabetes with mild nonproliferative diabetic retinopathy with } \\
\text { macular edema }\end{array}$ \\
\hline E10.329 & $\begin{array}{l}\text { Type } 1 \text { diabetes with mild nonproliferative diabetic retinopathy, no } \\
\text { macular edema }\end{array}$ \\
\hline E10.331 & $\begin{array}{l}\text { Type } 1 \text { diabetes with moderate nonproliferative diabetic retinopathy } \\
\text { with macular edema }\end{array}$ \\
\hline E10.339 & $\begin{array}{l}\text { Type } 1 \text { diabetes with moderate nonproliferative diabetic retinopathy, } \\
\text { no macular edema }\end{array}$ \\
\hline E10.341 & $\begin{array}{l}\text { Type } 1 \text { diabetes with severe nonproliferative diabetic retinopathy with } \\
\text { macular edema }\end{array}$ \\
\hline E10.349 & $\begin{array}{l}\text { Type } 1 \text { diabetes with severe nonproliferative diabetic retinopathy, no } \\
\text { macular edema }\end{array}$ \\
\hline E10.351 & $\begin{array}{l}\text { Type } 1 \text { diabetes with proliferative diabetic retinopathy with macular } \\
\text { edema }\end{array}$ \\
\hline E10.359 & $\begin{array}{l}\text { Type } 1 \text { diabetes with proliferative diabetic retinopathy, no macular } \\
\text { edema }\end{array}$ \\
\hline E10.36 & Type 1 diabetes with diabetic cataract \\
\hline E10.39 & Type 1 diabetes with other diabetic ophthalmic complication \\
\hline E10.40 & Type 1 diabetes with diabetic neuropathy, unspecified \\
\hline E10.41 & Type 1 diabetes with diabetic mononeuropathy \\
\hline E10.42 & Type 1 diabetes with diabetic polyneuropathy \\
\hline E10.43 & Type 1 diabetes with diabetic autonomic (poly)neuropathy \\
\hline E10.44 & Type 1 diabetes with diabetic amyotrophy \\
\hline E10.49 & Type 1 diabetes with other diabetic neurological complication \\
\hline E10.51 & Type 1 diabetes with diabetic peripheral angiopathy, no gangrene \\
\hline E10.52 & Type 1 diabetes with diabetic peripheral angiopathy with gangrene \\
\hline E10.59 & Type 1 diabetes with other circulatory complications \\
\hline E10.610 & Type 1 diabetes with diabetic neuropathic arthropathy \\
\hline E10.618 & Type 1 diabetes with other diabetic arthropathy \\
\hline E10.620 & Type 1 diabetes with diabetic dermatitis \\
\hline E10.621 & Type 1 diabetes with foot ulcer \\
\hline
\end{tabular}


Table D-2. (Continued)

\begin{tabular}{|c|c|}
\hline ICD-10 code & Code description \\
\hline E10.622 & Type 1 diabetes with other skin ulcer \\
\hline E10.628 & Type 1 diabetes with other skin complications \\
\hline E10.630 & Type 1 diabetes with periodontal disease \\
\hline E10.638 & Type 1 diabetes with other oral complications \\
\hline E10.641 & Type 1 diabetes with hypoglycemia with coma \\
\hline E10.649 & Type 1 diabetes with hypoglycemia, no coma \\
\hline E10.65 & Type 1 diabetes with hyperglycemia \\
\hline E10.69 & Type 1 diabetes with other specified complication \\
\hline E10.8 & Type 1 diabetes with unspecified complications \\
\hline E10.9 & Type 1 diabetes without complications \\
\hline E11.00 & $\begin{array}{l}\text { Type } 2 \text { diabetes with hyperosmolarity, no nonketotic hyperglycemic- } \\
\text { hyperosmolar coma }\end{array}$ \\
\hline E11.01 & Type 2 diabetes with hyperosmolarity with coma \\
\hline E11.21 & Type 2 diabetes with diabetic nephropathy \\
\hline E11.22 & Type 2 diabetes with diabetic chronic kidney disease \\
\hline E11.29 & Type 2 diabetes with other diabetic kidney complication \\
\hline E11.311 & $\begin{array}{l}\text { Type } 2 \text { diabetes with unspecified diabetic retinopathy with macular } \\
\text { edema }\end{array}$ \\
\hline E11.319 & $\begin{array}{l}\text { Type } 2 \text { diabetes with unspecified diabetic retinopathy, no macular } \\
\text { edema }\end{array}$ \\
\hline E11.321 & $\begin{array}{l}\text { Type } 2 \text { diabetes with mild nonproliferative diabetic retinopathy with } \\
\text { macular edema }\end{array}$ \\
\hline E11.329 & $\begin{array}{l}\text { Type } 2 \text { diabetes with mild nonproliferative diabetic retinopathy, no } \\
\text { macular edema }\end{array}$ \\
\hline E11.331 & $\begin{array}{l}\text { Type } 2 \text { diabetes with moderate nonproliferative diabetic retinopathy } \\
\text { with macular edema }\end{array}$ \\
\hline E11.339 & $\begin{array}{l}\text { Type } 2 \text { diabetes with moderate nonproliferative diabetic retinopathy, } \\
\text { no macular edema }\end{array}$ \\
\hline E11.341 & $\begin{array}{l}\text { Type } 2 \text { diabetes with severe nonproliferative diabetic retinopathy with } \\
\text { macular edema }\end{array}$ \\
\hline E11.349 & $\begin{array}{l}\text { Type } 2 \text { diabetes with severe nonproliferative diabetic retinopathy, no } \\
\text { macular edema }\end{array}$ \\
\hline E11.351 & $\begin{array}{l}\text { Type } 2 \text { diabetes with proliferative diabetic retinopathy with macular } \\
\text { edema }\end{array}$ \\
\hline E11.359 & $\begin{array}{l}\text { Type } 2 \text { diabetes with proliferative diabetic retinopathy without } \\
\text { macular edema }\end{array}$ \\
\hline E11.36 & Type 2 diabetes with diabetic cataract \\
\hline E11.39 & Type 2 diabetes with other diabetic ophthalmic complication \\
\hline E11.40 & Type 2 diabetes with diabetic neuropathy, unspecified \\
\hline E11.41 & Type 2 diabetes with diabetic mononeuropathy \\
\hline E11.42 & Type 2 diabetes with diabetic polyneuropathy \\
\hline
\end{tabular}


Table D-2. (Continued)

\begin{tabular}{ll}
\hline ICD-10 code & \multicolumn{1}{c}{ Code description } \\
\hline E11.43 & Type 2 diabetes with diabetic autonomic (poly)neuropathy \\
E11.44 & Type 2 diabetes with diabetic amyotrophy \\
E11.49 & Type 2 diabetes with other diabetic neurological complication \\
E11.51 & Type 2 diabetes with diabetic peripheral angiopathy, no gangrene \\
E11.52 & Type 2 diabetes with diabetic peripheral angiopathy with gangrene \\
E11.59 & Type 2 diabetes with other circulatory complications \\
E11.610 & Type 2 diabetes with diabetic neuropathic arthropathy \\
E11.618 & Type 2 diabetes with other diabetic arthropathy \\
E11.620 & Type 2 diabetes with diabetic dermatitis \\
E11.621 & Type 2 diabetes with foot ulcer \\
E11.622 & Type 2 diabetes with other skin ulcer \\
E11.628 & Type 2 diabetes with other skin complications \\
E11.630 & Type 2 diabetes with periodontal disease \\
E11.638 & Type 2 diabetes with other oral complications \\
E11.641 & Type 2 diabetes with hypoglycemia with coma \\
E11.649 & Type 2 diabetes with hypoglycemia, no coma \\
E11.65 & Type 2 diabetes with hyperglycemia \\
E11.69 & Type 2 diabetes with other specified complication \\
E11.8 & Type 2 diabetes with unspecified complications \\
E11.9 & Type 2 diabetes without complications \\
\hline
\end{tabular}

Data Source: Centers for Disease Control and Prevention. International Classification of Diseases, 10th revision, clinical modification (6 Nov 2015).

https://www.cdc.gov/nchs/icd/icd10cm.htm (accessed 11 Dec 2015). 


\section{VITA}

Jieyu Luo, born 1988, is from Memphis, TN. In 2010, she enrolled in the PharmD/PhD dual degree program at the University of Tennessee Health Science Center. She earned her Doctor of Pharmacy degree in 2014. She anticipates completing the requirements for her Doctor of Philosophy degree in Health Policy and Outcomes Research in 2021. Her research interests include health and healthcare disparities, mHealth, and public and community health. 